University of Tennessee Health Science Center

UTHSC Digital Commons

\title{
Integration of ATM, ATR, and DNA-PKcs Signaling Maintains Genome Integrity During Neurogenesis
}

Vanessa D. Enriquez-Rios

University of Tennessee Health Science Center

Follow this and additional works at: https://dc.uthsc.edu/dissertations

Part of the Genetic Processes Commons, and the Neurosciences Commons

\section{Recommended Citation}

Enriquez-Rios, Vanessa D. , "Integration of ATM, ATR, and DNA-PKcs Signaling Maintains Genome Integrity During Neurogenesis" (2015). Theses and Dissertations (ETD). Paper 72. http://dx.doi.org/10.21007/ etd.cghs.2015.0085.

This Dissertation is brought to you for free and open access by the College of Graduate Health Sciences at UTHSC Digital Commons. It has been accepted for inclusion in Theses and Dissertations (ETD) by an authorized administrator of UTHSC Digital Commons. For more information, please contact jwelch30@uthsc.edu. 


\title{
Integration of ATM, ATR, and DNA-PKcs Signaling Maintains Genome Integrity During Neurogenesis
}

\begin{abstract}
The DNA damage response (DDR) orchestrates a network of cellular processes such as cell cycle progression, DNA repair, and apoptosis when complex DNA lesions arise to maintain genomic integrity. ATM, ATR, and DNA-PKcs (encoded by PRKDC) are related phosphatidylinositol-3-kinase like serine/ threonine kinases (PIKK) that collectively regulate the DDR network. Studies have demonstrated these kinases can phosphorylate many of the same substrates, suggesting a significant potential for functional redundancy. However, deficiencies in these kinases have been linked to distinct neural degenerative and developmental disorders, underscoring their unique functions for maintain genomic integrity during nervous system development.

Here we utilized mouse genetic analyses to identify the functional interplay between these kinases during neurogenesis. DNA-PKcs function is directly involved in and most associated with the non-homologous end-joining (NHEJ) pathway. The function of DNA-PKcs during neurogenesis remains unclear despite evidence linking mutations in related NHEJ factor genes to neurological diseases. For example, deficiency in Ku70, Ku80, XRCC4, or DNA ligase IV (Lig4), but not DNA-PKcs results in defective embryonic neurogenesis in mice. This discrepancy may arise from the fact that ATM and ATR can compensate for the loss of DNAPKcs. For instance, if ATM and DNA-PKcs were capable of functioning redundantly in neural tissue, then DNA-PKcs-null mice would not necessarily have a noticeable phenotype. Determining functional redundancy is difficult since Atr germ line and [Atm;Prkdc] double-null mice are embryonic lethal. To overcome these challenges, we used mice with germ line Prkdc inactivated in combination with conditional alleles for Atm and Atr to assess if these kinases function cooperatively in the DDR during neural development, consequently defining the role(s) of DNA-PKcs during neurogenesis.
\end{abstract}

We found DNA-PKcs loss sensitized DNA damage induced p53-dependent apoptosis, and exacerbated checkpoint activation after ionizing radiation (IR) in a developmental stage and neural cell type-specific manner, independent of ATM and ATR. Our data suggests, during neurogenesis DNA-PKcs functions as a component of the DNA-PK holoenzyme to maintain genomic integrity in proliferating and non-proliferating neurons. We propose DNA-PK specifically enhances NHEJ DNA double-strand break repair kinetics during murine neurogenesis by acting as a scaffold protein, which is critical to maintain normal nervous development when high levels of genotoxic stress occur. In contrast, we found that ATM and ATR coordinated the DDR during neurogenesis to direct DNA damage induced apoptosis in proliferating and non-proliferating cortical neural progenitors. Furthermore, we found ATR controlled the IR-induced G2/M checkpoint, independent of ATM and DNA-PKcs.

In summary, this work established a basic understanding of DNA-PKcs function during nervous system development with respect to ATM and ATR. Importantly, our data implicates DNA damage induced p53-dependent apoptosis can be activated in the absence of all three PIKK DNA damage-signaling kinases during murine neurogenesis. The human neurodegenerative disease ataxia telangiectasia $(A-T)$ is thought to arise from mutations in ATM preventing the elimination of DNA damaged neurons during neurogenesis, which then fail to function appropriately, resulting in neural degeneration. It is thought murine models fail to recapitulate the neurodegenerative disease observed in humans because mice are more resistant to DNA damage. The observation of a PIKK-independent DNA damage induced apoptotic process occurring during murine neurogenesis suggests murine embryonic neurons posses a pathway to eliminate DNA damaged cells even in the absence of ATM, ATR, and DNA-PKcs. Therefore, murine models may fail to recapitulate $A-T$, not because mice are more resistant to DNA damage, but because they have an alternative mechanism to eliminate DNA damaged neurons during neural development. The emphasis on mouse genetics to dissect the important processes of these kinases during neurogenesis was an 
important step to ensure the data collected illustrated the DDR within a biological context. Overall, our work illustrates the divergent functions of these kinases, despite substrate overlap, to show how they play unique and essential cooperative roles during the DDR, underscoring the distinct neuropathology that develops when each is defective.

\section{Document Type}

Dissertation

Degree Name

Doctor of Philosophy (PhD)

\section{Program}

Biomedical Sciences

Research Advisor

Peter J. McKinnon, Ph.D.

\section{Keywords}

ATM, ATR, DNA-PKcs, DNA damage, DNA repair, neural development.

\section{Subject Categories}

Genetic Processes | Medical Sciences | Medicine and Health Sciences | Neurosciences

\section{Comments}

Six month embargo expired November 2015 
Integration of ATM, ATR, and DNA-PKes Signaling Maintains Genome Integrity During Neurogenesis

\author{
A Dissertation \\ Presented for \\ The Graduate Studies Council \\ The University of Tennessee \\ Health Science Center \\ In Partial Fulfillment \\ Of the Requirements for the Degree \\ Doctor of Philosophy \\ From The University of Tennessee
}

By

Vanessa D. Enriquez-Rios

May 2015 
Copyright (C) 2015 by Vanessa D. Enriquez-Rios. All rights reserved. 


\section{DEDICATION}

I dedicate this work to all those who have struggled and sacrificed so that I might pursue my dreams. 


\section{ACKNOWLEDGEMENTS}

I would like to acknowledge Dr. Suzanne Gronemeyer, Associate Director of Academic Programs at St. Jude, for supporting my career in science, and for assisting in the opportunity for me to complete my dissertation work at St. Jude through the University of Tennessee Health Science Center.

I would like to thank my mentor Peter J. McKinnon for the opportunity to pursue a PhD studying DNA repair with respect to the nervous system in his lab. Few mentors have an appreciation for feline humor, data within a physiological context, and the patience to understand that life, like experiments, rarely goes as planned.

I would like to thank my committee members: Dr. Tiffany Seagroves, Dr. David Solecki, Dr. J Paul Taylor, and Dr. Jian Zuo for your time and consideration. I always looked forward to meeting with all of you.

The McKinnon lab and the Genetics department provided a well of support throughout this work. Discussions with Dr. Sachin Katyal and Dr. Youngsoo Lee formulated the basis for my scientific reasoning and experimental design. Jeng Feng, thank you for weaving life wisdoms with useful techniques for superior Western blotting and genotyping. Suzy Downing, trusted colleague and friend, I highly value your opinions and advice. Yang Li, thank you for being my eyes down the microscope, and hands on the cryostat when my health was poor. Dr. Helen Russell, thank you for assisting with the management of my colonies. Thanks to Dr. L Dumintrache and Dr. C Camacho for data discussions and career advice. Shuntel Smith, thank you for your selflessness in helping others achieve their goals.

To my wife Dr. T Schroeder, thank you for never giving up on a diagnosis and for always supporting the completion of this work.

To Tricia Satkowski, coordinator of pred-doctoral studies at St. Jude, thank you for all of your support and due diligence that contributed to assisting me in the completion of this work.

Thank you to my fellow peers in the UTHSC IPBS program for all of the wonderful times at Central BBQ. 


\begin{abstract}
The DNA damage response (DDR) orchestrates a network of cellular processes such as cell cycle progression, DNA repair, and apoptosis when complex DNA lesions arise to maintain genomic integrity. ATM, ATR, and DNA-PKcs (encoded by PRKDC) are related phosphatidylinositol-3-kinase like serine/threonine kinases (PIKK) that collectively regulate the DDR network. Studies have demonstrated these kinases can phosphorylate many of the same substrates, suggesting a significant potential for functional redundancy. However, deficiencies in these kinases have been linked to distinct neural degenerative and developmental disorders, underscoring their unique functions for maintain genomic integrity during nervous system development.
\end{abstract}

Here we utilized mouse genetic analyses to identify the functional interplay between these kinases during neurogenesis. DNA-PKcs function is directly involved in and most associated with the non-homologous end-joining (NHEJ) pathway. The function of DNA-PKcs during neurogenesis remains unclear despite evidence linking mutations in related NHEJ factor genes to neurological diseases. For example, deficiency in $\mathrm{Ku} 70, \mathrm{Ku} 80$, XRCC4, or DNA ligase IV (Lig4), but not DNA-PKcs results in defective embryonic neurogenesis in mice. This discrepancy may arise from the fact that ATM and ATR can compensate for the loss of DNA-PKcs. For instance, if ATM and DNA-PKcs were capable of functioning redundantly in neural tissue, then DNA-PKcsnull mice would not necessarily have a noticeable phenotype. Determining functional redundancy is difficult since Atr germ line and [Atm;Prkdc] double-null mice are embryonic lethal. To overcome these challenges, we used mice with germ line Prkdc inactivated in combination with conditional alleles for Atm and Atr to assess if these kinases function cooperatively in the DDR during neural development, consequently defining the role(s) of DNA-PKcs during neurogenesis.

We found DNA-PKcs loss sensitized DNA damage induced p53-dependent apoptosis, and exacerbated checkpoint activation after ionizing radiation (IR) in a developmental stage and neural cell type-specific manner, independent of ATM and ATR. Our data suggests, during neurogenesis DNA-PKcs functions as a component of the DNA-PK holoenzyme to maintain genomic integrity in proliferating and nonproliferating neurons. We propose DNA-PK specifically enhances NHEJ DNA doublestrand break repair kinetics during murine neurogenesis by acting as a scaffold protein, which is critical to maintain normal nervous development when high levels of genotoxic stress occur. In contrast, we found that ATM and ATR coordinated the DDR during neurogenesis to direct DNA damage induced apoptosis in proliferating and nonproliferating cortical neural progenitors. Furthermore, we found ATR controlled the IRinduced G2/M checkpoint, independent of ATM and DNA-PKcs.

In summary, this work established a basic understanding of DNA-PKcs function during nervous system development with respect to ATM and ATR. Importantly, our data implicates DNA damage induced p53-dependent apoptosis can be activated in the absence of all three PIKK DNA damage-signaling kinases during murine neurogenesis. 
The human neurodegenerative disease ataxia telangiectasia (A-T) is thought to arise from mutations in ATM preventing the elimination of DNA damaged neurons during neurogenesis, which then fail to function appropriately, resulting in neural degeneration. It is thought murine models fail to recapitulate the neurodegenerative disease observed in humans because mice are more resistant to DNA damage. The observation of a PIKKindependent DNA damage induced apoptotic process occurring during murine neurogenesis suggests murine embryonic neurons possess a pathway to eliminate DNA damaged cells even in the absence of ATM, ATR, and DNA-PKcs. Therefore, murine models may fail to recapitulate A-T, not because mice are more resistant to DNA damage, but because they have an alternative mechanism to eliminate DNA damaged neurons during neural development. The emphasis on mouse genetics to dissect the important processes of these kinases during neurogenesis was an important step to ensure the data collected illustrated the DDR within a biological context. Overall, our work illustrates the divergent functions of these kinases, despite substrate overlap, to show how they play unique and essential cooperative roles during the DDR, underscoring the distinct neuropathology that develops when each is defective. 


\section{PREFACE}

The McKinnon lab at St. Jude Children's Research Hospital is interested in understanding the links between DNA damage deficiency and neurological diseases. It is within this context that we studied the DNA damage-signaling kinases ATM, ATR, and DNA-PKcs during nervous system development. Overall, this work sought to emphasize mouse genetics to determine the role of DNA-PKcs within the murine brain. The emphasis on in vivo analyses was an important step to ensure that data collected on the DNA damage response was in a biological context. 


\section{TABLE OF CONTENTS}

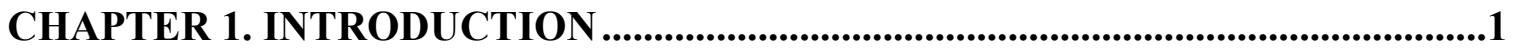

1.1 Corticogenesis as a Model System to Study DNA DSB Repair..............................

1.2 Regulation of DSB Repair by DNA Damage Signaling Kinases ............................

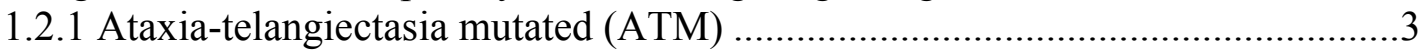

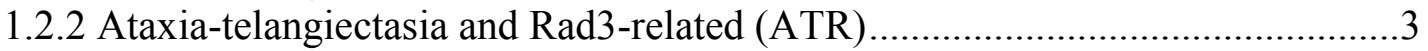

1.2.3 DNA-dependent protein kinase catalytic subunit (DNA-PKcs) ........................4

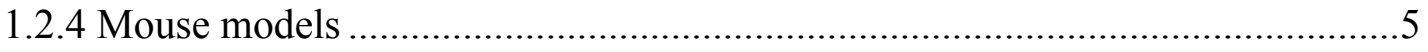

CHAPTER 2. EXPERIMENTAL PROCEDURES................................................

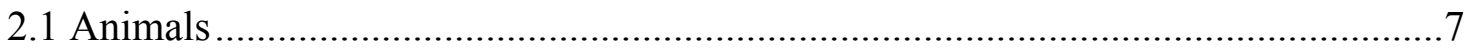

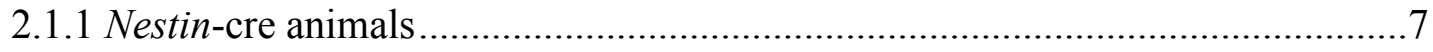

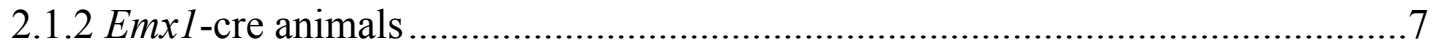

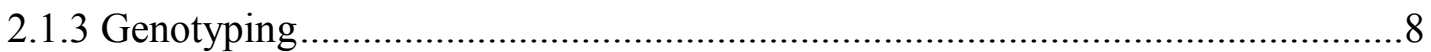

2.1.4 Real-time PCR ................................................................................. 9

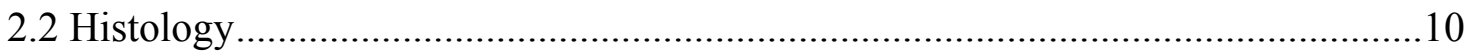

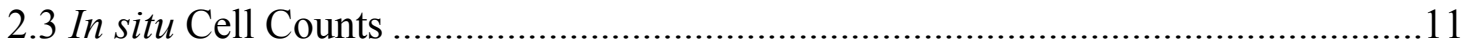

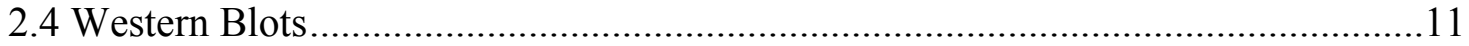

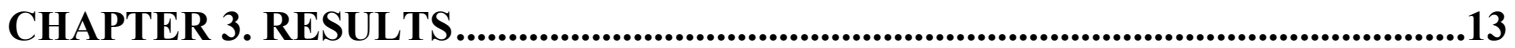

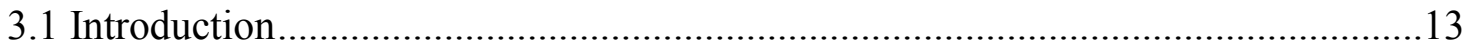

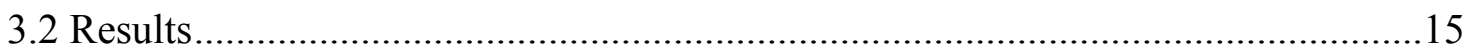

3.2.1 DNA-PKes loss sensitizes selective neurons to apoptosis in the postnatal

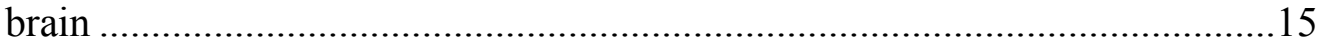

3.2.2 DNA-PKcs enhances NHEJ .................................................................. 17

3.2.3 Integration of apoptotic signaling of DNA damage is dynamic .......................22

3.2.4 Ionizing radiation-induced p53-dependent apoptosis occurs independent of

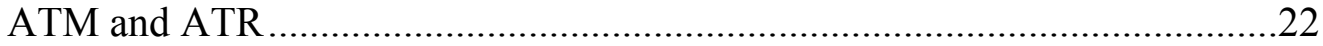

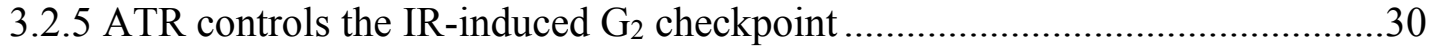

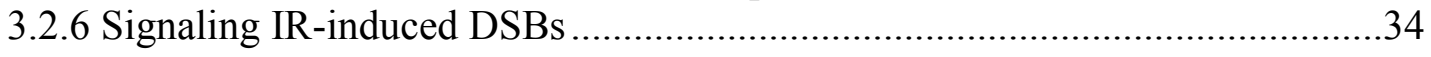

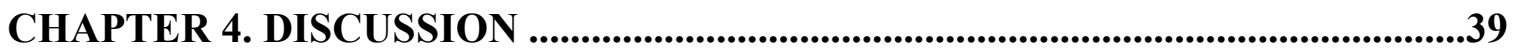

4.1 Analyses of ATM, ATR, and DNA-PKcs Revealed Novel DNA Damage

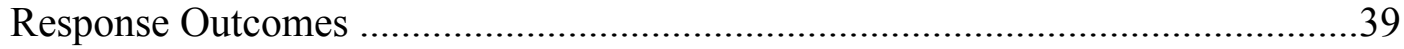

4.2 Proposed Function(s) of DNA-PKcs During Neurogenesis ................................40

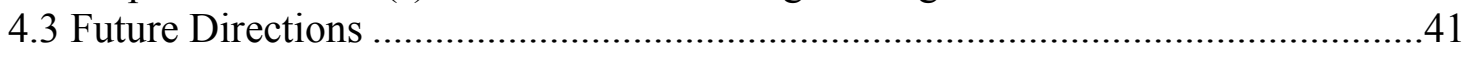

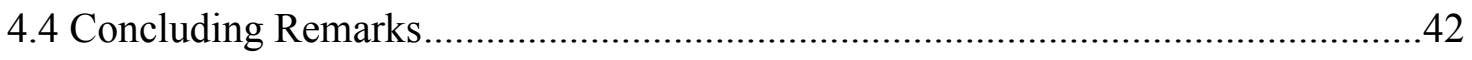

LIST OF REFERENCES .......................................................................................44

VITA 


\section{LIST OF FIGURES}

Figure 3-1. DNA-PKcs loss increases sensitivity to apoptosis in select neurons in the postnatal brain.

Figure 3-2. DNA-PKcs loss increases DSB signaling after IR. .....................................18

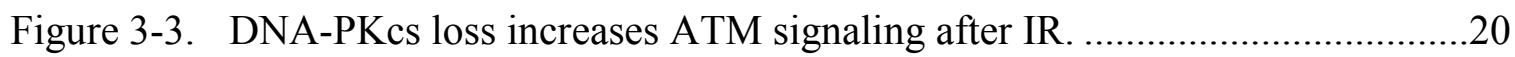

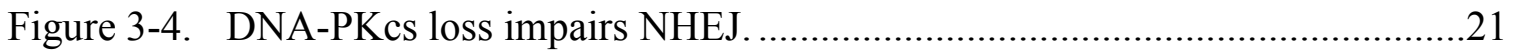

Figure 3-5. Integration of apoptotic signaling of DNA damage by ATM, ATR, and DNA-PKcs.

Figure 3-6. Apoptosis in TKO occurs independent of ATM and ATR and is IRinduced.

Figure 3-7. Nestin-cre mediated excision of Atm and Atr in TKO and DKO brain tissue is efficient, and confirmation of genotypes is consistent with TKO mice.

Figure 3-8. Ionizing radiation-induced apoptosis requires p53 but not ATM and ATR.

Figure 3-9. PCNA peri-nuclear stain is associated with apoptotic nuclei. .29

Figure 3-10. p53 is required for peri-nuclear PCNA localization after IR

Figure 3-11. ATR controls the DNA damage-induced $\mathrm{G}_{2}$ checkpoint

Figure 3-12. ATM mediates heterochromatin DNA double-strand breaks in adult neurons after ionizing radiation.

Figure 3-13. ATM and DNA-PKcs function redundantly to phosphorylate H2AX Ser139 in adult cortices after ionizing radiation.

Figure 3-14. Signaling dynamics of IR-induced $\gamma-\mathrm{H} 2 \mathrm{AX}$ in embryonic cortices. .38 


\section{LIST OF ABBREVIATIONS}

$\gamma \mathrm{H} 2 \mathrm{AX}$

A-T

ATM

ATM

Atm

Atm

Atm $^{\text {Emx 1-cre }}$

Atm $^{\text {Nes-cre }}$

ATR

ATR

Atr

Atr

ATRIP

Atr ${ }^{\text {Nes-cre }}$

ATR-SS

BrdU

CA1-3

$\mathrm{CP}$

Ctrl

CTX

DDR

DG

DNA-PK

DNA-PKcs

DSB

DSBs

EGL

E15.5

HR

IGL

IR

IZ

$\mathrm{kDa}$

$\mathrm{Ku} 70 / 80$

LIG4

LIG4

Lig4

Lig4

Lig4 $4^{\text {Nes-cre }}$

Mre11

MRN

$\mathrm{Nbs} 1$

NHEJ
Histone variant H2AX (phospho Ser139), chromatin DSB maker Ataxia-telangiectasia

Ataxia-telangiectasia mutated, human protein

Ataxia-telangiectasia mutated, human gene

Ataxia-telangiectasia mutated, mouse protein

Ataxia-telangiectasia mutate, mouse gene

Atm $^{\text {loxp/loxp }}$;Emx 1-cre

Atm ${ }^{\text {loxp/loxp }} ;$ Nestin-cre

Ataxia-telangiectasia mutated and Rad 3 related, human protein Ataxia-telangiectasia mutated and Rad 3 related, human gene Ataxia-telangiectasia mutated and Rad 3 related, mouse protein Ataxia-telangiectasia mutated and Rad 3 related, moue gene

ATR interacting protein

Atr ${ }^{\text {loxp/loxp }}$;Nestin-cre

ATR-Seckel Syndrome

5-Bromo-2'-deoxyuridine

Cornu Ammonis, regions 1-3, hippocampus anatomy

Cortical plate, upper layer of immature cortex

Control

Cortex

DNA damage response

Dentate gyrus, hippocampus anatomy

DNA-dependent protein kinase, $\mathrm{Ku} 70 / \mathrm{Ku} 80$, holoenzyme

DNA-dependent protein kinase, catalytic subunit

DNA double-strand break

DNA double-strand breaks

External granule layer, cerebellum

Embryonic day of gestation 15.5

Homologous Recombination, DSB repair pathway

Internal granule layer, cerebellum

Ionizing radiation

Intermediate zone, immature cortex

kilo Dalton

Heterodimer, NHEJ component

DNA ligase IV, human protein, NHEJ component

DNA ligase IV, human gene

DNA ligase IV, mouse protein

DNA ligase IV, mouse gene

Lig4 $4^{\text {loxp/loxp }}$;Nestin-cre

Meiotic recombination 11, mouse protein

Mre11/Ra50/Nbs1 complex, HR component

Nibrin (p95), mouse protein, HR component

Non-homologous end-joining, DSB repair pathway 
PCNA

PFA

PIKK

PRKDC

Prkdc

P0-21

QKO

RPA

SCID

SSB

ssDNA

SVZ

TKO

TopBP1

$\mathrm{VZ}$
Proliferating cell nuclear antigen

Paraformaldehyde

Phosphatidylinositol 3-kinase-related kinase (PI3K-like kinase)

Encodes DNA-PKcs, human gene

Encodes Dna-pkcs, mouse gene

Post-natal day 0-21

Quadruple knockout

Replication protein A

Sever compromised immunodeficiency

DNA single-strand break

Single-stranded DNA

Subventricular zone, immature cortex

Triple knockout

Topoisomerase (DNA) II binding protein

Ventricular zone 


\section{CHAPTER 1. INTRODUCTION}

\subsection{Corticogenesis as a Model System to Study DNA DSB Repair}

The rapid and enormous expansion of neural stem/progenitors during neurogenesis requires a large network of DNA repair pathways to maintain genomic homeostasis (McKinnon 2013). DNA double-strand breaks (DSBs) are the most deleterious DNA lesions because their persistence can result in the loss or gain of genomic information, leading to transformation (Shibata and Jeggo 2014). Endogenous DSBs arise primarily from DNA replication stress (McKinnon 2013). Importantly, neurogenesis occurs in a series of timely, organized expansions (Paridaen and Huttner 2014). Inefficiency in responding to DNA damage can impair the developmental timeline and have pathogenic consequences. The number and variety of human diseases associated with defective DNA damage signaling underscores the essential requirement for genomic stability during neural development (McKinnon 2009, Klement and Goodarzi 2014).

The developing neocortex is an excellent model to study the DNA damage response. Corticogenesis begins in the first layer called the ventricular zone (VZ), which is comprised of neural stem and progenitor cells (Molyneaux, Arlotta et al. 2007). Proliferation of neural stem and progenitors occurs in a spatiotemporal manner such that cells in mitosis accumulate at the apical regions of the VZ, whereas cells in S phase gather at the basal region, and cells in G1/G2 are found in between (Chan, Lorke et al. 2002). The neural progenitors expand both symmetrically and asymmetrically to maintain the VZ and construct the remaining cortical layers (Leclerc, Neant et al. 2012). A small population of neural progenitors and neurons migrate away from the $\mathrm{VZ}$ along radial glial cells where neurons begin differentiating, forming the subventricular zone (SVZ). Neurons continue migrating and maturing to form the intermediate zone (IZ), and finally the cortical plate (CP). Thus, the effects of deficiencies in DSB repair and signaling on neural cell-type, cell cycle progression, maturation, and development of specific layers during corticogenesis can be distinguished using specific markers and visualized by immunohistochemistry (Orii, Lee et al. 2006, Hevner 2007).

One of the first events to occur after DNA damage is chromatin modification (Goodarzi, Jeggo et al. 2010). The phosphorylation of histone H2A variant X at Serine 139 creates $\gamma \mathrm{H} 2 \mathrm{AX}$ foci, which recruit and retain additional DNA damage repair and signaling machinery specifically to DSB sites in chromatin (Rogakou, Nieves-Neira et al. 2000, Scully and Xie 2013). The visualization of these foci by immunohistochemistry is the standard for identifying the formation and resolution of DSBs (Lobrich, Shibata et al. 2010). H2AX loss in mice is not lethal, however genomic instability ensues, along with radiosensitivity, growth retardation, and immunodeficiency (Celeste, Petersen et al. 2002). The phosphorylation of transcriptional co-repressor KRAB-domain associated protein (KAP-1) at Serine 824 is a heterochromatin DSB marker important for promoting repair and chromatin relaxation (Ziv, Bielopolski et al. 2006, Noon, Shibata et al. 2010). ATM and DNA-PK have been shown to function redundantly in the phosphorylation of 
H2AX (phospho Ser139) after IR induced DNA damage, whereas KAP-1 (phospho S824) is generally a targeted by ATM alone (Stiff, O'Driscoll et al. 2004, White, Rafalska-Metcalf et al. 2012).

Proliferating neural stem and progenitors have two, biochemically distinct DNA DSB repair pathways: homologous recombination (HR) and the non-homologous endjoining (NHEJ) pathway. The HR pathway is known as the error free pathway as it employs a sister chromatid to use as a template for repair (Kass and Jasin 2010, Mazon, Mimitou et al. 2010, Moynahan and Jasin 2010). Access to sister chromatids restricts the availability of the HR pathway to cells in late S, early G2 phase. The HR pathway involves sensing and processing of DSBs by the Mre11/Rad50/Nbs1 (MRN) complex. MRN-mediated 5'-3' resection of DNA DSBs generates 3' single-strand DNA (ssDNA) tails, coated with replicating protein A (RPA). The Rad51 recombinase complex then loads onto the ssDNA, replacing RPA, and invades the sister chromatid in search of homology (Mazon, Mimitou et al. 2010). Once the homology sequence is identified, DNA polymerase extends along the 3' end forming a Holliday Junction (HJ). HJs are resolved in a Rad54-mediated process following repair.

Unlike the HR pathway, NHEJ does not use a template for repair. Consequently, the NHEJ repair pathway is prone to errors. In exchange for low fidelity repair, the NHEJ pathway is available throughout the cell cycle, as well as in non-cycling cells. In fact, NHEJ is preferred to HR in G2 cells (Shibata, Conrad et al. 2011), and becomes the sole DSB repair pathway beginning at differentiation in the SVZ, continuing throughout adulthood (Goodarzi and Jeggo 2013, McKinnon 2013). The NHEJ pathway involves the sensing and binding of free DNA ends by the heterodimer Ku70/80 followed by the recruitment of the DNA-dependent protein kinase, catalytic subunit (DNA-PKcs) to form the active serine/threonine holoenzyme, DNA-PK. The stable protein-DNA complex protects the ends from exonucleases and promotes the juxtaposition of DNA ends (Mahaney, Meek et al. 2009). DNA-PK then recruits the 5'-3' exonuclease Aretmis to process the free DNA ends, which are then filled and ligated by factors such as Pol $\mu$, DNA Ligase IV (Lig4), and XRCC4-XLF (Williams, Hammel et al. 2014).

\subsection{Regulation of DSB Repair by DNA Damage Signaling Kinases}

The repair of DNA lesions is regulated by the DNA damage response (DDR). The DDR orchestrates a network of cellular processes such as cell cycle, DNA repair, and apoptosis to maintain genomic integrity. The rapid expansion of neural stem/progenitors during neurogenesis requires efficient DNA sensing, signaling, and repair to maintain development (Paridaen and Huttner 2014). These tasks are carried out by the related phosphatidylinositol-3-kinase like serine/threonine kinases (PIKK) ATM (ataxia telangiectasia mutated), ATR (ATM and Rad3-related), and DNA-PKcs (DNA-dependent protein kinase catalytic subunit) (Sirbu and Cortez 2013). Deficiencies in these kinases are linked to distinct neural degenerative and developmental disorders. In fact, much of

our understanding of their functions is based upon studies of patient derived cell lines and DNA repair deficient mouse models attempting to recapitulate their respective 
neuropathologies (Friedberg and Meira 2006, Rosenthal and Brown 2007, Lavin 2013). Understanding fundamental brain development requires understanding how these kinases maintain genomic homeostasis during neurogenesis.

\subsubsection{Ataxia-telangiectasia mutated (ATM)}

ATM is a large protein ( $\sim 350 \mathrm{kDa})$ encoded by the ATM gene located at 11q2223, spanning $160 \mathrm{~kb}$ of DNA (Gatti, Berkel et al. 1988). Autosomal recessive mutations in the ATM gene result in a rare disorder called ataxia telangiectasia (A-T) (Shiloh 1995, Barlow, Hirotsune et al. 1996, Becker-Catania, Chen et al. 2000, Chaudhary and AlBaradie 2014). A-T is a multi-system disorder marked by ataxia (uncoordinated movements) caused by a progressive degeneration of the cerebellum (Tavani, Zimmerman et al. 2003, Shiloh 2014). A-T is also characterized by telangiectasia (dilated blood vessels) in the eyes and face, extreme radiosensitivity, immunodeficiency, predisposition to hematopoietic cancers, and sterility (Chaudhary and Al-Baradie 2014). Biochemical studies of patient derived cell lines demonstrate null mutations associated with homozygous and heterozygous mutations results in a complete lack of functional ATM protein (Becker-Catania, Chen et al. 2000, Valentin-Vega and Kastan 2012). A milder form of A-T, known as Variant A-T, is associated with a later onset of clinical signs, slower progression, expanded lifespan, and a lower incidence of extraneurological features (Saviozzi, Saluto et al. 2002).

ATM is the primary transducer of the DDR to DSBs (Bhatti, Kozlov et al. 2011, McKinnon 2012, Shiloh 2014), and A-T highlights the essential role of signaling appropriate responses to DNA DSBs to maintain genome stability during human nervous system development. Functionally, inactive ATM protein exists as a homodimer in the nucleus, and undergoes autophosphorylation to form active monomers when DSBs arise (Bakkenist and Kastan 2003). Active monomers are then recruited to DNA damage sites by the DSB sensor, MRN, to signal cell cycle arrest via Chk1 and Chk2 activation, facilitate DNA repair, or activate p53-dependent apoptosis in immature neural cells if the lesions are irreparable (Kastan, Onyekwere et al. 1991, Kastan, Zhan et al. 1992, Herzog, Chong et al. 1998, Hirao, Cheung et al. 2002, Hopfner, Craig et al. 2002, Shiloh 2003, Stracker, Theunissen et al. 2004, Moreno-Herrero, de Jager et al. 2005, Shull, Lee et al. 2009, Smith, Tho et al. 2010). Recently, topoisomerase-I cleavage complexes have also been shown to specifically activate ATM signaling (Katyal, Lee et al. 2014). However, ATM function in the nervous system is not limited to DNA damage signaling alone. ATM deficient cells are more sensitive to oxidative stress, and can be activated by this stress independent of DNA damage (Guo, Kozlov et al. 2010).

\subsubsection{Ataxia-telangiectasia and Rad3-related (ATR)}

Hypomorphic mutations in ATR can result in the neurodevelopmental disorder ATR-Seckel Syndrome (ATR-SS) (O'Driscoll, Ruiz-Perez et al. 2003, O'Driscoll, Gennery et al. 2004, Li, Chen et al. 2012, Li, Hart et al. 2013, Chaudhary and Al-Baradie 
2014). ATR-SS is characterized by severe microcephaly occurring from pre and postnatal retarded growth resulting in mental retardation (O'Driscoll, Jackson et al. 2006). ATR is activated by RPA bound ssDNA generated by stalled replication forks, or MRN resection of DNA DSBs, where it forms a complex with co-activator ATRIP, to localize additional activator TopBP1, leading to the phosphorylation of several DNA damage proteins including Chk1 and p53 (Tibbetts, Brumbaugh et al. 1999, Liu, Guntuku et al. 2000, Cortez, Guntuku et al. 2001, Zhao and Piwnica-Worms 2001, Kumagai, Lee et al. 2006, Cimprich and Cortez 2008, Mordes, Glick et al. 2008, Nam and Cortez 2011). Microcephaly is thought to arise due to defects in ATR signaling disrupting neural spindle orientation and mitotic progression of proliferating progenitors (Alderton, Joenje et al. 2004, Alderton, Galbiati et al. 2006, Gruber, Zhou et al. 2011).

\subsubsection{DNA-dependent protein kinase catalytic subunit (DNA-PKcs)}

DNA-PKcs is a $\sim 460 \mathrm{kDa}$ protein encoded by the PRKDC gene. DNA-PKcs function is essential for $\mathrm{V}(\mathrm{D}) \mathrm{J}$ recombination as cases of immunodeficiency syndrome have been identified in various mammalian species (Gu, Sekiguchi et al. 2000, Meek, Kienker et al. 2001, Ding, Bramble et al. 2002, Meek, Jutkowitz et al. 2009).

Surprisingly, only two cases of $P R K D C$ mutations have been linked to human disease despite cases of immunodeficiency originating from mutations in related NHEJ core factor Ligase IV (O'Driscoll, Gennery et al. 2004, van der Burg, van Dongen et al. 2009, Woodbine, Neal et al. 2013). The first patient to be identified with a PRKDC mutation showed severe combined immunodeficiency (SCID) associated with a minor missense mutation that did not affect protein length or expression levels, led to a minor impairment in the phosphorylation of the 5' to 3' exonuclease Artemis (van der Burg, Ijspeert et al. 2009). The second patient presented with microcephaly, severe neurological impairment, and SCID, associated with low, but detectable levels of DNA-PKcs (Woodbine, Neal et al. 2013). In contrast to ATM, DNA-PKcs is directly involved in the repair of DSBs in addition to being a transducer of the DDR (Burma and Chen 2004, Douglas, Gupta et al. 2005, Davis, Chen et al. 2014). DNA-PKcs is recruited to DSBs by the heterodimer complex Ku70/80 to form the holoenzyme DNA-PK, which then assists in the recruitment and activation of other components involved in NHEJ, the preferred DSB repair pathway in mammalian cells (Dobbs, Tainer et al. 2010, Davis, Chen et al. 2014). DNA-PK is regulated via autophosphorylation (Cui, Yu et al. 2005, Goodarzi, Yu et al. 2006, Uematsu, Weterings et al. 2007, Dobbs, Tainer et al. 2010). DNA-PKcs has been ascribed a variety of apparent non-DNA-damage related roles. For example, DNA-PK kinase was found to phosphorylate the transcription factor USF, whose activation is required for the activation of a central enzyme fatty acid synthase (FAS) in response to feeding and insulin signaling in mice, linking the kinase to metabolic gene regulation in response to insulin (Wong, Chang et al. 2009). Recent studies of the cytoplasmic response to DNA damage found a role for DNA-PK in phosphorylating Golgi dispersal protein GOLPH3, which leads to Golgi dispersal after DNA damage, conferring the observation of resistance to DNA-damaging agents in cancers over expressing GOLPH3 (Farber-Katz, Dippold et al. 2014). 


\subsubsection{Mouse models}

Mouse models of DNA repair mutants continue to advance our understanding of how genomic integrity is maintained during neurogenesis, however many challenges remain. Atm deficiency in mice recapitulates many extraneurological features of A-T, though all of the models, knock-in or knockout, fail to develop cerebellar degeneration (Lavin 2013). Nonetheless, studies have found that during neurogenesis proliferating neurons in HR deficient mice undergo ATM-independent apoptosis, in contrast to nonproliferating regions of NHEJ deficient mice undergo ATM-dependent apoptosis(Gao, Ferguson et al. 2000, Lee, Barnes et al. 2000, Shull, Lee et al. 2009).

Unlike Atm loss, Atr is absolutely essential for murine neurogenesis such that its deletion results in embryonic lethality (Brown and Baltimore 2000). Selective deletion of Atr in the developing nervous system using Nestin-cre results in slower overall growth, and reduced brain size, however with marked cerebellar developmental defects not observed in ATR-Seckel Syndrome (Lee, Shull et al. 2012). Analysis of the cerebellum of $A t r^{N e s-c r e}$ found progenitors underwent p53-independent cell cycle arrest, while other regions underwent apoptosis that was only partly directed by p53 (Lee, Shull et al. 2012). Further restrictive deletion of Atr in the dorsal telencephalic progenitors using Emxl-cre significantly affected hippocampal formation with moderate affects in cortical development (Gorski, Talley et al. 2002, Lee, Shull et al. 2012).

DNA-PKcs function during murine neurogenesis is dispensable despite requirements for ATM and ATR, as well as the core evolutionary conserved NHEJ factors Ku70/80, Lig4, and Xrcc4 (Gu, Jin et al. 1997, Gu, Sekiguchi et al. 2000, Douglas, Gupta et al. 2005). Consequently, the functions of DNA-PKcs during neurogenesis remain unclear. Evidence suggests DNA-PKcs loss leads to significantly greater levels of DNA damage induced cell death in cortical neurons, with subsequent loss of PolBeta, and in response to excitotoxic injury (Chechlacz, Vemuri et al. 2001, Vemuri, Schiller et al. 2001, Neema, Navarro-Quiroga et al. 2005, Niimi, Sugo et al. 2005).

The pervasive explanation for the poor recapitulation of neurological phenotypes between humans and mice is that mice are less sensitive to DNA damage. One strategy to address this challenge entails inducing exogenous DNA damage using ionizing radiation (IR). IR induces DNA damage lesions that are chemically identical to endogenous lesions formed as by-products of oxygen metabolism, including DNA DSBs (O'Neill P (O'Niell 1993, Errol C. Friedberg 1995, Gulston, Fulford et al. 2002). Irradiation studies of Atm deficient mice have shown that ATM is required for inducing p53-dependent apoptosis in non-cycling regions of the neocortex (Herzog, Chong et al. 1998, Chong, Murray et al. 2000, Lee, Chong et al. 2001). In cycling regions, ATM is only partially responsible for inducing p53-dependent apoptosis, suggesting ATM cooperates with ATR or DNA-PKcs to eliminate defective cortical neural stem and progenitor cells (Herzog, Chong et al. 1998, Gatz, Ju et al. 2011). Evidence indicates DNA-PKcs over ATR in this role as IR-induced Chk2 activation and p53 signaling were 
normal in Atr ${ }^{\text {Nes-cre }}$ progenitors (Lee, Shull et al. 2012). Furthermore, Atm and Prkdc mice are born healthy, while co-inactivation is lethal, implying a functional redundant relationship between ATM and DNA-PK during early embryogenesis (Gurley and Kemp 2001).

Here we explored how ATM, ATR, and DNA-PKcs integrate the DDR during neurogenesis using mice with germ line DNA-PKcs (encoded by Prkdc) inactivated in combination with conditional disruption of Atm and/or Atr function selectively in the murine nervous system. Collectively, our data are the first to show the dynamic interdependence of these three kinases within a physiological context to maintain genomic integrity during neurogenesis. 


\section{CHAPTER 2. EXPERIMENTAL PROCEDURES}

\subsection{Animals}

The animals used for this work were maintained in accordance with approved St. Jude Children's Research Hospital guidelines. The animal care program at St. Jude is fully accredited by the Association for the Assessment and Accreditation of Laboratory Animal Care, International (AAALAC-I). The last triennial accreditation site visit was conducted July 27-28, 2009. St. Jude is registered with the U.S. Department of Agriculture (63-R-0007) as a research facility and has an Assurance (Assurance No. A3077-01) on file with the Office of Laboratory Animal Welfare of the NIH. All of the animal procedures used were pre-approved by the institutional care and use committee at St. Jude Children's Research Hospital. The presence of a vaginal plug was considered day 0.5 (E0.5) and the day of birth as postnatal day 0 (P0). Mice were irradiated using a Cesium irradiator. All experimental groups included at least three animals of each genotype.

The mice carrying germ line mutations for the inactivation of Prkdc and $p 53$ have been described (Gao, Chaudhuri et al. 1998, Herzog, Chong et al. 1998). The $p 53$ floxed mice have been described (Laurie, Donovan et al. 2006). The Atr floxed mice have been described (Ruzankina, Pinzon-Guzman et al. 2007). Mice with Nestin-cre and Emxl-cre were obtained from Jackson Laboratory (B6.Cg-Tg(Nes-cre) $1 \mathrm{Kln} / \mathrm{J}$; JAX \#003771 and

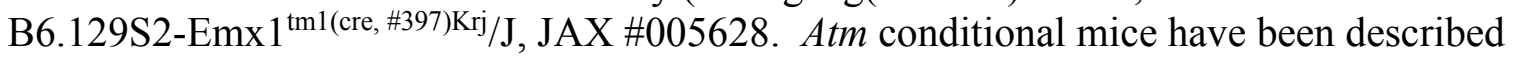
(Lee, Shull et al. 2012). Lig4 floxed mice have been described (Shull, Lee et al. 2009).

\subsubsection{Nestin-cre animals}

The $\operatorname{Prkdc}^{--}$, Atr $^{\text {loxp/loxp}}$, Atm $^{\text {loxp/loxp }}$, and Nestin-cre were interbred to obtain

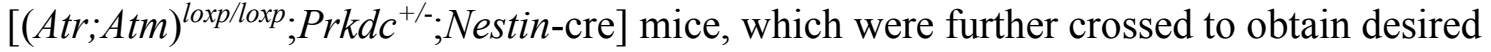
triple, double, and single knockouts. The control group (Ctrl) used was either

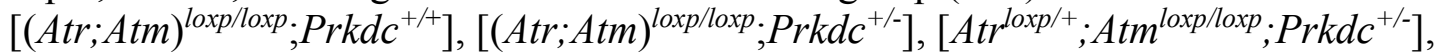
$\left[\right.$ Atr ${ }^{\text {loxplloxp }} ;$ Atm $^{\text {loxp } /+} ;$ Prkdc $\left.^{+/-}\right],\left[\right.$Atr $^{\text {loxp } /+} ;$ Atm $^{\text {loxp } /+} ;$ Prkdc $^{+/} ;$Nestin-cre $]$.

\subsubsection{Emx1-cre animals}

The Atr ${ }^{\text {loxp/loxp }}, p 53^{\text {loxp/loxp }}$, and Emxl-cre were interbred to obtain $\left[(\text { Atr; } ; 53)^{l o x p / l o x p} ; E m x 1\right.$-cre $]$ mice. These mice were then interbred with $\left[(\text { Atr } ; \text { Atm })^{\left.\text {loxp/loxp } ; P r k d c^{+-}\right]}\right.$to generate desired quadruple knockouts

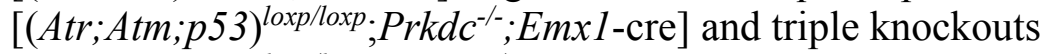
$\left[\left(\right.\right.$ Atr;Atm;p53) ${ }^{\text {loxp/loxp }} ;$ Prkdc ${ }^{+/-} ; E m x 1$-cre]. The control group was $\left[(\text { Atr } ; \text { Atm } ; \text { p53 })^{\text {loxp } /+} ;\right.$ Prkd $\left.^{+/-}\right]$or $\left[(\text {Atr } ; \text { Atm } ; \text { p53 })^{\text {loxp } /+} ;\right.$ Prkdc $^{+/-} ;$Emxl-cre $]$. 


\subsubsection{Genotyping}

Genomic DNA was isolated using lysis buffer with final concentrations of 200 $\mathrm{mM} \mathrm{NaCl}, 5 \mathrm{mM}$ EDTA, $0.2 \%$ SDS, $100 \mathrm{mM}$ Tris $\mathrm{pH} 8.5$ prepared from combining 20 $\mathrm{mL}$ of $5 \mathrm{M} \mathrm{NaCl}, 5 \mathrm{~mL}$ of $0.5 \mathrm{M}$ EDTA, $10 \mathrm{~mL} \mathrm{10 \%} \mathrm{SDS,} 50 \mathrm{~mL}$ of $1 \mathrm{M}$ Tris $\mathrm{pH} 8.5$, and $415 \mathrm{~mL}$ of $\mathrm{dH}_{2} 0$. A piece of mouse tail was combined with $500 \mathrm{~mL}$ lysis buffer and 10 $\mathrm{uL}$ Proteinase $\mathrm{K}$ (just before use) and allowed to incubate at $56^{\circ} \mathrm{C}$ overnight. $20 \mathrm{uL}$ of

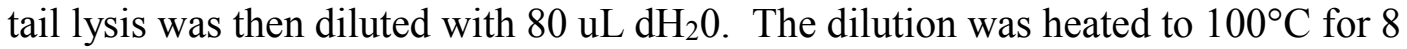
minutes, followed by centrifugation for ten minutes at 13.2 x $1000 \mathrm{rcf}$.

All PCR reactions were completed using Promega GoTaq ${ }^{\circledR}$ Flexi DNA

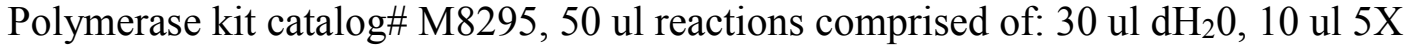
Green GoTaq ${ }^{\circledR}$ Flexi buffer, 0.5 ul dNTP [25 mM], 3 ul Magnesium Chloride Solution [25mM], 1 ul primer solutions; generally [10 mM], 1 ul DNA, 0.3 ul GoTaq ${ }^{\circledR}$ DNA Polymerase.

Genotyping for Atr ${ }^{\text {loxp/loxp }}$ (Lee, Shull et al. 2012) and Atm ${ }^{\text {loxp/loxp }}$ (Lee, Shull et al. 2012) was performed by PCR.

Prkdc genotyping by PCR used the following primers:

Prkdc Wild-type alleles were amplified with:

Forward primer: 5'-TGACAGCAAGTGCCTGTAAAGTGC-3'

Reverse primer: 5'-ATAGTCCCTTCAGACAGCCAGC-3'

The Prkdc-null allele was amplified in lines not crossed with cre using primers:

Forward primer: 5'-TGACAGCAAGTGCCTGTAAAGTGC-3'

Reverse primer: 5'-GAAGCGGGAAGGGACTGGCTGCTA-3'

The Prkdc-null allele was amplified in lines crossed with cre using primers:

Forward primer: 5'-TGACAGCAAGTGCCTGTAAAGTGC-3'

Reverse primer: 5'-CGCAGCGCATCGCCTTCTATCGCC-3'

Nestin-cre genotyping by PCR used the following general cre primers:

Forward primer: 5'-CTGCCACGACCAAGTGACAGC-3'

Reverse primer: 5'- ACCTGCGGTGCTAACCAGCG-3'

Emx 1-cre genotyping by PCR used the following primers:

Forward primer: 5'-CTGGCCACTCCTTAGCCAGGC-3'

Reverse primer: 5'-CATCACTCGTTGCATCGACCG-3'

p53 $3^{\text {loxp/loxp }}$ genotyping by PCR used the following primers:

p53 wild-type and null alleles were amplified using:

Forward primer: 5'-CACAAAAACAGGCAGAGAC-3'

Reverse primer: 5'-AGCACATAGGAGGCAGAGAC-3'

p534 allele was amplified by using the following primers: 
Forward primer: 5'-CACAAAAACAGGCAGAGAC-3'

Reverse primer: 5'-ATGGCGGGAAGTAGACTGGC-3'

p53 germ line wild-type alleles genotyped by PCR using the following primers:

Forward primer: 5'-ACAGCGTGGTGGTACCTTAT-3'

Reverse primer: 5'-TATACTCGAGCCGGCCT-3

$p 53$ germ line null alleles were amplified using primers:

Forward primer: 5'-TCCTCGTGCTTTACGGTATC-3'

Reverse primer: 5'-TATACTCAGAGCCGGCCT-3'

Lig $4^{\text {loxp/loxp }}$ mice were genotyped by PCR using the following primers:

Lig4 wild-type alleles were amplified using primers:

Forward primer: 5'-ATCGCTCTTGTCCCAGTACACCTGC-3'

Reverse primer: 5'-GTGCATTAAATGGAGTGCTGTGC-3'

Lig4-null alleles were amplified using the following primers:

Forward primer: 5'-CACCAGTTCCATCCTGTAGC-3'

Reverse primer: 5'-GTGCATTAAATGGAGTGCTGTGC-3'

\subsubsection{Real-time PCR}

RT-PCR was performed to determine the levels of gene deletion for Atr and Atm in conditional single-knockout, double-knockout, and triple knockout mice as previously described (Lee, Shull et al. 2012). Briefly, genomic DNA was extracted from tissue sections using phenol/chloroform and suspended in TE buffer. DNA concentration was determined using an UV/Visible Spectrophotometer at $\mathrm{A}_{260}$. DNA standards were prepared using serial dilutions at 1:5 beginning with a concentration of $100 \eta \mathrm{g} / \mu \mathrm{l}$. Test samples were diluted to a concentration of $100 \mathrm{\eta g} / \mu \mathrm{l}$ with an equal amount of DNA in each reaction. DNA was mixed with $\mathrm{iQ}^{\mathrm{TM}} \mathrm{SYBR}{ }^{\circledR}$ Green supermix (BioRad) containing forward or reverse primers for either the targeted exon 44 of Atr/ 58 of Atm, or the control exon 29 of Atr/ 52 of Atm. The reactions were carried out using a iQ ${ }^{\mathrm{TM}} 5$ Multicolor Real-Time Detection System (BioRad). SYBR Green concentrations were fit to a standard curve and used to automatically determine the reaction measurement numbers. Targeted exon product was normalized to control exon for each sample.

Atr exon 29 forward primer: 5' ACTCTGGCTGTAGCGTCCTTTC Atr exon 29 reverse primer: 5' TGCTTCTTTTCTGTAATAAATGACTCAAA

Atr exon 44 forward primer: 5' GAAAGGAGCTTCGCCAGTGT Atr exon 44 reverse primer: 5' GGGCAGGAGTAATTCTTGGAATAC Atm exon 52 forward primer: 5' ATGGAATGAAGATTTCATCCTATAAGTTT Atm exon 52 reverse primer: 5' ATCCTAGGCCTCCCGTCATTT Atm exon 58 forward primer: 5' TCAGCGAAGCGGTGTTCTC Atm exon 58 reverse primer: 5' TCATTTGGCCTGTATCTTCTATGTG 


\subsection{Histology}

Transcardial perfusions were performed on mice with $4 \%$ paraformaldehyde (PFA). Tissues were allowed to fix in $4 \%$ PFA over night at $4{ }^{\circ} \mathrm{C}$. The collected tissues were then cryoprotected in $25 \%$ PBS-buffered sucrose solution at $4^{\circ} \mathrm{C}$ for two weeks, and then embedded in clear tissue freezing medium (TFM ${ }^{\mathrm{TM}}$ ), catalog\# TFM-5. $10 \mu \mathrm{m}$ sagittal brain sections were collected using a Microm HM500M cryostat.

Immunohistochemistry and immunofluorescence were performed using the following antibodies were used following citrate based antigen retrieval: anti-KAP1phospho-Ser-824 (rabbit, 1:500; Bethyl labs); anti-active caspase-3 (rabbit, 1:500; BD Biosciences); anti-phospho-H2AX-Ser-139 (rabbit, 1:200; Cell Signaling); anti-phosphoH3-Ser-10 (rabbit, 1:500; Cell Signaling); anti-BrdU (rate, 1:500; Upstate); anti-Tuj1 (mouse; 1:500; Covance); anti-PCNA (mouse, 1:500; Santa Cruz). The antigen retrieval solution used was comprised of $41 \mathrm{~mL}$ of [0.1 M] sodium citrate, $9 \mathrm{~mL}[0.1 \mathrm{M}$ ] citric acid combined with $450 \mathrm{~mL}$ of $\mathrm{dH}_{2} 0$, and adjusted to $\mathrm{pH} 6.1$ using $\mathrm{N} \mathrm{NaOH}$. Tissue section slides were incubated in antigen retrieval solution for ten minutes at room temperature, and then heated twice for five minutes at $70 \%$ power using a microwave (topped off in between heating). Sections were allowed to cool to room temp for one hour, and washed with PBS three times for five minutes.

Immunohistochemical analyses: Sections were then quenched of endogenous peroxidase using $0.6 \%$ hydrogen peroxide solution in methanol $(2 \mathrm{~mL}(30 \%)$ from Fisher Chemical catalog\# H325-100 and $100 \mathrm{~mL}$ methanol) at room temperature for thirty minutes. Sections were then blocked using $500 \mathrm{uL}$ goat blocking solution per slide for one hour at room temperature (Goat blocking: $5 \mathrm{~mL}$ goat serum, $1 \mathrm{~g}$ recrystallized bovine serum, per $100 \mathrm{~mL}$ PBS-T (0.4\% Triton-X)). Primary antibodies were allowed to incubate overnight at room temperature in a humidified chamber. Tissues were treated with secondary biotinylated goat IgG (1:500; Jackson ImmunoResarch, catalog\# 705065-147) for 1.5 hours, followed by 1.5 hour incubation with avidin-biotin complex (ABC solution: 5 mL PBS to 1 drop A, 1 drop B; Vector Laboratories, Vectastain ABC Kit, Elite PK-6100 Standard). Immunoreactivity was visualized with VIP substrate kit (Vector VIP, SK-4600, Vector) using 500 ul VIP solution/ slide [VIP solution is comprised of $4.5 \mathrm{~mL}$ PBS, $0.5 \mathrm{~mL}$ PBS-T (0.4\% Triton-X), three drops Vector 1, 2, 3, and hydrogen peroxide] for experimentally determined times. Sections were counterstained with $0.1 \%$ methyl green (Vector Laboratories), dehydrated, and mounted with DPX (Fluka).

Immunofluorescent staining: After two, five minute washes with PBS, sections were washed with PBS-T $(0.4 \%$ Triton-X) for five minutes. Sections were then blocked using $500 \mathrm{uL}$ goat blocking solution per slide for one hour at room temperature (Goat blocking: $5 \mathrm{~mL}$ goat serum, $1 \mathrm{~g}$ recrystallized bovine serum, per $100 \mathrm{~mL}$ PBS-T $(0.4 \%$ Triton-X)). Primary antibodies were allowed to incubate overnight at room temperature in a humidified chamber. Signals were visualized using FITC (1:200) or Cy3 (1:400) 
conjugated secondary antibody (Jackson ImmunoResearch), and counterstained with 4'6'-diamidino-2-phenylindole (DAPI) or propidium iodide (Vector Laboratories).

In Vivo proliferation assays were carried out on pregnant females by peritoneal injection of BrdU at $50 \mu \mathrm{g} / \mathrm{g}$ of body weight (Sigma-Aldrich). The embryos were removed either 2 or $6 \mathrm{~h}$ after injection and fixed in $4 \%$ PBS-buffered PFA at $4{ }^{\circ} \mathrm{C}$ for 48 hours. Embryos were then cryoprotected in 25\% PBS-buffered sucrose solution at $4{ }^{\circ} \mathrm{C}$ for two weeks, and then embedded in clear tissue freezing medium (TFM ${ }^{\mathrm{TM}}$ ), catalog\# TFM-5. $10 \mu \mathrm{m}$ sagittal brain sections were collected using a Microm HM500M cryostat.

TUNEL was used to identify apoptotic cells according to manufacturer's instructions using ApopTag Fluorescein In Situ Detection S7110, Chemicon Intl. The $\mathrm{TdT}$ enzyme was incubated at $37^{\circ} \mathrm{C}$ for fifty minutes, and secondary fluorescein was incubated at room temperature for fifty minutes in the dark.

\subsection{In situ Cell Counts}

Quantification of immunopositive signals from anti-active caspase-3 and antiphospho-H3-Ser-10 were measured from at least three representative sections (images equivalent in size and magnification) per embryo brain. Three brains per genotype were analyzed for each time point. Immunopositive cells for active caspase-3 were measured within 10x images of the P5 CA1 region. P5 cerebellar cells were measured within 68 $\mu \mathrm{m}^{2}$ area for active caspase-3. The developing cerebellum was divided into two areas: white matter (WM) and the external granule layer (EGL). Immunpositive cells for antiphospho-H3-Ser10 in the apical region of the ventricular zone (VZ) of the embryonic forebrain were measured within 40x images $\left(\sim 168 \mathrm{~mm}^{2}\right)$ of E15.5 embryos. The bar graphs represent mean values of replicates, error bars s.e.m., and $P$ values were all calculated using unpaired Student's $t$ test, Prism (v5.0, Graphpad); $P<0.05$ was considered significant.

\subsection{Western Blots}

Western blot analyses were performed with cerebellar tissues of P5 and P0 cortices using control mice Prkdc ${ }^{+/+},\left[\right.$Atr $^{\text {loxp } / l o x p} ;$ Atm $^{\text {loxp/loxp }} ;$ Prk $\left.\mathrm{Cc}^{+/+}\right]$, or $\left[\right.$ Atr ${ }^{\text {loxp/loxp }} ;$ Atm $^{\text {loxp } / \text { loxp }} ;$ Prkdc $\left.^{+/-}\right]$, or $\left[\right.$Atr $^{\text {loxp } /+} ;$ Atm $^{\text {loxp/loxp }} ;$ Prkd $\left.^{+/-}\right]$, or $\left[\right.$ Atr ${ }^{\text {loxp } / \text { loxp }} ;$ Atm $^{\text {loxp } /+} ;$ Prkdc $\left.^{+/-}\right]$, or $\left[\right.$Atr $^{\text {loxp/+ }} ;$ Atm $^{\text {loxp } /+} ; P r k d c^{+/-} ;$Nes-cre $]$, and knockout mice Prkdc $^{-/}$, p53 $^{-/-}$, Atm $^{\text {Nes-Cre }}$, Atm $^{\text {Nes-Cre }} ;$ Prkdc $^{-/},\left[\right.$Atr $^{\text {loxp } / l o x p} ;$ Atm $^{\text {loxp/loxp }} ;$ Prkdc $^{-/-} ;$Nes-cre $]$.

Protein extraction: Extracts were prepared from lysis buffer $(50 \mathrm{mM}$ Tris- $\mathrm{HCl}$, $200 \mathrm{nM} \mathrm{NaCl}, 1 \%$ Tween-20, 0.2\% NP-40, 2 mM PMSF, $50 \mathrm{mM} \beta$-glycerol phosphate, half tablet of protease inhibitor cocktail (Roche Complete mini, Catalog \# 11836153 001) per 1-5 mL volume of lysis buffer, and half a tablet of phosphatase inhibitor cocktail (Roche Catalog \# 04906845 001) per 1-5 mL volume of lysis buffer. Proteins (at least $40 \mu \mathrm{g}$ per lane and up to $180 \mu \mathrm{g}$ per lane) were separated through 4-12\% Bis-Tris SDS 
polyacrylamide gel (Invitrogen, NuPage 4-12\% Bis-Tris Gels, $1.5 \mathrm{~mm}$ x 10 well; Catalog \# NP0335BOX). Tissue samples were suspended in lysis buffer, and allowed to lyse on shaker in a cold room for 2-3 hours. Once lysed, samples were spun at $4^{\circ} \mathrm{C}$ for ten minutes at maximum RPM.

Protein concentration: Protein concentrations were determined using the Bio-Rad Protein Assay (Catalog \# 500-0006) Bradford Reagent (1:5 dilution of Bradford reagent to water). $2 \mu \mathrm{L}$ of sample lysate was placed into $1 \mathrm{ml}$ of diluted Bradford reagent. A BSA standard plot was created using Excel XY plotting of BSA standards concentrations (1:10 dilution with a final concentration of $1 \mu \mathrm{g} / \mu \mathrm{l})$ and their respective absorbance reading at 595. The trend line of the BSA standard plot produced from the XY scatter plot in Excel was used to calculate sample protein concentrations.

Blots were transferred using pre-cooled NuPage transfer buffer $(50 \mathrm{~mL} 20 \mathrm{x}$

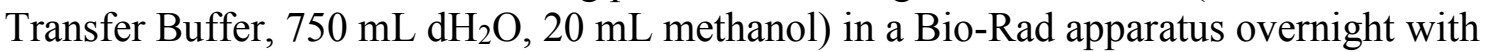
a stirrer in a cold room. The starting current ranged from 0.04-0.05 A. Voltage was adjusted to $40-50 \mathrm{~V}$ for this. Blots were transferred for 15-17 hours on $0.2 \mu \mathrm{m}$ nitrocellulose. Blots were blocked using 5\% milk prepared in TBS-T (10\% Tween-20) for one hour at room temperature on shaker. Blots were sequentially immunostained. Blots were washed in between staining with TBS-T for two hours at room temperature on shaker.

The following antibodies and conditions were used for immunostaining:

- DNA-PKcs: anti-DNA-PKcs Ab-4 Cocktail (mouse, 1/100; Fisher). Blot was stained with $50 \mu \mathrm{L}$ of antibody diluted into $4 \mathrm{~mL}$ TBS-T, plus $1 \mathrm{~mL} 5 \%$ milk (TBS-T) for two hours at room temp on shaker. The blot was then washed (three, five minute washes) with TBS-T before incubating with HRP-conjugated secondary antibodies (1:2000) in 5\% milk TBS-T for hour at room temperature. HRP antibodies were detected using SuperSignal chemiluminscence reagent (ThermoScientific).

- ATM: anti-ATM (D2E2) (rabbit, 1:1000; Cell Signaling), ATR: anti-ATR (goat, 1:500; Santa Cruz), Chk2 shift: anti-Chk2 (mouse, 1:1000; Millipore), pATM: anti-pATM(S1981) (mouse, 1:1000; Abcam), anti-p53(Ser18) (rabbit, 1:1000; Cell Signaling), anti-pKAP1(S824) (rabbit, 1:1000; Bethyl Labs), anti-KAP1 (rabbit, 1:2000; Abcam), anti-Actin (goat, 1:500; Santa Cruz) were all diluted using 5\% milk (TBS-T), and allowed to immunostain overnight on a shaker at room temperature. Blots were washed (three, five minutes washes) in TBS-T before incubating with HRP-conjugated secondary antibodies (1:2000) in 5\% milk TBS-T for hour at room temperature. HRP antibodies were detected using ECL Plus (GE Healthcare) or Super Signal (ThermoSci).

- Loading controls: Protein loading controls of the transferred membrane consisted of ponceau staining and anti-actin immunoblotting as described above. 


\section{CHAPTER 3. RESULTS}

\subsection{Introduction}

Maintaining genomic integrity during neurogenesis is essential to prevent neurologic disease (Abbaszadeh, Clingen et al. 2009, McKinnon 2013, Suberbielle, Sanchez et al. 2013, Chaudhary and Al-Baradie 2014). Genomic integrity can be compromised by DNA damage arising primarily from endogenous sources such as byproducts of oxygen metabolism or stalled replication forks, but also from exogenous sources such as gamma irradiation (Gulston, Fulford et al. 2002, Vignard, Mirey et al. 2013, Mazouzi, Velimezi et al. 2014). During neurogenesis, neural progenitors undergo rapid expansion requiring efficient DNA damage sensing, signaling, and repair to maintain development (McKinnon 2012, Greig, Woodworth et al. 2013, McKinnon 2013, Paridaen and Huttner 2014). Thus, how DNA damage signaling coordinates the appropriate responses to neurogenesis is fundamental for understanding brain development.

ATM, ATR, and DNA-PKcs (encoded by PRKDC) are related phosphatidylinositol-3-like serine/threonine kinases (PIKK) that coordinate the DNA damage response (DDR) to initiate DNA repair, activate cell cycle arrest to allow time for repair, or induce apoptosis if the lesions are irreparable (Serrano, Li et al. 2013, Sirbu and Cortez 2013, Yan, Sorrell et al. 2014). The activation of individual kinases is dependent upon by the type of DNA lesion generated. The inactive ATM homodimer undergoes intermolecular autophosphorylation to the active monomer upon the generation of DSBs (Bakkenist and Kastan 2003, Serrano, Li et al. 2013, Sirbu and Cortez 2013, Yan, Sorrell et al. 2014). ATM is then recruited to DSB sites by the MRN (Mre11/Rad50/Nbs1) complex to signal cell cycle arrest, facilitate DNA repair, or activate apoptosis in immature neural cells (Barlow, Brown et al. 1997, Uziel, Lerenthal et al. 2003, Buis, Wu et al. 2008, Shiloh and Ziv 2013). Topoisomerase-1 cleavage complexes have also been shown to specifically activate ATM signaling (Katyal, Lee et al. 2014). ATR is activated by the generation of RPA (replication protein A) bound single-stranded DNA generated by MRN resection of DSBs or replication stress (Cimprich and Cortez 2008, Nam and Cortez 2011). DNA-PKcs is recruited to DSBs by the heterodimer complex Ku70/80 to form the holoenzyme DNA-PK, which then recruits and activates other components involved in the non-homologous end-joining (NHEJ) pathway, the preferred DSB pathway in mammalian cells as it is accessible in both proliferating and non-proliferating cells (Dobbs, Tainer et al. 2010, Davis, Chen et al. 2014). Therefore, DNA-PKcs is directly involved in the repair of DSBs in addition to being a transducer of the DDR (Burma and Chen 2004, Douglas, Gupta et al. 2005, Davis, Chen et al. 2014).

In humans, the loss of ATM and hypomorphic ATR mutations can result in the neurodegenerative syndrome ataxia telangiectasia (A-T), or the neurodevelopmental disorder ATR-Seckel Syndrome (Taylor, Harnden et al. 1975, Gatti, Berkel et al. 1988, Becker-Catania, Chen et al. 2000, Brown and Baltimore 2000, de Klein, Muijtjens et al. 
2000, O'Driscoll, Ruiz-Perez et al. 2003, O'Driscoll, Dobyns et al. 2007, Chaudhary and Al-Baradie 2014). In humans, only two cases of PRKDC mutations have been linked to disease, despite cases of immunodeficiency syndromes documented in other various mammalian species (Gu, Sekiguchi et al. 2000, Meek, Kienker et al. 2001, Ding, Bramble et al. 2002, Meek, Jutkowitz et al. 2009, van der Burg, Ijspeert et al. 2009, van der Burg, van Dongen et al. 2009, Woodbine, Neal et al. 2013). The first patient to be identified with a $P R K D C$ mutation showed severed combined immunodeficiency (SCID) associated with a minor impairment in kinase autophosphorylation (van der Burg, Ijspeert et al. 2009). The second patient presented with microcephaly, severe neurological impairment, and SCID, associated with low, but detectable, levels of DNA-PKcs (van der Burg, Ijspeert et al. 2009, Woodbine, Neal et al. 2013). Thus, like ATR, DNA-PKcs function is likely require for human life. In contrast to humans, DNA-PKcs function in mice is dispensable for NHEJ (Gu, Sekiguchi et al. 2000, Douglas, Gupta et al. 2005). Consequently, DNA-PKcs function during neurogenesis is controversial with evidence suggesting DNA-PKcs loss leads to significantly higher levels of DNA damage induced p53-dependent cell death alone, with subsequent loss of PolBeta, and in response to excitotoxic injury (Chechlacz, Vemuri et al. 2001, Vemuri, Schiller et al. 2001, Neema, Navarro-Quiroga et al. 2005, Niimi, Sugo et al. 2005). Additionally, DNA-PKcs has been ascribed to a variety of apparent non-DNA-damage related roles (Wong and Sul 2009, Rajagopalan, Moyle et al. 2010, Kong, Shen et al. 2011).

How these three kinases collectively coordinate the appropriate responses to DNA damage within a physiological context remains unclear. Given each kinase is critical in the human nervous system, we focused on this tissue as a paradigm for understanding functional cooperativity between these key DDR transducers. One challenge to addressing these questions within a physiological context is embryonic lethality of mice after inactivation of Atr or Atm;Prkdc (Brown and Baltimore 2000, Gurley and Kemp 2001, Wong and Sul 2009, Rajagopalan, Moyle et al. 2010, Kong, Shen et al. 2011). Interestingly, single Atm and Prkdc knockouts are born healthy, suggesting ATM and DNA-PKcs are functionally redundant during early embryogenesis. Here, we explored how these kinases manage the DDR during neurogenesis using mice with germ line Dnapkcs (encoded by Prkdc) inactivated in combination with conditional deletion of Atm and/or Atr function selectively in the murine nervous system.

Here we show that during murine neurogenesis DNA-PKcs most likely functions classically as a component of the DNA-PK holoenzyme to enhance NHEJ repair of DSBs. The combined loss of DNA-PKcs with ATM and/or ATR increased cell death in a p53 dependent manner. Our data provides direct evidence that p53 dependent IR-induced apoptosis can occur independent of ATM and ATR (Herzog, Chong et al. 1998, Gatz, Ju et al. 2011), which may be useful for understanding why subsequent deletion of $p 53$ but not Atm rescues Lig4 mutants from IR-induced apoptosis (Gurley, Moser et al. 2009, Shull, Lee et al. 2009). Furthermore, we demonstrate ATR controls the IR-induced G2 to $M$ checkpoint independent of ATM or DNA-PKcs status, challenging in vitro studies (Bartek and Lukas 2001, Jazayeri, Falck et al. 2006, Stiff, Walker et al. 2006, Gurley, Moser et al. 2009, Shull, Lee et al. 2009, Tomimatsu, Mukherjee et al. 2009). Our data is the first to show the dynamic interdependence on these three kinases within a 
physiological context to protect genomic integrity during neurogenesis, which affords proper brain development.

\subsection{Results}

\subsubsection{DNA-PKes loss sensitizes selective neurons to apoptosis in the postnatal brain}

While ATM and ATR are directly linked to neural maintenance, the role(s) for DNA-PKcs in this tissue remain less clear. DNA-PKcs has been linked to the excitotoxic stress response, and recently, as a critical factor for human brain development (Neema, Navarro-Quiroga et al. 2005, Woodbine, Neal et al. 2013). To address this, we examined the requirement for DNA-PKcs during neurogenesis and challenged these mice to doses of 4 or 10 Gy at postnatal day 5 (P5) and allowing six hours of recovery. In the DNAPKcs-null cerebellum, enhance cell death based on levels of active Casp-3 was found in areas of active neurogenesis including the EGL and WM compared to the control (Figure 3-1B). Notably, Prkdc loss sensitizes the postmitotic population of the CA1 (Cornu Amonis) region of the hippocampus as active Casp-3 was found (Figure 3-1A, B) distributed throughout this region in the DNA-PKcs-null mouse. Interestingly, we observed similar amounts of Casp-3 immunopositive cells, but with increased intensity of staining in the dentate gyrus (DG) of $P r k d c^{-/}$compared to control. In regards to comparing Prkdc loss in mature vs. immature cerebellar neurons, granule cell progenitors that comprise the EGL (external granule layer) are more sensitive to Prkdc loss upon DNA damage than post-mitotic neurons in the white matter (WM) because mature, nonproliferating neurons are generally resistant to IR-induced apoptosis (Puck and Marcus 1956, Romero, Gross et al. 2003). Thus, our observation of active Casp-3 staining in the mature neurons in the CA1 region of $\mathrm{Prkdc}^{-/-}$compared to control was unexpected. This is the case because even at $10 \mathrm{~Gy}$, control tissue failed to show active Casp-3 staining, suggesting that direct DNA damage per se was not causative for this response, moreover mature tissue in the brain are known to be resistant to apoptosis after radiation. To verify the effect of Prkdc loss was specific to mature CA1 neurons, immature, non-cycling hippocampal neurons were distinguished from mature, non-cycling neurons using proliferation marker Ki67 (Figure 3-1C)

p53-null immature neurons are resistant to IR-induced apoptosis (Herzog, Chong et al. 1998). To verify if $p 53$ is also required for the activation of active Casp-3 observed in IR-treated Prkdc deficient CA1 mature neurons we treated P14 Prkdc ${ }^{-/}$and Prkdc/$; p 53^{-/-}$with a dose of $10 \mathrm{~Gy}$, and allowed them to recover for six hours. We did not observe any active Casp-3 in the CA1 region of the treated control or Prkdc ${ }^{-/}$at P14. However, we did observe active Casp-3 in treated Prkd ${ }^{-/}$and NHEJ deficient mutant Lig $4^{\text {Nes-cre }}$ that is absent in Prkdc $c^{-/-} ; 53^{-/-}$with respect to the proliferating DG (Figure 3-1D). Data suggests $p 53$ is required to activate Casp-3 in Prkdc deficient proliferating neurons in response to DNA damage. The function of DNA-PKcs and p53 signaling in P5 CA1 neurons remains unclear. 


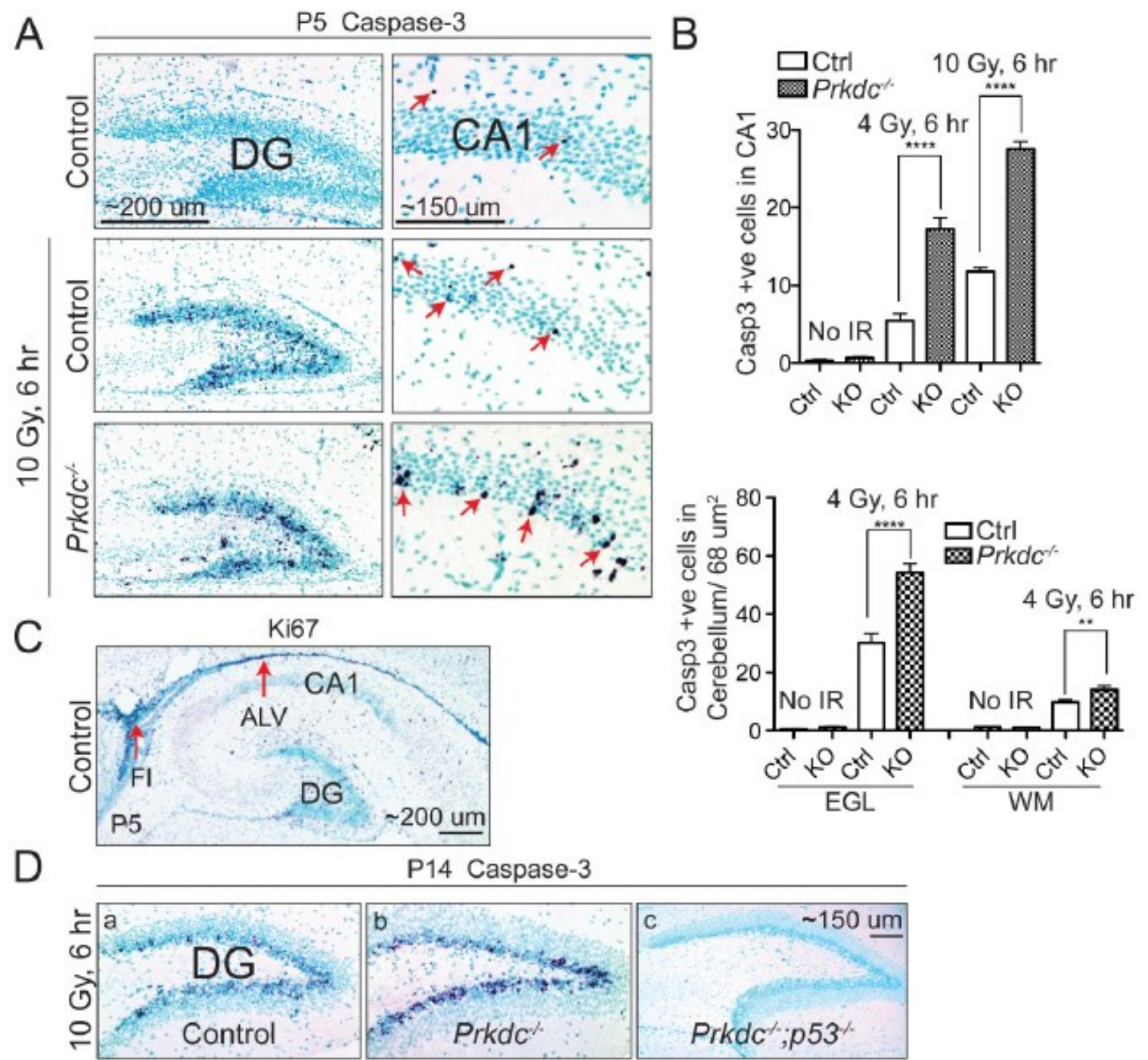

Figure 3-1. DNA-PKcs loss increases sensitivity to apoptosis in select neurons in the postnatal brain.

(A) Anti-active caspase-3 (Casp-3) immunostaining demonstrates DNA-PKcs loss sensitizes the cornu ammonis 1 (CA1) in the hippocampus. Immunostaining of the dentate gyrus (DG) shows similar amounts of immunopositive Casp-3 cells, but with stronger staining in the Prkdc $c^{-/}$compared to control. (B) At postnatal day 5 (P5), quantitative analysis shows radiation induced apoptosis is significantly greater in the CA1 region of Prkdc ${ }^{-/}$compared to control at both 4 and $10 \mathrm{~Gy}$. (C) Immunostaining of P5 untreated control with proliferation marker Ki67 demonstrates CA1 neurons are noncycling compared to cycling immunopositive cells in the DG. (D) Active caspase-3 staining of P14 DG shows radiation-induced apoptosis in Prkdc requires $p 53$. The bar graphs represent mean values of replicates ( $\mathrm{n}=3$ animals per group, 9 images per group), error bars s.e.m.; $* * P=0.0080, * * * * P<0.001$. $P$ values were all calculated using unpaired Student's $t$ test, Prism (v5.0, Graphpad); P $<0.05$ was considered significant. 
To determine the basis for enhanced sensitivity to genotoxic stress we considered that his could be due to either increased DNA damage because of compromised NHEJ, or a defect in kinase activity after DNA-PKcs loss that affected DNA damage signaling. While DNA-PKcs is involved in NHEJ, it's not critical for organismal development, in contrast to other evolutionary conserved NHEJ components such as DNA Ligase IV (Lig4) (Gu, Sekiguchi et al. 2000, Douglas, Gupta et al. 2005, Tomimatsu, Tahimic et al. 2007, Gatz, Ju et al. 2011). However DNA-PKcs phosphorylates histone H2AX (phospho S139) to generate $\gamma \mathrm{H} 2 \mathrm{AX}$ foci after DNA DSBs to facilitate the DNA damage response, and it has been implicated in other diverse processes (Stiff, O'Driscoll et al. 2004, Dickey, Redon et al. 2009, An, Huang et al. 2010, Rajagopalan, Moyle et al. 2010, Kong, Shen et al. 2011, Goodwin and Knudsen 2014). Thus, the effect of DNA-PKcs loss toward the hypersensitivity of neural cells to DNA damage could result from multiple factors.

DNA-PKcs suppression of ATM IR-induced apoptotic signaling was a possible factor of interest as ATM is a key effector of p53-dependent IR-induced apoptosis in nonproliferating neurons (Herzog, Chong et al. 1998). Thus, we explored a requiremet for ATM signaling IR-induced active Casp-3 observed in IR treated Prkdc ${ }^{-/}$. ATM phosphorylation of KAP-1 (phospho S824) is important for accessing IR-induced DSBs occurring in heterochromatin for repair (Ziv, Bielopolski et al. 2006, Noon, Shibata et al. 2010, Goodarzi, Kurka et al. 2011). Histological analyses employing KAP-1 (phospho S824) showed that not only was staining substantially greater in treated Prkdc compared to control (Figure 3-2A), but also distributed throughout the CA and DG in contrast to active Casp-3 staining. Similarly, greater staining of anti- $\gamma \mathrm{H} 2 \mathrm{AX}$ (Ser139) foci, a marker of DSBs in chromatin, was observed in the CA1 region in treated Prkdc ${ }^{-/}$compared to control (Figure 3-2B).

Together, the data suggests Prkdc loss sensitizes neurons to DNA damage, which amplifies ATM signaling. Thus, DNA-PKcs may reduce excessive exogenous DNA damage in the postnatal murine brain, likely via NHEJ, enhancing DSB repair kinetics, and this is critical for replicating cells, but also in select postmitotic regions. Alternatively, DNA-PKcs might function in the developing nervous system to suppress IR-induced ATM-dependent signaling to minimize neuronal loss during development. In the alternative case, DNA-PKcs function is likely beneficial in the short term by maintaining critical development schedules during early development. However, rescuing DNA damaged neurons from IR-induced apoptosis during this critical time could predispose the nervous system to disease in the long term; particularly organisms that have larger neural expansions, and live for longer periods of time unlike mice.

\subsubsection{DNA-PKes enhances NHEJ}

To further understand how DNA-PKcs modulates DNA damage related effects, we utilized the developing neocortex as a model system to carefully delineate the spatiotemporal effects of the cellular response to genotoxic stress. In the murine 
A
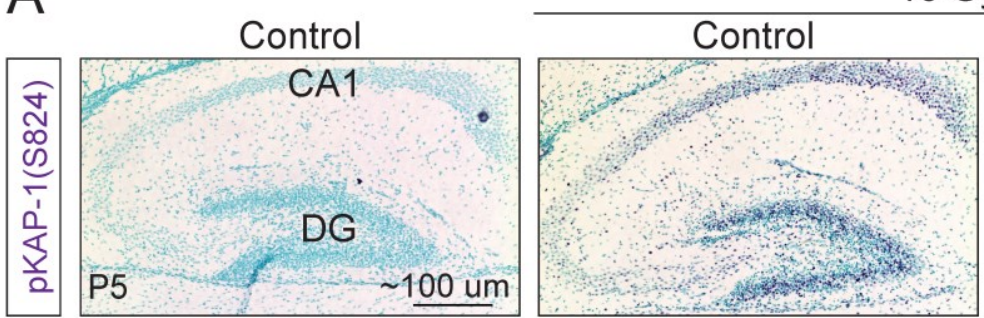

$10 \mathrm{~Gy}, 6 \mathrm{hr}$
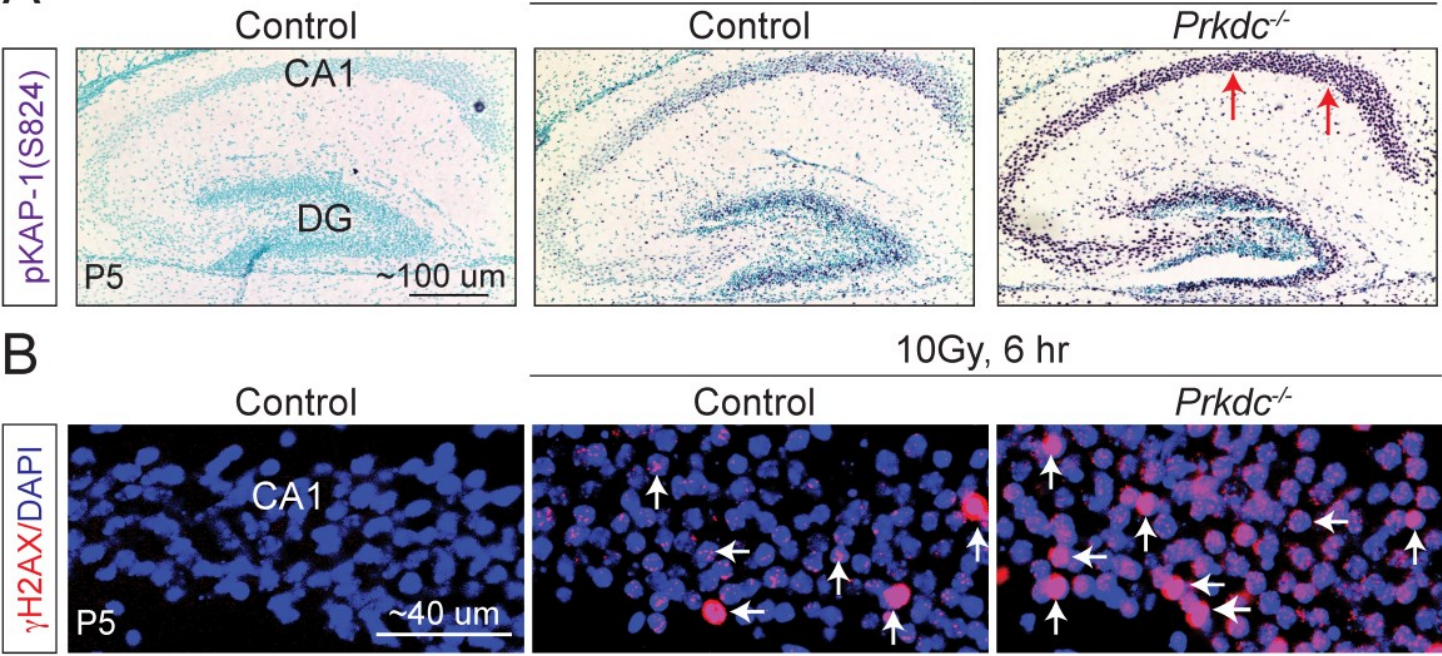

Figure 3-2. DNA-PKcs loss increases DSB signaling after IR.

(A) KAP-1 (phospho S824) immunostaining of the hippocampus and (B) $\gamma \mathrm{H} 2 \mathrm{AX}$ foci staining in the CA1 are both increased in irradiated postnatal day 5 (P5) Prkdc ${ }^{-/}$ compared to controls. Red and white arrows indicate immunopositive cells. 
neocortex the ventricular zone (VZ) is where neural stem/progenitors proliferate, and the subventricular zone (SVZ) is where the majority of neural cells exit the cell cycle and differentiate. Differentiating cells occupy the intermediate zone (IZ), and the cortical plate (CP) is where mature neurons and glial cells reside (Molyneaux, Arlotta et al. 2007). Thus, the cortex provides an in vivo setting to elucidate how the DDR functions physiologically. DNA-PKcs and the NHEJ DSB repair pathway function in both proliferating and non-proliferating cells, although, NHEJ is the only DSB repair pathway available in non-proliferating cells at $\mathrm{HR}$ is limited to S/G2 phases of the cell cycle as it requires access to sister chromatids to use as templates for repair (McKinnon 2009). Therefore, we hypothesized that if DNA-PKcs functions primarily as a DNA repair factor, its loss would likely have the greatest effect on cells in the IZ and CP.

We analyzed the developing cortex of E15.5 Prkdc $^{-/-}$embryos and assessed IRinduced ATM-dependent phosphorylation of KAP-1 (phospho S824). We determined ATM-dependence by crossing conditional $\mathrm{Atm}^{\text {Nes-cre }}$ mice onto a Prkdc ${ }^{-/}$background to produce $\left[\mathrm{Atm}^{\mathrm{Nes}-\mathrm{cre}} ; \mathrm{Prkd}^{-/-}\right]$animals and exposed these E15.5 compound mutants to $4 \mathrm{~Gy}$ of IR with recovery times of 1 or $6 \mathrm{hr}$. Immunostaining of $\mathrm{dKO}$ cortices confirmed DNA-PKcs loss significantly increases the number of KAP-1 (phospho S824) positive cells in an ATM-dependent manner as staining is absent in both $\mathrm{Atm}^{\text {Nes-cre }}$ and $\mathrm{Atm}^{\text {Nes- }}$ ${ }^{c r e}$;Prk $d c^{-/}$] (Figure 3-3A). At $1 \mathrm{hr}$, KAP-1 (phospho S824) showed ATM activity increases with increasing neural differentiation in treated Prkdc ${ }^{-/-}$compared to control (Figure 3-3A). By $6 \mathrm{hr}$, only the CP neurons are KAP-1 (phospho S824) positive in $\mathrm{Prkd}^{-/-}$compared to control, consistent with slower repair in non-cycling differentiated cells containing higher concentrations of heterochromatin, requiring longer recovery time. We also confirmed increased IR-induced ATM-dependent signaling using Western blot analyses of treated P5 Prkdc ${ }^{-/}$cerebellum, which showed p53 (phospho S15) and KAP-1 (phospho S824) activation were elevated compared to treated control, but attenuated in treated $\left[\mathrm{Atm}^{\text {Nes-cre }} ; \mathrm{Prkdc}^{-/}\right]$and $\mathrm{Atm}^{\text {Nes-cre }}$ tissues (Figure 3-3B).

After assessing IR-induced ATM activity in the absence of DNA-PKcss we used the developing cortices to identify when Prkdc deficiency effects DDR signaling. For these experiments, we used a lower IR dose of 2 Gy, to induce fewer DSBs, reducing the overall recovery time, to capture a more complete picture of DDR signaling at E15.5. We found the majority of IR-induced DNA damage is resolved by $6 \mathrm{hr}$ post-IR via immunostaining with DSB heterochromatin marker KAP-1 (phospho S824), and identified the greatest difference in KAP-1 (phospho S824) levels between Prkdc and control occurred at $3 \mathrm{hr}$ post-IR (Figure 3-4A). Higher levels of DNA damage in treated $\mathrm{PrkdC}^{-/-}$three hours post-IR were also associated with greater death compared to treated controls, as determined by active Casp-3 and TUNEL immunostaining (Figure 3-4B, C). KAP-1 (phospho S824) staining and apoptotic levels in controls were similar to Prkdc ${ }^{-/}$ by 6 hours post-IR. In contrast to TUNEL, active Casp-3 stain localized in the VZ and CP layers in both Prkdc ${ }^{-/}$and control at $3 \mathrm{hr}$ post-IR (Figure 3-4B, C). Unexpectedly, active Casp-3 stain shows apoptotic induction begins in the CP and VZ layers (outer regions), and spreads inwards towards the IZ, which eventually appears equally distributed throughout all layers under normal conditions. 

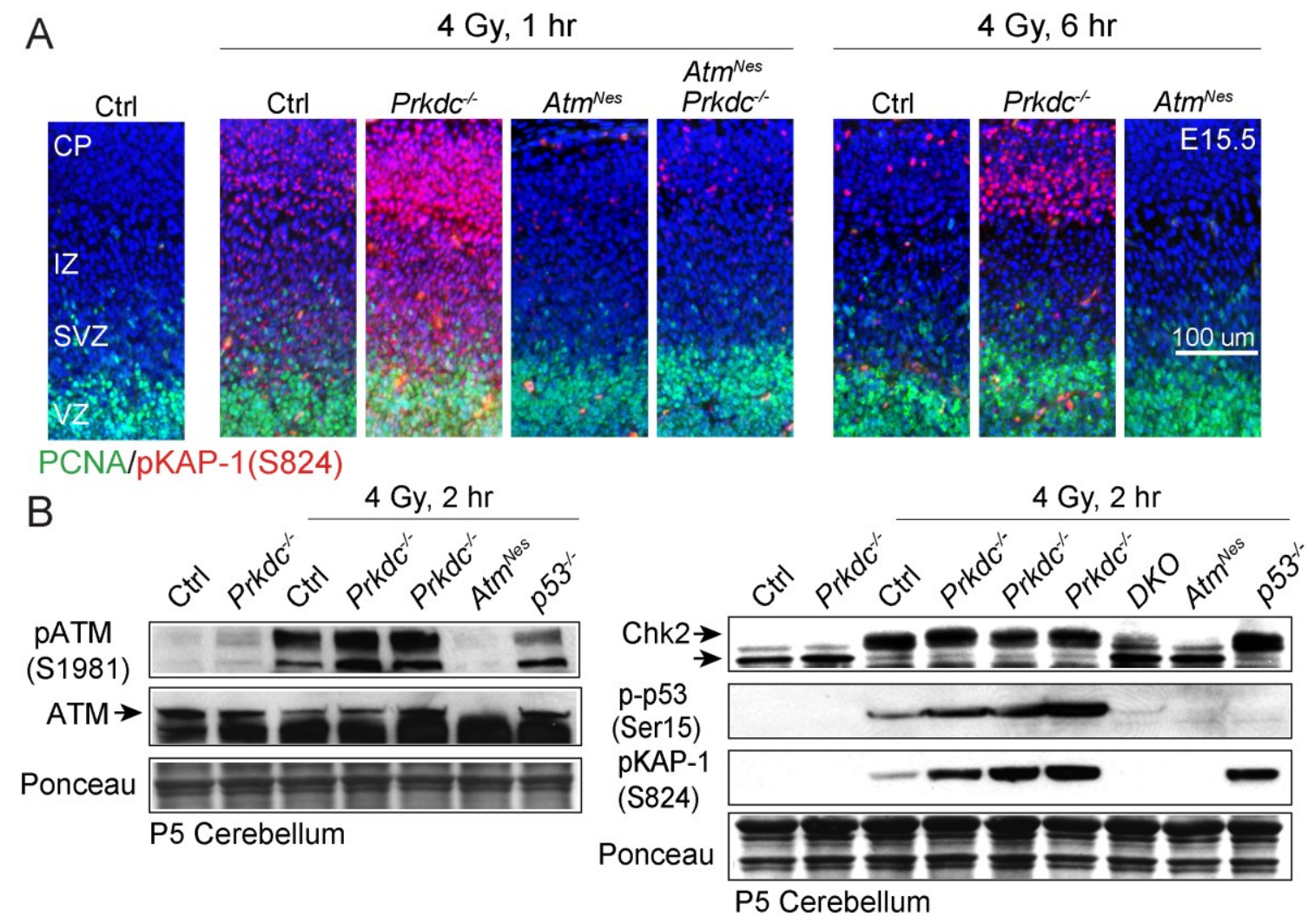

Figure 3-3. DNA-PKes loss increases ATM signaling after IR.

(A) The phosphorylation of KAP-1 (phospho S824) (red) at $1 \mathrm{hr}$ post-IR is increased in Prkdc ${ }^{-/}$compared to controls, and persists in Prkdc/- $6 \mathrm{hr}$ after ionizing radiation compared to controls. Immunostaining of $\left[\mathrm{Atm}^{\text {Nes-cre }} ; \mathrm{Prkdc}^{-/-}\right]$demonstrates IR-induced phosphorylation of KAP-1(phospho S824) in embryonic neurons occurs in an ATMdependent manner. PCNA (green) immunostaining identified proliferating cortical neurons in E15.5 neocortices. CP: cortical plate, IZ: intermediate zone, SVZ: subventricular zone, VZ: ventricular zone. Sections were counterstained with DAPI (blue). (B) After IR, ATM (phospho S1981), p53 (phospho S15), and KAP-1 (phospho 824) phosphorylation was increased in $\mathrm{Prkdc}^{-/-}$cerebellar tissues, whereas Chk2 levels were equivalent (Chk2 band shift). The absence of p53 (phospho S15) and KAP-1 (phospho S824) signal in $\left[\right.$ Atm $^{\text {Nes-cre }} ;$ Prkdc $\left.^{--}\right]$demonstrates ATM-dependent activation of these substrates. Ponceau staining shows equal protein loading and transfer. 

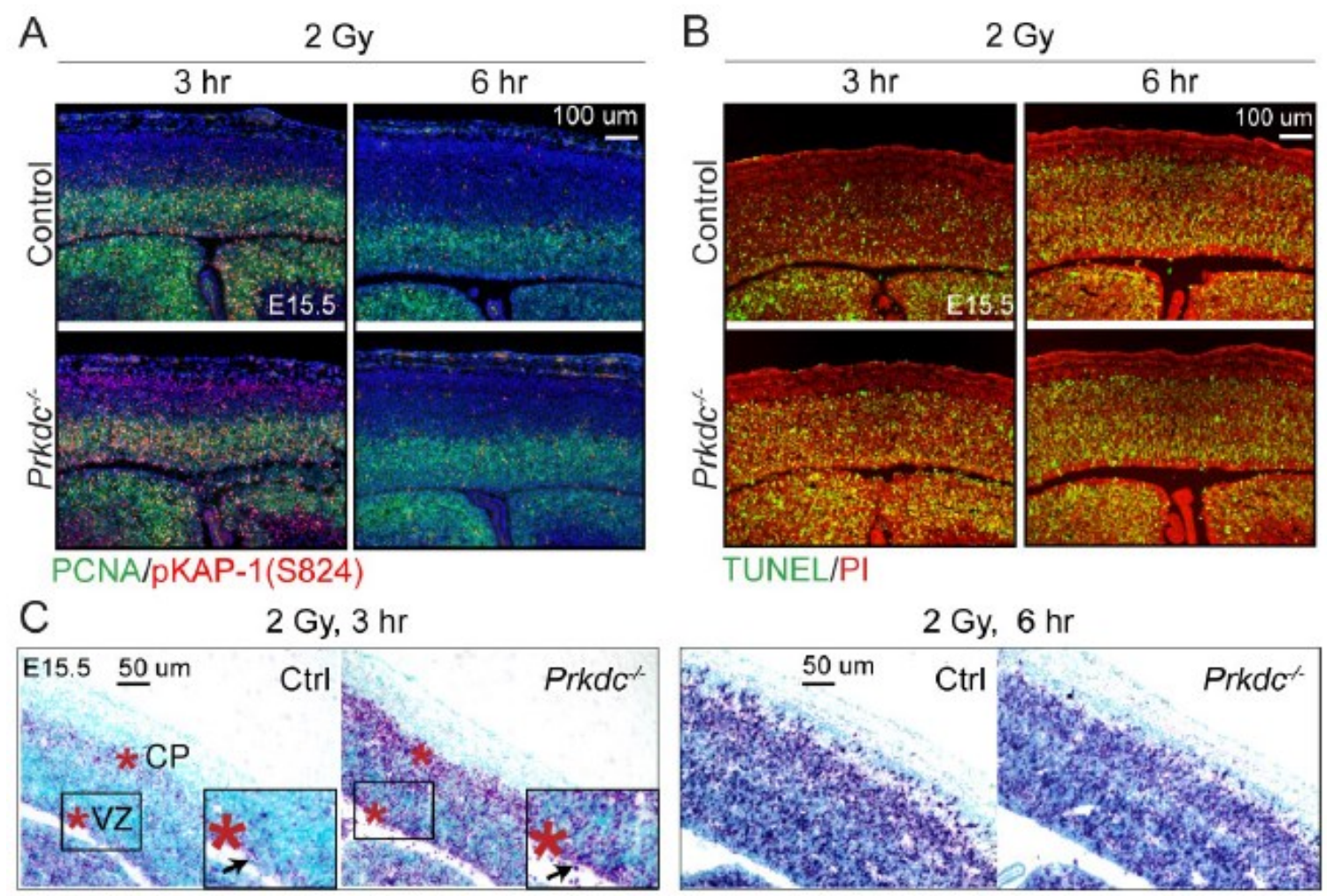

Caspase-3

Figure 3-4. DNA-PKcs loss impairs NHEJ.

(A) Using a lower dose of IR to induce fewer DSBs identified the greatest difference between KAP-1 (phospho S824) levels between treated Prkdc/-- and control occurred at 3 hr post-IR, whereas levels were similar by $6 \mathrm{hr}$ post ionizing radiation. Similarly, higher levels of DNA damage induced cell death occurred at $3 \mathrm{hr}$ post-IR in treated Prkdc/compared to controls as determined by active caspase-3 (B) and TUNEL (C immunostaining, which were similar by $6 \mathrm{hr}$ post-IR. 
Our data implies Prkdc deficiency increases levels of DNA damage and accelerates apoptotic induction to IR, resulting in early increases of cell death in Prkdccompared to control. Collectively, the transient attenuated DDR observed in treated Prkdc tissues suggests DNA-PKcs loss delays the repair of DSBs, which the DDR integrates as a greater induction of DNA damage. Thus, during murine neurogenesis DNA-PKcs likely functions classically as a component of the DNA-PK holoenzyme to enhance NEHJ repair of DSBs.

\subsubsection{Integration of apoptotic signaling of DNA damage is dynamic}

To further our analysis of DNA-PKcs and its role in responding to DNA damage during neural development we determined if the additional combinatorial loss of ATM and/or ATR with DNA-PKcs would alter IR-induced apoptotic signaling dynamics in the E15.5 developing cortex. For these experiments we generated mice with germ line Dnapkcs inactivated in combination with conditional disruption of Atm and/or Atr function selectively in the nervous system using Nestin-cre. E15.5 embryos of various genotypes were exposed to an IR dose of $4 \mathrm{~Gy}$, and allowed to recover for six hours. Histological analyses of these cortices using active Casp-3 showed that while ATM loss lacked Casp3 activation, the combined loss of Prkdc with $\mathrm{Atm}\left[\mathrm{Atm}^{\text {Nes-cre }} ; \mathrm{Prkdc}^{-/-}\right]$, or Prkdc with $\mathrm{Atr}$ $\left[\right.$ Atr $^{\text {Nes-cre }} ;$ Prkdc $\left.^{-/}\right]$, resulted in further sensitization of neurons to IR-induced apoptosis compared to their respective single knockout $\mathrm{Atm}^{\text {Nes-cre }}$ or $A t r^{\text {Nes-cre }}$, especially in CP neurons (Figure 3-5). This data indicates the DDR likely integrates the effects of DNAPKcs loss with effects attributed to ATM or ATR loss, amplifying apoptotic signaling, resulting in more death. The combined loss of Atm and Atr [(Atm;Atr $\left.)^{\text {Nes-cre }}\right]$ completely eliminated IR-induced apoptotic signaling throughout the cortex as demonstrated by a lack of active Casp-3 staining. Following these same pattern, the additional deletion of Prkdc with Atm and Atr [(Atm;Atr $)^{\text {Nes-cre }} ;$ Prkd $^{-/-}$; hereafter TKO], sensitized predominantly non-proliferating neurons to IR-induced death, and active Casp-3 staining increased with neuronal differentiation.

\subsubsection{Ionizing radiation-induced p53-dependent apoptosis occurs independent of ATM and ATR}

During neurogenesis, p53 is required for IR-induced apoptosis in the embryonic murine brain (Herzog, Chong et al. 1998, Gatz, Ju et al. 2011). Interestingly, Atm loss also rescues p53 proficient neurons from IR-induced apoptosis suggesting ATM is also essential for IR-induced apoptosis (Herzog, Chong et al. 1998). Our studies suggest IRinduced p53-dependent cell death can occur when all three DNA-damage signaling kinases are absent, similar to Ligase IV IR response (Lee, Barnes et al. 2000, Shull, Lee et al. 2009, Gatz, Ju et al. 2011). Since ATM and ATR were conditionally deleted we wanted to verify protein expression of ATM and ATR was sufficiently suppressed in the TKO. Western blot analyses of untreated and IR treated TKO cortices confirmed efficient protein deletion of all three kinases, eliminating residual protein as a source for the IR-induced apoptosis observed in treated TKO (Figure 3-6A). To further exclude the 
Figure 3-5. Integration of apoptotic signaling of DNA damage by ATM, ATR, and DNA-PKes.

IR-induced apoptotic signaling assessed by active caspase-3 immunostaining of E15.5 cortices. (A) Control levels of apoptosis shown with the relative cortical layers: cortical plate (CP; highlighted by black boxes), sub-plate (SP), subventricular zone (SVZ), ventricular zone (VZ) are listed. (B) Prkdc loss sensitizes neurons to ionizing radiation, particularly neurons in the CP. (C) Atm ${ }^{\text {Nes-cre }}$ deletion substantially reduced apoptotic signaling after IR. (D) Coincident loss of $\mathrm{Atm}^{\mathrm{Nes}-\mathrm{Cre}}$ with Prkdc/- increased levels of apoptosis compared to Atm $^{\text {Nes-cre }}$ alone. (E) Apoptosis in Atr ${ }^{\text {Nes-cre }}$ is similar to control. (F) Coincident loss of $A t r^{\text {Nes-cre }}$ with Prkdc further sensitizes cortical neurons to IR compared to Atr $r^{\text {Nes-cre }}$ alone. (G) The combined loss of Atm ${ }^{\text {Nes-cre }}$ and Atr Nes-cre eliminates IR-induced apoptotic signaling. (H) Prkdc loss continues to sensitize cortical neurons to IR-induced apoptosis even in the absence of $\mathrm{Atm}^{\text {Nes-cre }}$ and $\mathrm{Atr}^{\mathrm{Nes}-\mathrm{cre}}$. 


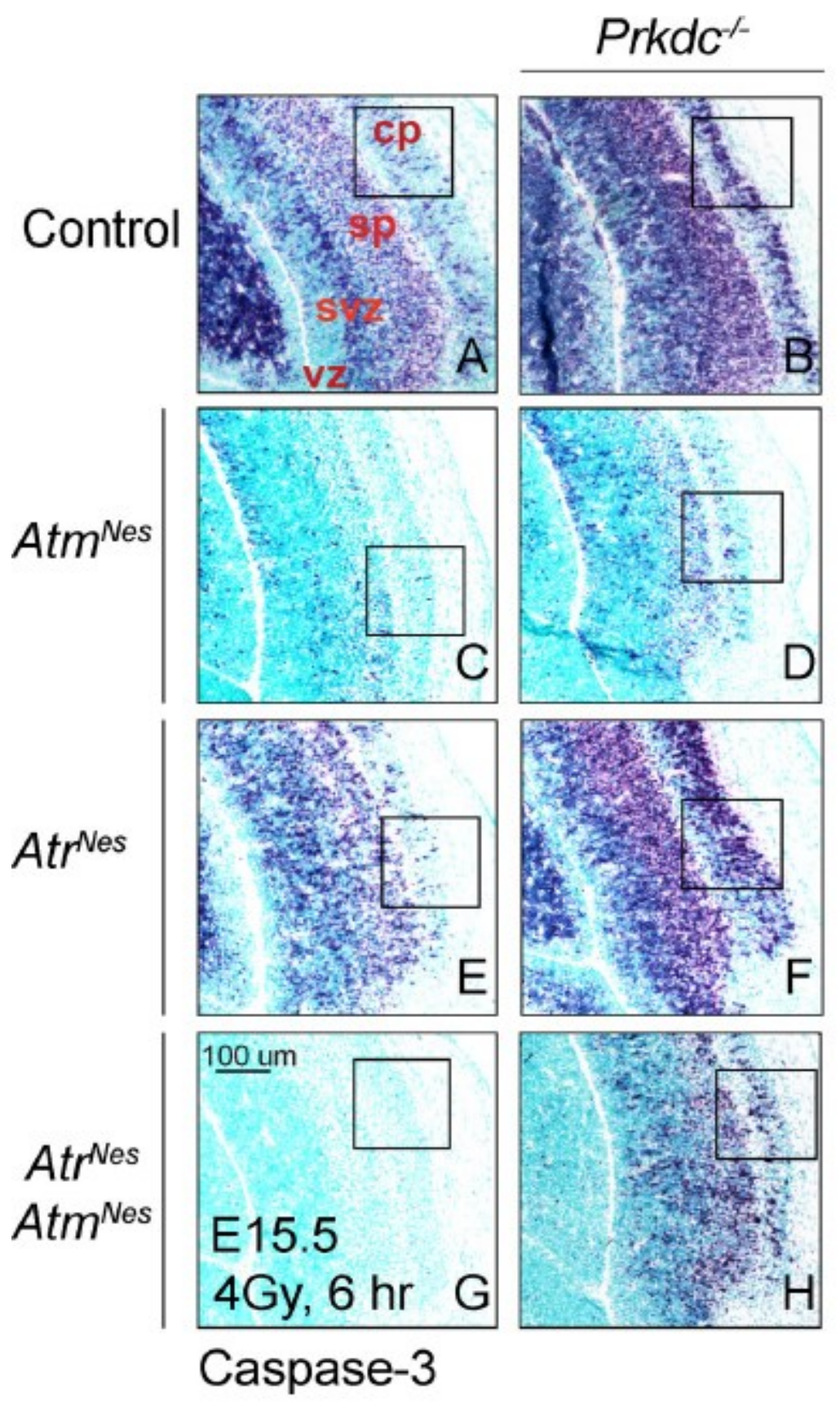



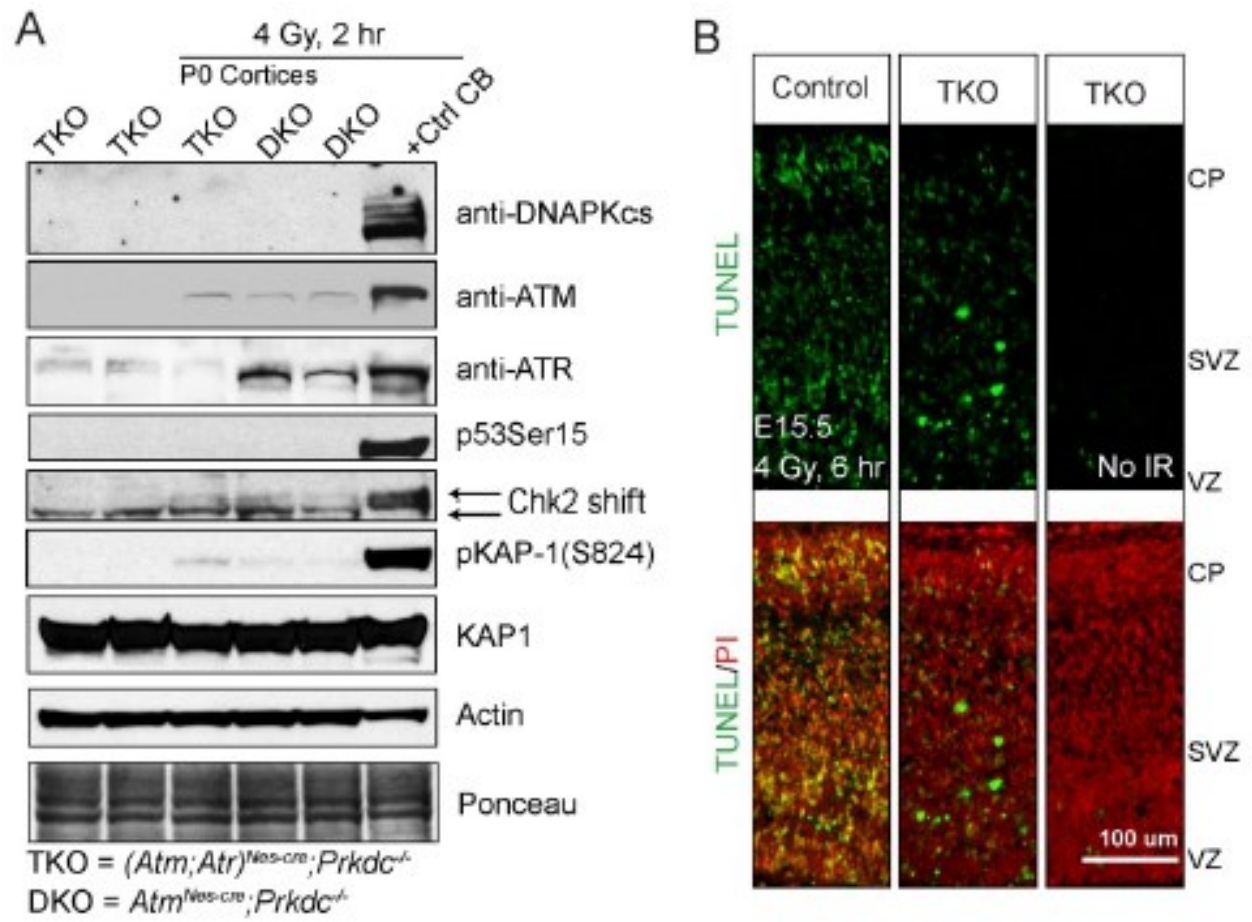

Figure 3-6. Apoptosis in TKO occurs independent of ATM and ATR and is IRinduced.

(A) Western blot analyses confirm significant protein deletion of ATM, ATR and DNAPKcs of postnatal day 0 (P0) TKO cortices. (B) TUNEL analysis of treated and untreated TKO E15.5 cortices shows that cell death is induced rather than endogenous. The layers are labeled: cortical plate (CP), subventricular zone (SVZ), and ventricular zone (VZ). 
possibility of an endogenous induction of apoptosis occurring in the absence of all three kinases we analyzed untreated and treated TKOs and controls using the TUNEL assay. TUNEL staining verified the cell death observed in the treated TKOs using active Casp-3 was IR-induced an not an endogenous effect, as TUNEL signal was completely absent in untreated TKO compared to IR treated TKO and controls (Figure 3-6B). Lastly, RTPCR was employed to confirm efficient conditional deletion of Atm and Atr by Nestin-cre in brain tissue sections (Figure 3-7A). PCR of respective brain tissue sections was employed to confirm the TKO genotypes (Figure 3-7B).

To determine whether or not the IR-induced apoptosis observed in the absence of these three kinases required $p 53$ we generated mice with germ line Dna-pkcs inactivated (encoded by Prkdc) in combination with p53-null, as well as in combination with conditional disruption of Atm, Atr, and $p 53$ function selectively in the murine cortex using Emx l-cre (Gorski, Talley et al. 2002). We began with verifying a requirement for p53 signaling of IR-induced apoptosis in E15.5 treated Prkdc/- using an IR dose of 2 Gy, and a $3 \mathrm{hr}$ recovery since these were the conditions where we previously observed the greatest difference in embryonic IR-induced cell death between rrk $^{-/-}$and control. Again, we observed active Casp-3 staining in treated $\operatorname{Prk}^{-/-}$, but not in $\left[\operatorname{Prkdc}^{-/} ; \mathrm{p5}^{-/-}\right]$, confirming the requirement for p53 in signaling DNA damage induced apoptosis in the absence of Prkdc alone in embryonic cortices (not shown).

Next, we analyzed the Emxl-cre compound mutants. The use of Emxl-cre overcame postnatal lethality observed in TKO pups shortly after birth. Therefore, we anticipated $p 53$ deletion would rescue $\left[(\text { Atm; Atr })^{\text {Emxl-cre }}\right]$ cortical neurons from IRinduced cell death. Indeed, histological analyses using active Casp-3 did not indicate any IR-induced cell death in irradiated cortices of [(Atm;Atr;p53 $)^{\text {Emxl-cre }]}$ embryos compared to control (Figure 3-8A, B). We hypothesized that if a p53-independent apoptotic pathway was involved in IR-induced cell death observed in [ $\mathrm{Atm} ; \mathrm{Atr})^{\mathrm{Nes}-\mathrm{cre}} ; \mathrm{Prkdc}^{-/}$; TKO], then germ line deletion of Prkdc along with Emxl-cre conditional deletion of Atm, Atr, and p53 would be positive for active Casp-3. However, irradiated [(Atm;Atr;p53) Emxl-cre $;$ Prkdc $c^{-/}$; hereafter quadruple knockout, QKO] cortices were also negative for active Casp-3 (Figure 3-8C). These data indicated that all the IR-induced cell death requires p53, and further implies p53 activation is not limited to PIKK DNAdamage signaling kinases during neurogenesis.

Proliferating cell nuclear antigen (PCNA) is an important factor for DNA replication and repair in proliferating neurons. Under normal conditions PCNA stain is nuclear in proliferating cortical neural stem/progenitor cells, but become peri-nuclear after IR (Figure 3-9). Per-nuclear PCNA immunostaining was observed in IR treated control, Prkdc $c^{-/}$, and $A t r^{\text {Nes-cre }}$ (Figure 3-9A). In contrast, PCNA staining of treated Atm $^{\text {Nes-cre }}$ cortices looked identical to untreated control. To determine if the PCNA pernuclear stain was associated with apoptotic nuclei we co-immunostained PCNA with $\gamma \mathrm{H} 2 \mathrm{AX}$ (phospho Ser139) in Atr $^{\text {Nes-cre }}$ since ATM and DNA-PK phosphorylate $\gamma \mathrm{H} 2 \mathrm{AX}$ (phospho Ser139) in a redundant manner in response to IR (Stiff, O'Driscoll et al. 2004), and pan-nuclear $\gamma \mathrm{H} 2 \mathrm{AX}$ staining is associated with apoptotic nuclei. We observed perinuclear PCNA immunostaining with and without co-localization with pan-nuclear 
A
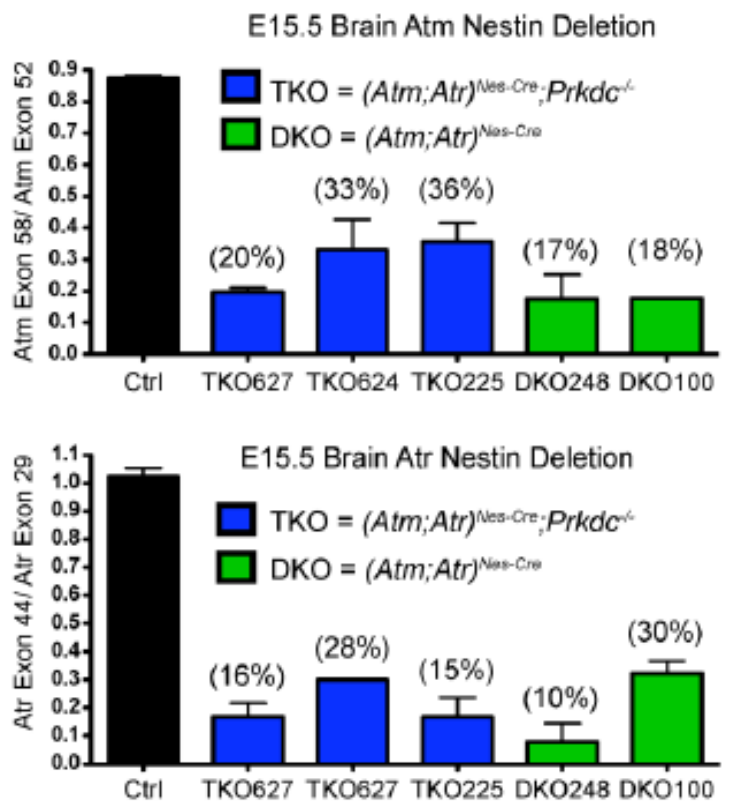

B

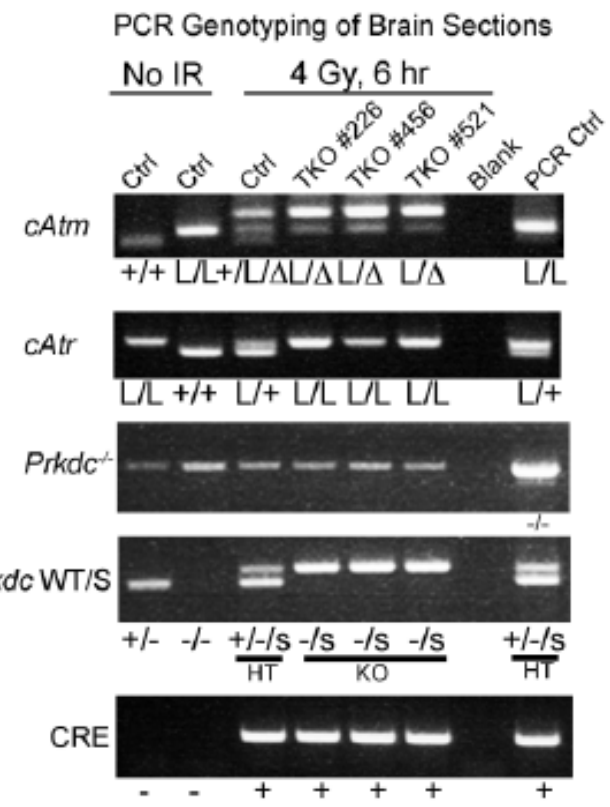

Figure 3-7. Nestin-cre mediated excision of Atm and Atr in TKO and DKO brain tissue is efficient, and confirmation of genotypes is consistent with TKO mice.

(A) Atm and Atr conditional deletion by Nestin-cre is sufficient as determined by RTPCR of [(Atm;Atr $)^{\text {Nes-cre }} ; \mathrm{Prkd}^{-/}$; TKO] and [(Atm;Atr $)^{\text {Nes-cre }}$; dKO] E15.5 brain tissue sections. (B) PCR of E15.5 brain sections confirmed the TKO and control genotypes of the tissue sections analyzed by immunohistochemistry in the studies above. 


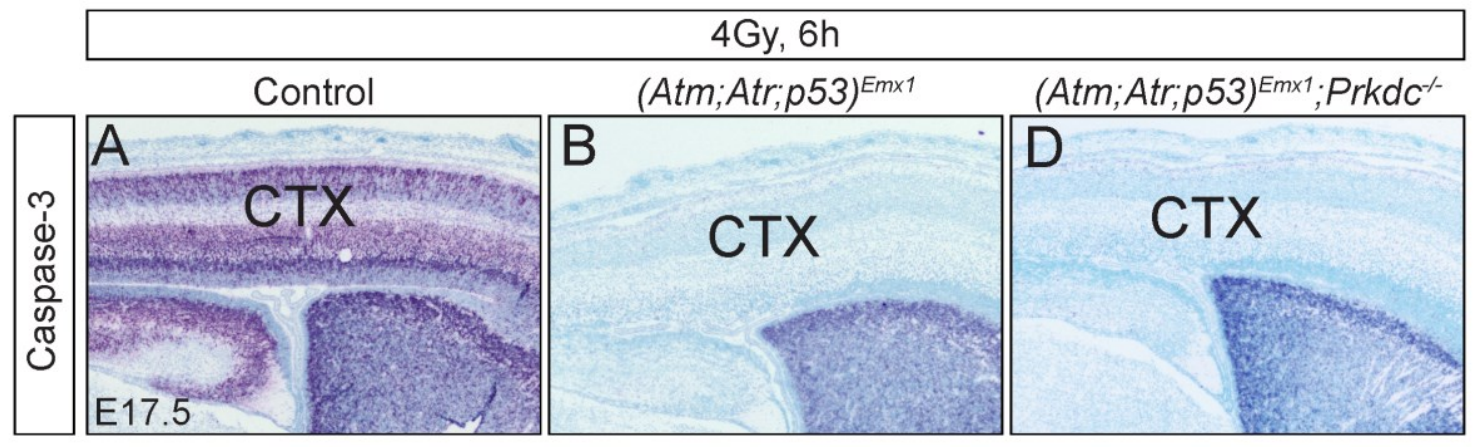

Figure 3-8. Ionizing radiation-induced apoptosis requires p53 but not ATM and ATR.

Active caspase-3 staining of (A) control, (B) [(Atm;Atr;p53) $\left.)^{\text {Emxl-cre }}\right]$, and (C) $\left[\left(\right.\right.$ Atm;Atr;p53) ${ }^{\text {Emx I-cre }} ;$ Prkdc $\left.^{-/} ; \mathrm{QKO}\right]$ demonstrates the apoptosis observed in $\left[(\text { Atm;Atr })^{\text {Nes-cre }} ;\right.$ Prkdc $\left.^{--}\right]$requires p53, but not ATM or ATR. 


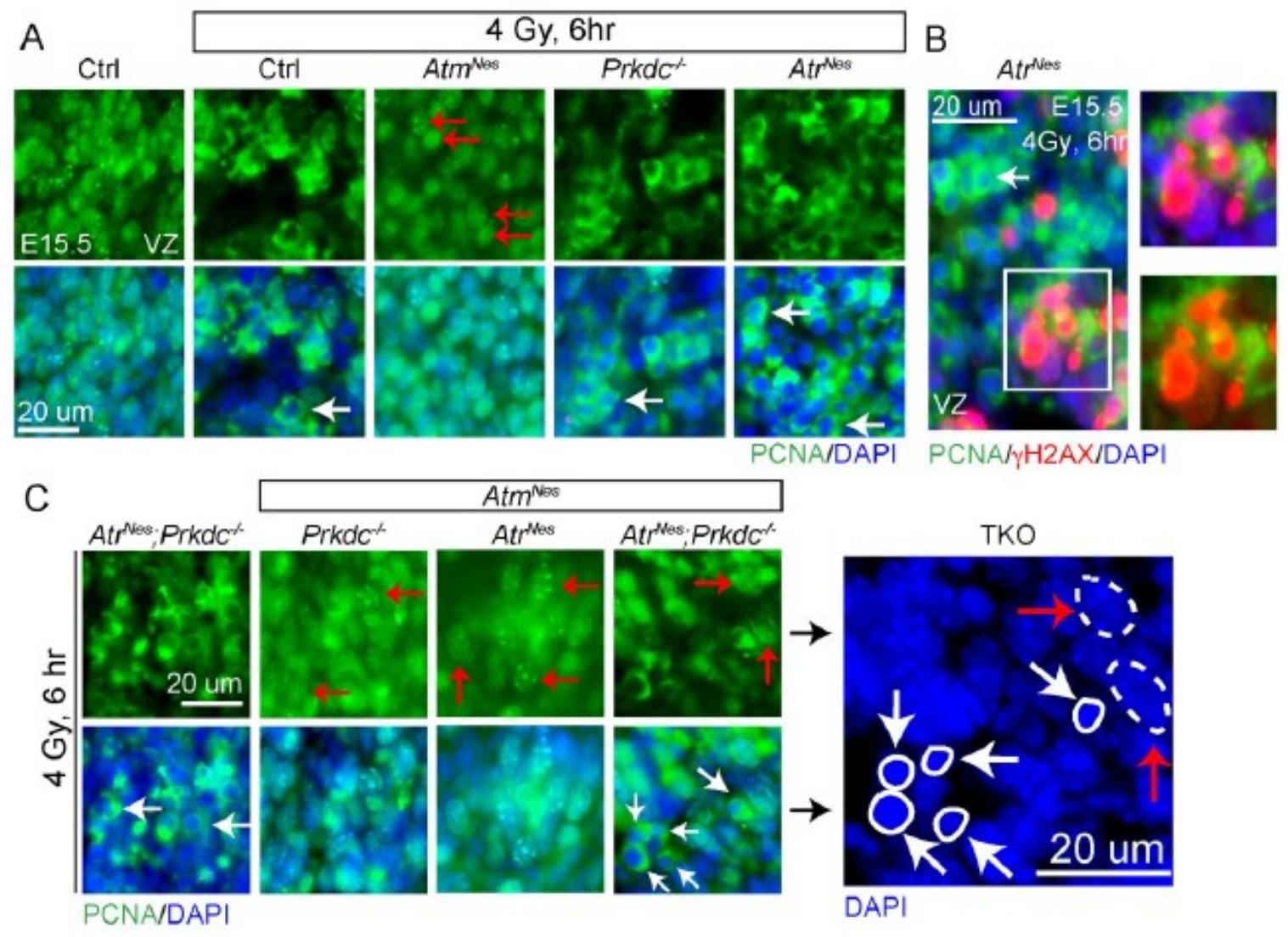

Figure 3-9. PCNA peri-nuclear stain is associated with apoptotic nuclei.

(A) PCNA staining of proliferating neural stem/progenitors in the ventricular zone (VZ) of E15.5 neocortices shows peri-nuclear staining after IR treatment of Prkdc--, Atr Nes-cre, and control, but not $\mathrm{Atm}^{\text {Nes-cre }}$. (B) PCNA staining was observed with and without pannuclear $\gamma \mathrm{H} 2 \mathrm{AX}$ staining in IR-treated E15.5 $\mathrm{Atr}^{\text {Nes-cre }}$. (C) The observation of both pan and per-nuclear PCNA staining of treated [ $\left(\mathrm{Atm} ; \mathrm{Atr}^{\mathrm{Nes}-\mathrm{cre}} ; \mathrm{Prkd}^{-/-} ; \mathrm{TKO}\right]$ indicates PCNA localization is independent of ATM, and that PCNA location reflects apoptosis. Sections were counterstained with DAPI (blue). DAPI stain of treated TKO nuclei revealed peri-nuclear PCNA staining is associated with condensed, circular nuclei, compared to nuclear PCNA positive nuclei that have the same morphology as untreated cells. Red arrows indicated pan-nuclear PCNA immunopositive cells. White arrows indicate peri-nuclear PCNA immunopositive cells. Solid circles indicate dense DAPI immunopositive nuclei indicative of apoptotic cells, compared to dashed lines indicating normal DAPI immunopositive nuclei. 
$\gamma \mathrm{H} 2 \mathrm{AX}$ (phospho Ser139) (Figure 3-9B). We then analyzed treated $\left[\mathrm{Atm}^{\text {Nes-cre }} ;\right.$ Prkdc $\left.^{-/}\right]$, $\left[(\mathrm{Atm} ; \mathrm{Atr})^{\mathrm{Nes}-\mathrm{cre}}\right]$, and $\left[\mathrm{Atr}^{\mathrm{Nes}-\mathrm{Cre}} ; \mathrm{PrkdC}^{-/}\right]$cortices to determine if peri-nuclear PCNA staining was linked to ATM-dependent apoptotic function (Figure 3-9C). We observed nuclear PCNA staining in both treated $\left[\mathrm{Atm}^{\mathrm{Nes-cre}} ; \mathrm{Prkdc}^{-/}\right]$and $\left[(\mathrm{Atm} ; \mathrm{Atr})^{\mathrm{Nes-cre}}\right]$ cortices. In contrast, $\left[\mathrm{Atr}^{\mathrm{Nes}-\mathrm{cre}} ; \mathrm{PrkdC}^{--}\right]$showed peri-nuclear staining. Unexpectedly, we observed a mix of both peri-nuclear and nuclear PCNA staining in the irradiated TKO. Closer inspection of the nuclear morphologies in the treated TKO using DAPI found that perinuclear PCNA is associated with condensed, circular nuclei, whereas nuclear PCNA positive nuclei have the same morphology as untreated cells. We do not suggest ATM is required for peri-nuclear PCNA localization. The lack of the peri-nuclear PCNA associated with the absence of Atm is indicative of the lack of apoptosis occurring under those conditions in which Atm is absent, as ATM is required to signal IR-induced p53dependent apoptosis (Herzog, Chong et al. 1998). Simply, peri-nuclear PCNA localization is indicative of apoptosis, independent of ATM status.

Lastly, we determined if p53 was required to observe IR-induced peri-nuclear PCNA staining. For these studies, we used a relatively low dose of IR with a $3 \mathrm{hr}$ recovery time, which is the earliest time point we identified for IR-induced apoptotic signaling (Figure 3-4B, C). Indeed, IR treated E15.5 $\mathrm{p5}^{-/-}$cortices were negative for peri-nuclear PCNA staining compared to treated controls (Figure 3-10). Thus, further supporting our claim that peri-nuclear PCNA staining is indicative of an apoptotic process.

From our data we propose peri-nuclear PCNA staining of irradiated cortices identifies S cells that have entered an apoptotic pathway, independent of ATM status. Thus, the peri-nuclear PCNA positive cells in the treated TKO support our TUNEL and Casp-3 data that suggests p53-dependent IR-induced apoptosis can occur independent of PI3K kinase signaling.

\subsubsection{ATR controls the IR-induced G2 checkpoint}

It has been proposed that ATR minimally phosphorylates a small subset of ATM substrates involved in signaling cell cycle arrest (Tomimatsu, Mukherjee et al. 2009). We were interested in determining if ATR functions similarly during neurogenesis within a physiological context. For these studies we focused on the G2/M cell cycle checkpoint. To achieve this, we analyzed IR-induced G2/M cell cycle dynamics in cortical neural stem/progenitors cell after DNA damage. Proliferating neural cells reside in the VZ, with a small population found in the SVZ. Neural cells in M phase can easily be identified using mitotic marker histone phospho-H3 Ser10 (Figure 3-11A). We found only cortices deficient in Atr $^{\text {Nes-cre }}$ were defective in signaling G2/M checkpoint activation reflective in the high number of phospho-H3 positive cells observed in this genotype compared to control (Figure 3-11B). Immunostaining of combinatorial genetic crosses of Atr ${ }^{\text {Nes-cre }}$ with Atm $^{\text {Nes-cre }}$ and/or Prkdc $c^{-/}$using phospho-H3 demonstrated ATR alone controls the IR in $\left[\right.$ Atr $^{\text {Nes-cre }} ;$ Prkdc $\left.^{-/}\right]$, with a smaller effect observed in $\left[(\text {Atm;Atr })^{\text {Nes-cre }}\right]$ cortices (Figure 


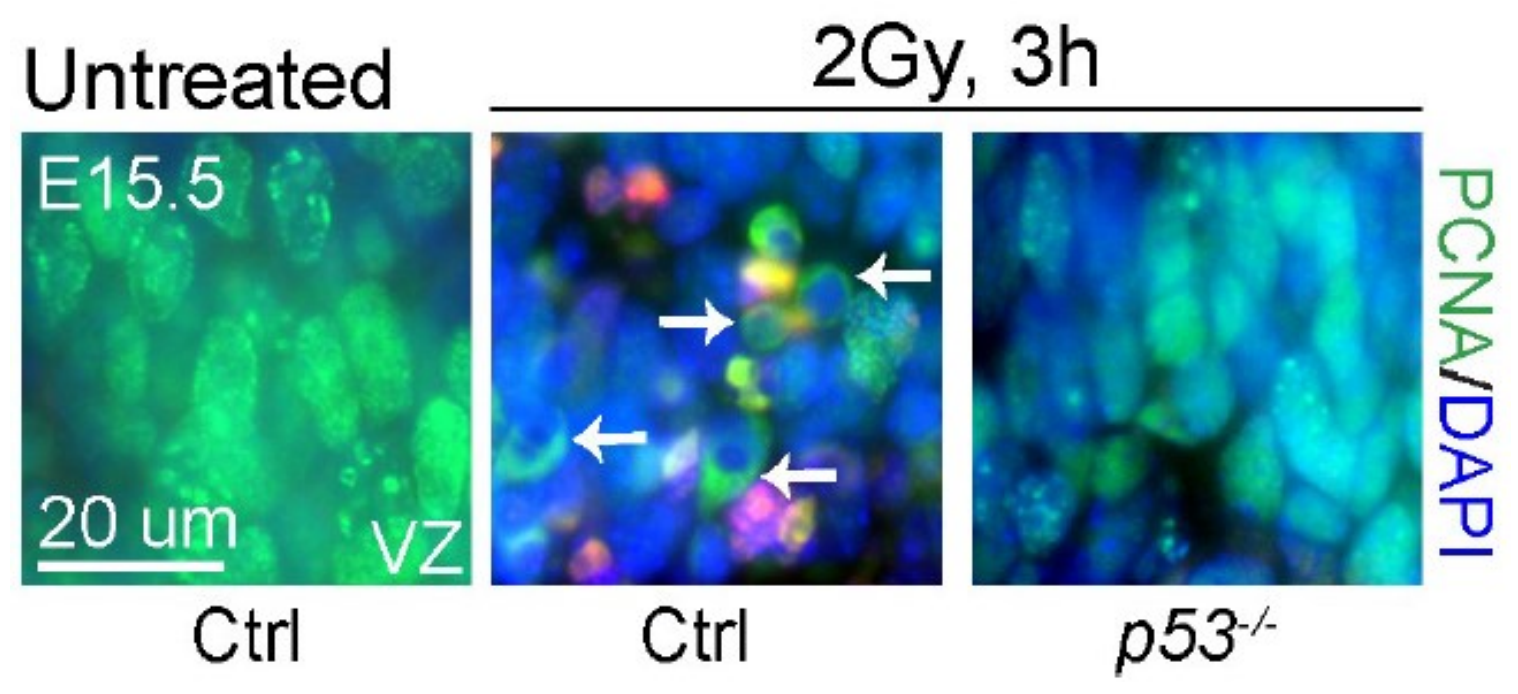

Figure 3-10. p53 is required for peri-nuclear PCNA localization after IR.

Immunostaining neural stem/progenitors in the ventricular zone (VZ) of E15.5 cortices with anti-PCNA (green) shows per-nuclear localization after IR requires $\mathrm{p} 53$. Sections were counterstained in DAPI (blue). 
Figure 3-11. ATR controls the DNA damage-induced $\mathbf{G}_{2}$ checkpoint.

(A) E15.5 cortical neural progenitors in mitosis are shown relative to the cortical layers in an untreated control at 10x (I) and 40x (II) using mitotic marker histone H3 (phospho $\mathrm{S} 10$ ) (p-H3; red) to identify cells in G2/M, and neuronal differentiation marker Tuj1 (green). Cortical plate (CP), sub-plate (SP), subventricular zone (SVZ), ventricular zone (VZ) are listed. (B) Only E15.5 treated Atr ${ }^{\text {Nes-cre }}$ neocortices show untreated levels of p$\mathrm{H} 3$ after DNA damage indicating ATR alone controls the G2/M checkpoint. (C) Coincident loss of $\mathrm{Atr}^{\text {Nes-cre }}$ with $\mathrm{Atm}^{\text {Nes-cre }}$ and/or Prkdc ${ }^{-/-}$results in the accumulation of p-H3 after DNA damage. (D) Quantitative representation of p-H3 positive cells in the various genotypes and control show ATR regulates the murine G2/M checkpoint. The bar graphs represent mean values of replicates $(n=3$ animals per group, 9 images per group), error bars s.e.m.; $* * * * P<0.0001 . P<0.05$ was considered significant. (E) At E15.5, greater staining of p-H3 positive cells in treated $A t r^{\text {Nes-cre }}$ is associated with a reduction in the number of BrdU positive proliferating cells compared to control after ionizing radiation. (F) Higher exposure times of $\mathrm{p}-\mathrm{H} 3$ marker show foci, identifying neural stem/progenitors cells in $\mathrm{G}_{2}$ phase of the cell cycle. Fewer foci were observed in $\left[\mathrm{Atm}^{\mathrm{Nes}-\mathrm{cre}} ; \mathrm{Prkdc}^{-/}\right]$compared to single knockouts and control after DNA damage.

Sections were counterstained in DAPI (blue). 

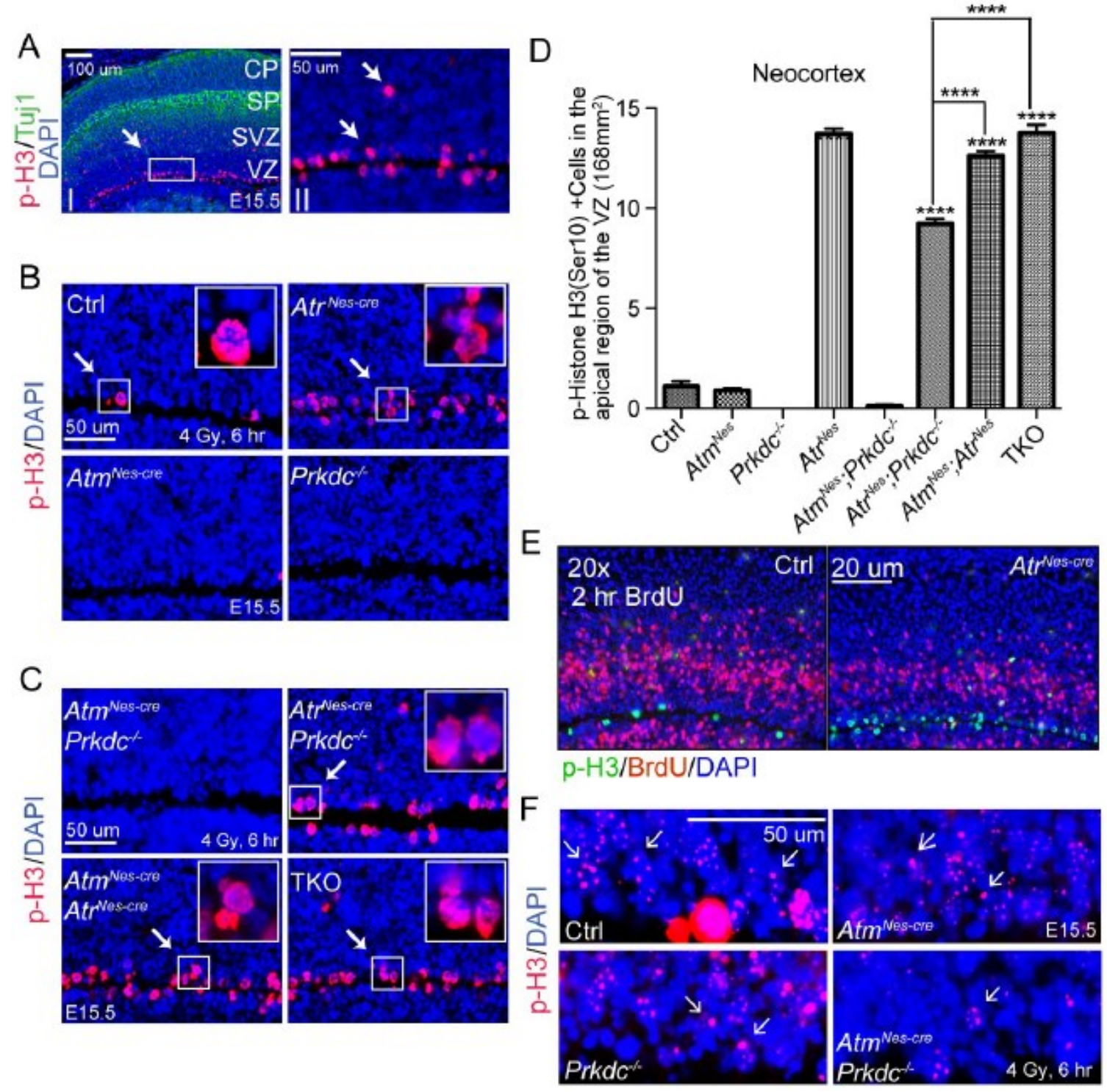
3-11D). Previously, we did not observed a proliferation defect in untreated E15.5 Atr ${ }^{\text {Nes- }}$ cre cortical neural stem/progenitors when compared to control (Lee, Shull et al. 2012). However, we did observe significantly fewer BrdU positive cells in IR treated Atr Nes-cre compared to control (Figure 3-11E). A reduction in proliferating cells in IR treated $A t r^{\text {Nes-cre }}$ may arise because cells fail to undergo cell cycle arrest and continue through to mitosis.

The immunostaining pattern of phospho-H3 can also be used to identify cells in G2 phase (Factor, Seo et al. 2010). The phospho-H3 foci indicative of G2 cells are most distinguishable at longer time exposures compared to those optimal for observing mitotic phospho-H3 positive cells. Thus, phospho-H3 foci were evaluated in mutants with Atr intact (Figure 3-11F). We observed substantially fewer phospho-H3 foci in $\left[\mathrm{Atm}^{\mathrm{Nes}-}\right.$

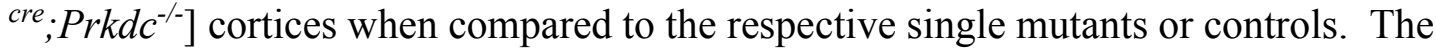
considerable reduction in phospho-H3 foci observed in $\left[\mathrm{Atm}^{\text {Nes-cre }} ; \mathrm{Prkdc}^{-/}\right]$suggests the combined loss of these two kinases further delays DSB repair, which DDR integrates as a greater number of DSBs, resulting in a more robust response by ATR to prevent damaged $\mathrm{S}$ cells from advancing to $\mathrm{G} 2 / \mathrm{M}$. Overall the data supports ATR is required for efficient IR-induced G2/M checkpoint activation.

\subsubsection{Signaling IR-induced DSBs}

Finally, we compared the DDR in mature neurons to the neurogenesis studies above. In stark contrast to neurogenesis, adult neurons are resistant to IR-induced apoptosis (Puck and Marcus 1956, Romero, Gross et al. 2003). Nonetheless, DNA damage occurs as an ongoing process, and DSB repair involving NHEJ is essential to prevent damage accumulation (Shull, Lee et al. 2009). Histological analyses of IR treated adult brains using DSB heterochromatin marker KAP-1 (phospho S824) uncovered similar patterns as those observed in embryonic and postnatal brains. Again, KAP-1 (phospho S824) staining was substantially greater in treated adult (5 months or older) Prkdc ${ }^{-/}$compared to control brains, occurring in an ATM-dependent manner (Figure 3-12). We found both immature neurons in the dentate gyrus (DG) and mature cortical neurons (CTX) are sensitized to IR by Prkdc loss by co-immunostaining with KAP-1 (phospho S824) and Tuj1. Not surprisingly, we observed significantly greater endogenous levels of KAP-1 (phospho S824) in untreated Lig4 $4^{\text {Nes-cre }}$ (12 months old) compared to exogenous levels in treated control adult cortices after a $6 \mathrm{hr}$ recovery, since Lig4 is required for DSB repair via NHEJ (Figure 3-12A, panels e, h) (Barnes, Stamp et al. 1998, Gatz, Ju et al. 2011). Thus, we were surprised to observe equivalent or less endogenous KAP-1 (phospho S824) staining in untreated DG of Lig $4^{\text {Nes-cre }}$ compared to levels in treated control (Figure 3-12A, panels a, d). Most surprisingly, we observed the intensity of KAP-1 (phospho S824) staining in treated Prkdc/- cortices is similar to

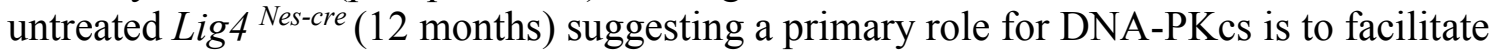
DNA repair via NHEJ suggesting a primary role for DNA-PKcs to facilitate DNA repair via NHEJ (Figure 3-12A, panels e, h). 


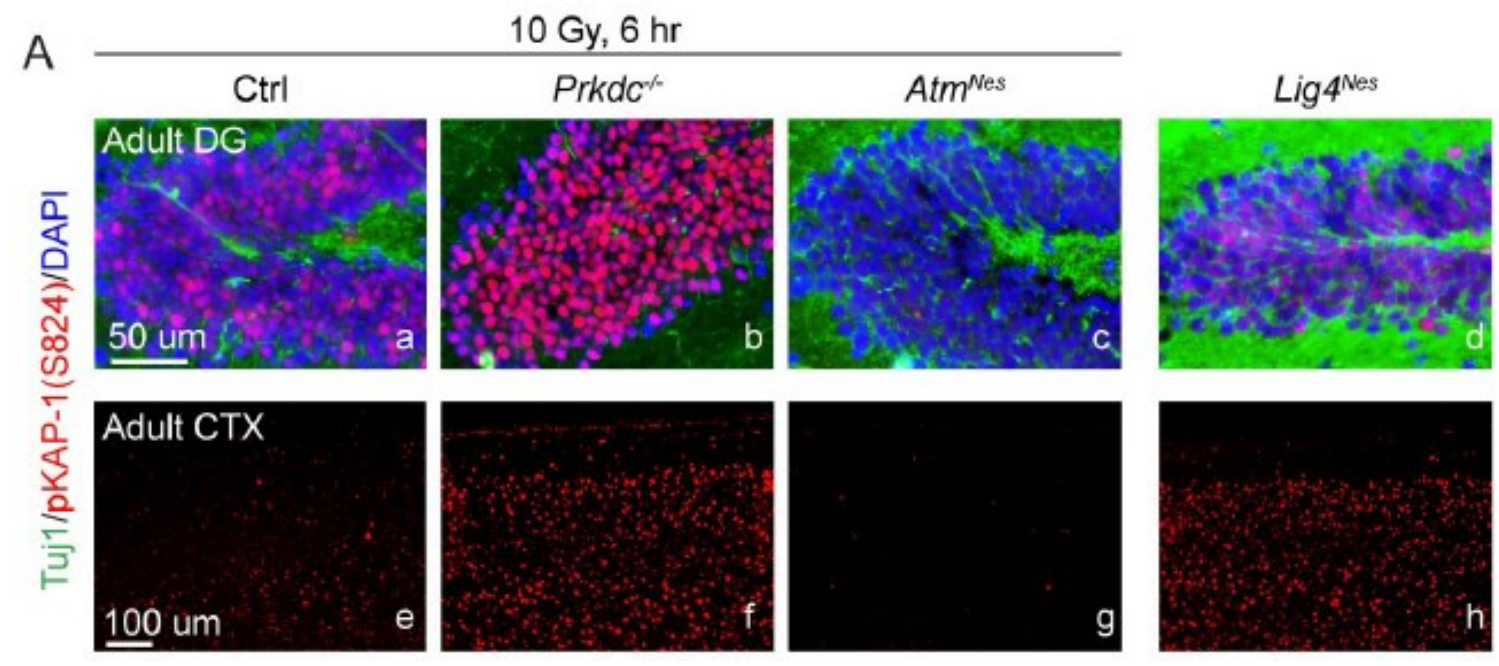

Figure 3-12. ATM mediates heterochromatin DNA double-strand breaks in adult neurons after ionizing radiation.

Co-immunostaining with heterochromatin DSB marker KAP-1 (phospho S824) and neuronal differentiation marker Tuj1 showed immature neurons in the dentate gyrus (DG) and mature cortical neurons in the cortex (CTX) in adult brains (5 months or older) are both sensitized to IR by the loss of Prkdc. The intensity of KAP-1 (phospho 824) staining of irradiated Prkdc/- is similar to untreated Lig $4^{\text {Nes-cre }}$ cortices. The lack of immunopositive cells in irradiated $\mathrm{Atm}^{\text {Nes-cre }}$ tissues demonstrates signaling of IR-induced DSBs in heterochromatin is ATM-dependent 
Next we analyzed adult cortices using the standard DSB chromatin marker $\gamma \mathrm{H} 2 \mathrm{AX}$ (phospho Ser139) (Figure 3-13). Analysis of untreated adult Prkd ${ }^{-/}$cortices found endogenous $\gamma \mathrm{H} 2 \mathrm{AX}$ foci accumulate with age more than untreated control, but significantly less than untreated $\mathrm{Lig} 4^{\text {Nes-cre }}$, further supporting a role for DNA-PK in NHEJ DSB repair (Figure 3-13A). For our radiation-induced DNA damage studies, endogenous $\gamma \mathrm{H} 2 \mathrm{AX}$ foci levels were measured in one year old Lig $4^{\text {Nes-cre }}$ cortices used to establish the standard time exposure because $\mathrm{Lig} 4^{\text {Nes-cre }}$ are deficient in DSB repair, and also fail to undergo IR-induced apoptosis (Barnes, Stamp et al. 1998, Gurley, Moser et al. 2009, Shull, Lee et al. 2009, Gatz, Ju et al. 2011). We found $\gamma \mathrm{H} 2 \mathrm{AX}$ foci were only augmented when both $\mathrm{Atm}$ and Prkdc [ $\left.\mathrm{Atm}^{\text {Nes-cre }} ; \mathrm{Prkdc}^{--}\right]$were deleted (Figure 3-13B). These results are in agreement with in vitro studies using patient derived cell lines of non-neurological origin (Tomimatsu, Mukherjee et al. 2009).

In contrast to adult cortices, we did not observe a substantial difference in $\gamma \mathrm{H} 2 \mathrm{AX}$ foci between treated Prkdc and control embryonic cortices at recovery times ranges from 1-4 hr (not shown). $\gamma \mathrm{H} 2 \mathrm{AX}$ foci form abundantly shortly after IR, wit neural stem/progenitors active in mitosis being the most sensitive during embryogenesis (Figure 3-14). By six hours after IR, the foci have been resolved, and the majority of $\gamma \mathrm{H} 2 \mathrm{AX}$ staining is pan-nuclear. $\gamma \mathrm{H} 2 \mathrm{AX}$ pan-nuclear positive cells are indicative of the apoptotic process (de Feraudy, Revet et al. 2010). DAPI staining of IR treated control nuclei after six hours further supports these findings as $\gamma \mathrm{H} 2 \mathrm{AX}$ pan-nuclear positive nuclei have morphed from an oval to a round, condensed form.

Our analysis demonstrates ATM and DNA-PKcs signal DSBs (in a redundant manner) in adult cortices. The attenuation of DSBs in adult neurons compared to embryonic neurons suggests DSB repair slows with age, and emphasizes the requirement for rapid responses to DNA damage during embryonic neurogenesis. 
A

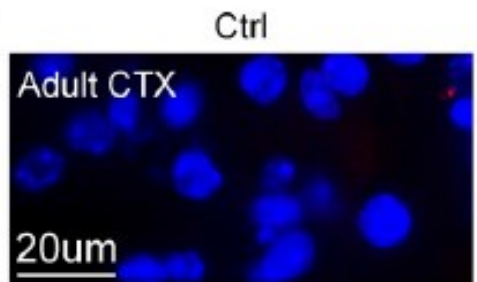

$\gamma \mathrm{H} 2 \mathrm{AX} / \mathrm{DAPI}$
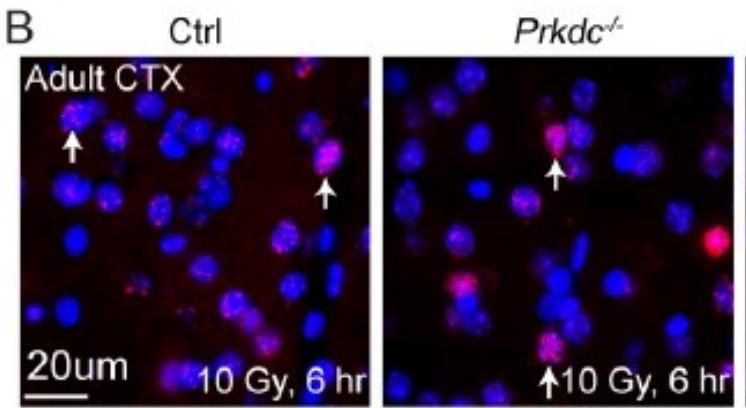

Lig4 $4^{\text {Nes }}$
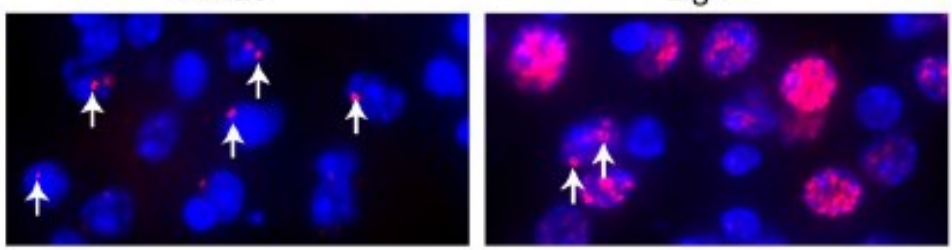

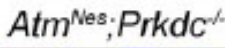

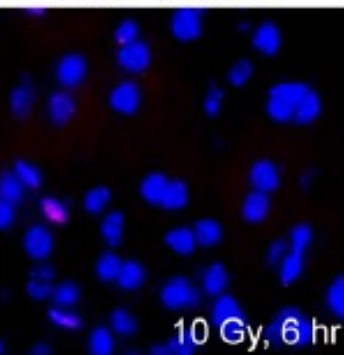

Figure 3-13. ATM and DNA-PKes function redundantly to phosphorylate H2AX Ser139 in adult cortices after ionizing radiation.

Immunostaining with chromatin DSB marker H2AX (phospho Ser139) ( $\gamma \mathrm{H} 2 \mathrm{AX}$ foci) of (A) untreated control, Prkdc/-- and Lig $4^{\text {Nes-cre }}$ identified endogenous DSBs occur in Prkdc ${ }^{-/}$compared to control. (B) $\gamma \mathrm{H} 2 \mathrm{AX}$ foci in irradiated control, Prkdc ${ }^{-/}, \mathrm{Atm}^{\text {Nes-cre }}$, and $\left[\mathrm{Atm}^{\text {Nes-cre }} ; \mathrm{Prkdc}^{-/}\right]$showed ATM and DNA-PKcs function redundantly to phosphorylate H2AX Ser139 after IR. 

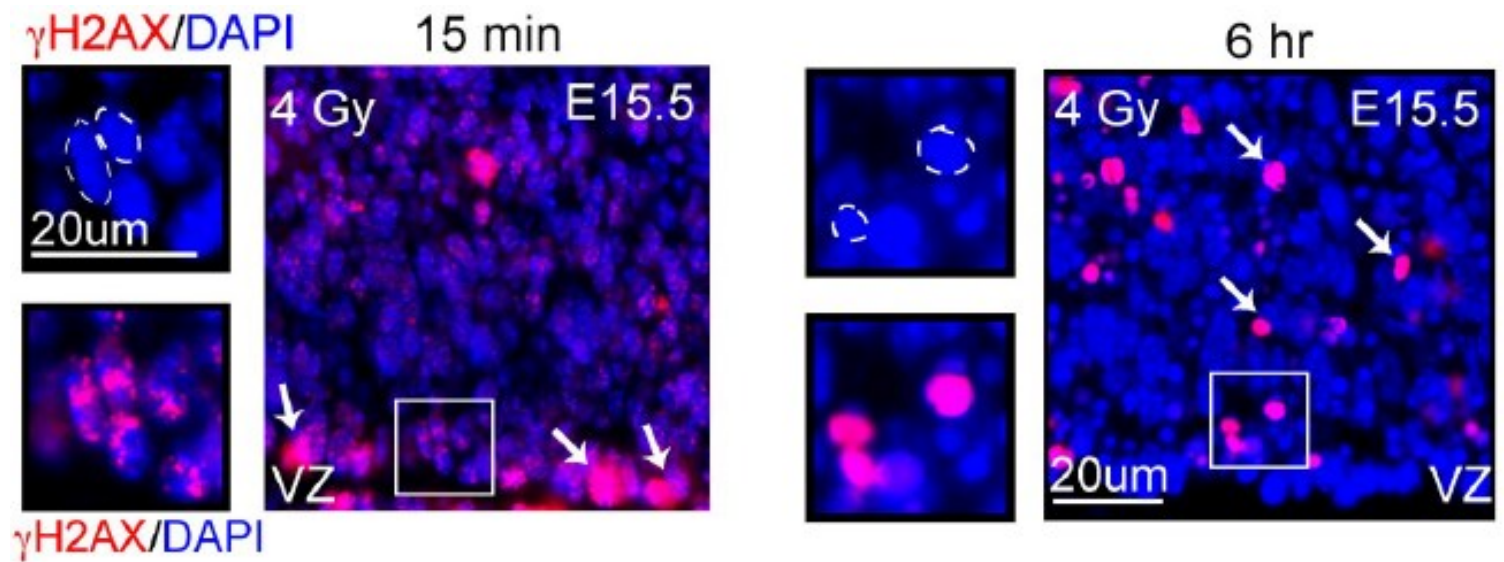

Figure 3-14. Signaling dynamics of IR-induced $\boldsymbol{\gamma}$-H2AX in embryonic cortices. $\gamma \mathrm{H} 2 \mathrm{AX}$ foci levels were measured in the ventricular zone (VZ) of E15.5 embryonic cortices 15 minutes and $6 \mathrm{hr}$ after IR to demonstrate the differences in morphology. Oval shaped DAPI nuclei are associated with $\gamma \mathrm{H} 2 \mathrm{AX}$ foci that rapidly form shortly after IR. $\mathrm{H} 2 \mathrm{AX}$ (phospho Ser139) staining by $6 \mathrm{hr}$ is pan-nuclear, and co-stains with condensed, circular DAPI positive nuclei, indicative of apoptosis. 


\section{CHAPTER 4. DISCUSSION}

\subsection{Analyses of ATM, ATR, and DNA-PKes Revealed Novel DNA Damage Response Outcomes}

ATM, ATR, and DNA-PKcs are critical for nervous system development (Sedgwick RP 1991, Farina, Uggetti et al. 1994, O'Driscoll 2009, van der Burg, van Dongen et al. 2009, McKinnon 2012, Woodbine, Neal et al. 2013). How these kinases cooperate to maintain genomic integrity during neurogenesis remains unclear. Here we employed mouse genetics to explore PIKK DDR signaling functions of these kinases during neurogenesis within a biological context. The combinatorial analyses of all three kinases was required to reveal novel DDR outcomes, as we show these results were not always inferable based upon results of single and double knockouts

The apoptotic DDR is essential to maintain the genomic integrity of neural stem/progenitors residing in the VZ/SVZ as these cells readily undergo apoptosis in response to minor levels of radiation (Gatz, Ju et al. 2011). Previous studies have shown ATM is responsible for most, but not all of the IR-induced apoptosis occurring in the VZ/SVZ (Shull, Lee et al. 2009, Gatz, Ju et al. 2011). Our studies substantiate these findings, but also show ATM cooperates with ATR to signal radiation induced apoptosis in the VZ/SVZ. In contrast, Prkde deletion alone and in combination with Atm or Atr sensitized neurons to apoptosis, particularly in non-proliferating neurons in the IZ/CP at E15.5. We assumed treated TKOs $\left[(\mathrm{Atm} ; \mathrm{Atr})^{\text {Nes-cre }} ; \mathrm{PrkdC}^{--}\right]$would be deficient in signaling IR-induced apoptosis just like [(Atm;Atr $\left.)^{\text {Nes-cre }}\right]$. Surprisingly, we observed active Casp-3 and TUNEL stain in the SVZ/IZ/CP of treated TKOs. These findings were supported by our discoveries linking apoptotic signaling and PCNA localization. After IR, we observed PCNA becomes peri-nuclear and co-stain with condensed DAPI positive nuclei. Again, PCNA localization studies of single and double knockouts alone would have concluded the re-localization of PCNA after IR required ATM. However, we observed peri-nuclear PCNA staining after IR in TKOs, but not in p53, $\left[(\text { Atm;Atr;p53 })^{\text {Emxl-cre }}\right]$, or in [(Atm;Atr;p53 $)^{\text {Emxl-cre }} ;$ Prkdc $\left.^{-/} ; \mathrm{QKO}\right]$ embryonic cortices. Overall, our findings demonstrate $P r k d c$ loss continues to sensitize neurons to apoptotic signaling in the absence of both Atm $^{\text {Nes-cre }}$ and Atr ${ }^{\text {Nes-cre }}$ in a p53-dependent manner.

Similar to the apoptotic DDR, cell cycle checkpoint substrates are thought to be predominantly under the control of ATM in response to IR, with a small subset phosphorylated by ATR (Tomimatsu, Mukherjee et al. 2009). Our studies clearly demonstrate for the first time that ATR alone controls the murine IR induced G2/M checkpoint independent of Atm or Prkdc status. Interestingly, the combination of $\mathrm{Atm}^{\mathrm{Nes}-}$ ${ }^{c r e}$ and $P r k d c^{-/}$loss significantly reduced the number of proliferating neurons from entering $\mathrm{G} 2 / \mathrm{M}$ compared to any other genetic combination. A vigorous ATM-dependent G1/S checkpoint response is likely responsible for this observation. Similarly, we observed fewer cells entering G2 after IR in $\left[\mathrm{Atm}^{\mathrm{NescCre}} ; \mathrm{PrkdC}^{-/}\right]$compared to single knockouts and controls that is likely arising from greater ATR-dependent $\mathrm{S}$ checkpoint activation. 
Our studies highlight the dynamic relationships among these three kinases within a biological context. Importantly, our study is a cautionary for inferring outcomes of the DDR as our data suggests PIKK signaling remains unpredictable.

\subsection{Proposed Function(s) of DNA-PKes During Neurogenesis}

Our findings demonstrate DNA-PKcs (encoded by Prkdc) loss exacerbates both apoptosis and cell cycle arrest checkpoint signaling during murine embryonic neurogenesis in response to exogenous DNA damage. We propose two possible functions for DNA-PKcs in this context; DNA-PKcs enhances DSB repair kinetics by functioning as a scaffold protein that is required during times of rapid neural expansions; or DNA-PKcs may regulate ATM apoptotic signaling directly to preserve critical neuronal populations to maintain development. Both of these functions become increasingly important in species that require significantly larger numbers of rapid neuronal expansions and mature over longer periods of time. The persistence of $\gamma \mathrm{H} 2 \mathrm{AX}$ foci is the hallmark of a DSB repair deficiency (Rogakou, Nieves-Neira et al. 2000, Abbaszadeh, Clingen et al. 2009, Scully and Xie 2013). We did not observe any differences in $\gamma \mathrm{H} 2 \mathrm{AX}$ foci staining between Prk $^{-/-}$and control at any time points used in our studies employing an IR dose of 2 Gy despite observing differences in KAP-1 (phospho S824) and active Casp-3 staining at $3 \mathrm{hr}$ post-IR. The discrepancy in $\gamma \mathrm{H} 2 \mathrm{AX}$ foci staining fails to support a role for DNA-PKcs in NHEJ repair. Instead, the data could be interpreted as supporting our second proposal. Since KAP-1 (phospho S824) and $\gamma \mathrm{H} 2 \mathrm{AX}$ (phospho S139) are substrates of ATM, and the apoptosis occurring in the absence of Prkdc signaling is p53 dependent, which is also a substrate of ATM, and ATM activity increases in the absence of Prkdc, all suggests DNA-PKcs may directly regulated ATM.

The paradox of DDR signaling observed in Prkdc deficient neurons likely arises from the facts that as neurons mature they become completely dependent upon the NHEJ pathway, and at the same time DDR signaling of IR-induced apoptotic signaling is being eliminated as an outcome. For example, at E15.5 we found active Casp-3 and TUNEL staining to be in agreement at a specific recovery time post-IR. However, at P5, only active Casp-3 and not TUNEL stain was greater in the CA1 of treated Prkdc $c^{-/}$compared to control. Similar observations have been made in other studies of DNA-PKcs functions in the adult brain. For instance, the CA1-CA3 regions of adult DNA-PKcs-null mice have been reported to undergo p53-dependent cell death four days following acid induced brain seizures as demonstrated by a greater number of pyknotic nuclei and a greater loss of cellularity by Nissl, but without observing significant differences in TUNEL stain (Rogakou, Nieves-Neira et al. 2000, Neema, Navarro-Quiroga et al. 2005, Abbaszadeh, Clingen et al. 2009, Scully and Xie 2013). Collectively, these findings support DNAPKcs loss sensitizes neurons in the DG to exogenous stress. This DNA-PKcs role could be distinct from functioning as a component of the NHEJ pathway, as we observed reduced sensitization of DG neurons to both exogenous and endogenous DNA damage in NHEJ deficient mutant, Lig4 $4^{\text {Nes-cre }}$. Indeed, the dynamics of DDR outcomes observed in the developing nervous system, particularly in the developing hippocampus, is an 
excellent paradigm to explore neural specific DNA-PKcs-dependent functions, and novel neural specific DDR outcomes.

Our observation of an extended, early DDR signaling in Prkdc/- linked to a delay in DSB repair is in agreement with Goodarzi et al. who applied a chemical DNA-PKcs inhibitor to slow DSB repair thereby prolonging KAP-1 (phospho S824) phosphorylation and DSB chromatin relaxation (Goodarzi, Kurka et al. 2011) pg. 832. Our findings showing Prkdc loss sensitizes embryonic cortical neurons in the IZ/CP are in agreement with a previous study using a Lig4 mutant created to study the effects of delayed DSB repair (Gatz, Ju et al. 2011). NHEJ is available in both proliferating and nonproliferating neurons unlike HR that is limited to proliferating neurons. Thus, neurons become completely reliant upon the NHEJ pathway to repair DSBs as they differentiate, making DNA-PKcs increasingly advantageous for improving the NHEJ response. Therefore, DNA-PKcs likely enhances NHEJ DSB repair to meet critical developmental time constraints during neurogenesis.

In a comparable study of the DDR during embryogenesis, Gatz et al. demonstrated the IZ is sensitive to the persistence of DSBs after IR (Gatz, Ju et al. 2011). Interestingly, we show at three hours post-IR active Casp-3 and KAP-1 (phospho S824) staining occurs in the VZ/SVZ and CP in both control and Prkdc ${ }^{-/}$. By six hours, active Casp-3 staining is evenly distributed throughout all cortical zones, and KAP-1 (phospho S824) is essentially resolved in all zones in both control and Prkdc ${ }^{-/}$. The delay in the DDR we observed in the IZ at three hours in both genotypes appears to substantiate their findings. However, we show IZ sensitivity to DSBs can be observed at much shorter recovery times via a delay in active Casp-3 stain. Moreover, this strategy allowed us to demonstrate for the first time that the CP is equally sensitive to IR-induced DSBs as the VZ (Hoshino and Kameyama 1988, Hoshino, Kameyama et al. 1991, Gatz, Ju et al. 2011). Together, our findings show NHEJ, including DNA-PKcs, functions efficiently in all cortical zones in the developing cortex, which is consistent with Gatz et al. (Gatz, Ju et al. 2011).

\subsection{Future Directions}

We propose that understanding the p53-dependent apoptotic processes occurring in the triple and quadruple knockouts examined here may aid in resolving numerous paradoxes that plague the field such as why $p 53$ loss but not Atm $^{\text {Nes-cre }}$ rescues Ligase IV deficient neurons from IR-induced apoptosis, or similarly why p53 loss but not Atm rescues $B r c a 2^{\text {Nes-cre }}$ deficient neurons from apoptosis (Frappart, Lee et al. 2007). Our findings that DNA damage induced p53-dependent apoptosis can occur independent of ATM and ATR demand further investigation to identify novel DDR pathways and the contexts for which they apply. Such studies could lead to furthering our understanding of the differences of how DDR integrates stress signaling in humans vs. mice. This finding is essential to move the field beyond rationalizing that PIKK deficient mouse models fail

to recapitulate the human neurological phenotypes because they are "less sensitive" to DNA damage. The field must define what pathways and factors contribute to sensitizing 
the murine DDR to DNA damage during neurogenesis to better translate our finding into effective therapies.

Another area of future interest is to further investigate the role the DDR in managing oxidative stress in the brains of TKOs $\left[(\mathrm{Atm} ; \mathrm{Atr})^{\mathrm{Nes}-\mathrm{cre}} ; \mathrm{Prkdc}^{-/}\right]$during the fetal-to-neonatal transition. The TKO lifespan ranged from 18-26 hr after birth (Data now shown) due to what appeared to be dehydration. Previously, we have shown Atr $^{\text {Nes- }}$ cre show signs of endogenous replication stress induced apoptosis beginning at E16.5 (Lee, Shull et al. 2012). While we did not find evidence of endogenous DNA-induced apoptosis in E15.5 TKO cortices, the Atr $^{\text {Nes-cre }}$ phenotype suggests, endogenous DNA damage is likely enhanced in the aging TKO embryos. We hypothesize, the combination of endogenous DNA damage in the TKO and the increase in oxygenation during the fetal-to-neonatal transition likely induces rapid apoptosis. Studies prolonging the uterolike low oxygenation levels in mouse pups after birth were able to diminish oxidative stress levels in the lung and brains, improving postnatal morbidity and mortality (Escobar, Cubells et al. 2013). If the increase in oxidative stress is functioning in the death of TKOs during the fetal-to-neonatal transition, then prolonging utero-like oxygenation levels may significantly increase their lifespan. If this were the case, this data were further support the importance of the DDR in managing oxidative stress during neural development. Understanding the functions of PIKKs during this critical transition would be extremely useful, as the primary source of DNA damage during neurogenesis is oxidative stress.

Lastly, understanding how deficiencies in signaling and repairing DNA damage during neurogenesis and the impact this has on neural network formation may be useful for understanding why TKOs die shortly after birth. One can imagine factors that impede synaptic firing, would result in the removal of that neuron. If a large number of neurons fail to communicate effectively during the fetal-to-neonatal transition due to impeding build-up of DNA damage and insufficient signaling, then a large number of neurons would likely be removed, to the extent of eliminating life.

Ultimately, identifying the fetal-to-neonatal transition as a point of significant therapeutic intervention in infants with DNA repair deficiencies would create opportunities to alter the course of disease.

\subsection{Concluding Remarks}

The work completed here sought to address how ATM, ATR, and DNA-PKcs collectively coordinate the appropriate responses to DNA damage within a physiological context. Given that each kinase is critical for nervous system development, we focused on this tissue as a paradigm for understanding functional cooperative relationships between these key DDR factors. We provide evidence suggesting that during murine neurogenesis DNA-PKes functions classically as a component of the DNA-PK holoenzyme to enhance NHEJ repair of DSBs in proliferating and non-proliferating neurons. We show DNA-PKcs loss sensitized p53-dependent apoptosis and exacerbated 
checkpoint activation after IR in a developmental stage and neural cell type-specific manner, independent of ATM and ATR. We found ATM and ATR coordinated the DDR during neurogenesis to direct apoptosis in cycling and non-cycling cortical neurons. Additionally, we found that the IR-induced G2/M checkpoint controlled by ATR, independent of ATM and DNA-PKcs status. Our results provide valuable insights into how each kinase plays a unique and essential role during the DDR reflective of the specific neuropathology induced when each is defective. 


\section{LIST OF REFERENCES}

Abbaszadeh, F., P. H. Clingen, C. F. Arlett, P. N. Plowman, E. C. Bourton, M. Themis, E. M. Makarov, R. F. Newbold, M. H. Green and C. N. Parris (2009). "A novel splice variant of the DNA-PKcs gene is associated with clinical and cellular radiosensitvity in a xeroderma pigmentosum patient." J Med Genet.

Alderton, G. K., L. Galbiati, E. Griffith, K. H. Surinya, H. Neitzel, A. P. Jackson, P. A. Jeggo and M. O'Driscoll (2006). "Regulation of mitotic entry by microcephalin and its overlap with ATR signalling." Nat Cell Biol 8(7): 725-733.

Alderton, G. K., H. Joenje, R. Varon, A. D. Borglum, P. A. Jeggo and M. O'Driscoll (2004). "Seckel syndrome exhibits cellular features demonstrating defects in the ATRsignalling pathway." Hum Mol Genet 13(24): 3127-3138.

An, J., Y. C. Huang, Q. Z. Xu, L. J. Zhou, Z. F. Shang, B. Huang, Y. Wang, X. D. Liu, D. C. Wu and P. K. Zhou (2010). "DNA-PKcs plays a dominant role in the regulation of $\mathrm{H} 2 \mathrm{AX}$ phosphorylation in response to DNA damage and cell cycle progression." $\mathrm{BMC}$ Mol Biol 11: 18.

Bakkenist, C. J. and M. B. Kastan (2003). "DNA damage activates ATM through intermolecular autophosphorylation and dimer dissociation." Nature 421(6922): 499-506.

Barlow, C., K. D. Brown, C. X. Deng, D. A. Tagle and A. Wynshaw-Boris (1997). "Atm selectively regulates distinct p53-dependent cell-cycle checkpoint and apoptotic pathways." Nat Genet 17(4): 453-456.

Barlow, C., S. Hirotsune, R. Paylor, M. Liyanage, M. Eckhaus, F. Collins, Y. Shiloh, J. N. Crawley, T. Ried, D. Tagle and A. Wynshaw-Boris (1996). "Atm-deficient mice: a paradigm of ataxia telangiectasia." Cell 86(1): 159-171.

Barnes, D. E., G. Stamp, I. Rosewell, A. Denzel and T. Lindahl (1998). "Targeted disruption of the gene encoding DNA ligase IV leads to lethality in embryonic mice." Curr Biol 8(25): 1395-1398.

Bartek, J. and J. Lukas (2001). "Mammalian G1 - and S-phase checkpoints in response to DNA damage." Curr Opin Cell Biol 13(6): 738-747.

Becker-Catania, S. G., G. Chen, M. J. Hwang, Z. Wang, X. Sun, O. Sanal, E. Bernatowska-Matuszkiewicz, L. Chessa, E. Y. Lee and R. A. Gatti (2000). "Ataxiatelangiectasia: phenotype/genotype studies of ATM protein expression, mutations, and radiosensitivity." Mol Genet Metab 70(2): 122-133.

Bhatti, S., S. Kozlov, A. A. Farooqi, A. Naqi, M. Lavin and K. K. Khanna (2011). "ATM protein kinase: the linchpin of cellular defenses to stress." Cell Mol Life Sci 68(18): 2977-3006. 
Brown, E. J. and D. Baltimore (2000). "ATR disruption leads to chromosomal fragmentation and early embryonic lethality." Genes Dev 14(4): 397-402.

Buis, J., Y. Wu, Y. Deng, J. Leddon, G. Westfield, M. Eckersdorff, J. M. Sekiguchi, S. Chang and D. O. Ferguson (2008). "Mre11 nuclease activity has essential roles in DNA repair and genomic stability distinct from ATM activation." Cell 135(1): 85-96.

Burma, S. and D. J. Chen (2004). "Role of DNA-PK in the cellular response to DNA double-strand breaks." DNA Repair (Amst) 3(8-9): 909-918.

Celeste, A., S. Petersen, P. J. Romanienko, O. Fernandez-Capetillo, H. T. Chen, O. A. Sedelnikova, B. Reina-San-Martin, V. Coppola, E. Meffre, M. J. Difilippantonio, C. Redon, D. R. Pilch, A. Olaru, M. Eckhaus, R. D. Camerini-Otero, L. Tessarollo, F. Livak, K. Manova, W. M. Bonner, M. C. Nussenzweig and A. Nussenzweig (2002). "Genomic instability in mice lacking histone H2AX." Science 296(5569): 922-927.

Chan, W. Y., D. E. Lorke, S. C. Tiu and D. T. Yew (2002). "Proliferation and apoptosis in the developing human neocortex." Anat Rec 267(4): 261-276.

Chaudhary, M. W. and R. S. Al-Baradie (2014). "Ataxia-telangiectasia: future prospects." Appl Clin Genet 7: 159-167.

Chechlacz, M., M. C. Vemuri and J. R. Naegele (2001). "Role of DNA-dependent protein kinase in neuronal survival." J Neurochem 78(1): 141-154.

Chong, M. J., M. R. Murray, E. C. Gosink, H. R. Russell, A. Srinivasan, M. Kapsetaki, S. J. Korsmeyer and P. J. McKinnon (2000). "Atm and Bax cooperate in ionizing radiationinduced apoptosis in the central nervous system." Proc Natl Acad Sci U S A 97(2): 889894.

Cimprich, K. A. and D. Cortez (2008). "ATR: an essential regulator of genome integrity." Nat Rev Mol Cell Biol 9(8): 616-627.

Cortez, D., S. Guntuku, J. Qin and S. J. Elledge (2001). "ATR and ATRIP: partners in checkpoint signaling." Science 294(5547): 1713-1716.

Cui, X., Y. Yu, S. Gupta, Y. M. Cho, S. P. Lees-Miller and K. Meek (2005).

"Autophosphorylation of DNA-dependent protein kinase regulates DNA end processing and may also alter double-strand break repair pathway choice." Mol Cell Biol 25(24): 10842-10852.

Davis, A. J., B. P. Chen and D. J. Chen (2014). "DNA-PK: A dynamic enzyme in a versatile DSB repair pathway." DNA Repair (Amst).

de Feraudy, S., I. Revet, V. Bezrookove, L. Feeney and J. E. Cleaver (2010). "A minority of foci or pan-nuclear apoptotic staining of gammaH2AX in the S phase after UV damage contain DNA double-strand breaks." Proc Natl Acad Sci U S A 107(15): 6870-6875. 
de Klein, A., M. Muijtjens, R. van Os, Y. Verhoeven, B. Smit, A. M. Carr, A. R. Lehmann and J. H. Hoeijmakers (2000). "Targeted disruption of the cell-cycle checkpoint gene ATR leads to early embryonic lethality in mice." Curr Biol 10(8): 479-482.

Dickey, J. S., C. E. Redon, A. J. Nakamura, B. J. Baird, O. A. Sedelnikova and W. M. Bonner (2009). "H2AX: functional roles and potential applications." Chromosoma 118(6): 683-692.

Ding, Q., L. Bramble, V. Yuzbasiyan-Gurkan, T. Bell and K. Meek (2002). "DNA-PKcs mutations in dogs and horses: allele frequency and association with neoplasia." Gene 283(1-2): 263-269.

Dobbs, T. A., J. A. Tainer and S. P. Lees-Miller (2010). "A structural model for regulation of NHEJ by DNA-PKcs autophosphorylation." DNA Repair (Amst) 9(12): 1307-1314.

Douglas, P., S. Gupta, N. Morrice, K. Meek and S. P. Lees-Miller (2005). "DNA-PKdependent phosphorylation of $\mathrm{Ku} 70 / 80$ is not required for non-homologous end joining." DNA Repair (Amst) 4(9): 1006-1018.

Errol C. Friedberg, G. C. W., Wolfram Siede (1995). DNA Repair and Mutagenesis, ASM Press, 1995.

Escobar, J., E. Cubells, M. Enomoto, G. Quintas, J. Kuligowski, C. M. Fernandez, I. Torres-Cuevas, J. Sastre, J. Belik and M. Vento (2013). "Prolonging in utero-like oxygenation after birth diminishes oxidative stress in the lung and brain of mice pups." Redox Biol 1: 297-303.

Factor, V. M., D. Seo, T. Ishikawa, P. Kaposi-Novak, J. U. Marquardt, J. B. Andersen, E. A. Conner and S. S. Thorgeirsson (2010). "Loss of c-Met disrupts gene expression program required for G2/M progression during liver regeneration in mice." PLoS One 5(9).

Farber-Katz, S. E., H. C. Dippold, M. D. Buschman, M. C. Peterman, M. Xing, C. J. Noakes, J. Tat, M. M. Ng, J. Rahajeng, D. M. Cowan, G. J. Fuchs, H. Zhou and S. J. Field (2014). "DNA damage triggers Golgi dispersal via DNA-PK and GOLPH3." Cell 156(3): 413-427.

Farina, L., C. Uggetti, A. Ottolini, A. Martelli, R. Bergamaschi, L. Sibilla, F. Zappoli, M. G. Egitto and G. Lanzi (1994). "Ataxia-telangiectasia: MR and CT findings." J Comput Assist Tomogr 18(5): 724-727.

Frappart, P. O., Y. Lee, J. Lamont and P. J. McKinnon (2007). "BRCA2 is required for neurogenesis and suppression of medulloblastoma." EMBO J 26(11): 2732-2742.

Friedberg, E. C. and L. B. Meira (2006). "Database of mouse strains carrying targeted mutations in genes affecting biological responses to DNA damage Version 7." DNA Repair (Amst) 5(2): 189-209. 
Gao, Y., J. Chaudhuri, C. Zhu, L. Davidson, D. T. Weaver and F. W. Alt (1998). "A targeted DNA-PKcs-null mutation reveals DNA-PK-independent functions for KU in V(D)J recombination." Immunity 9(3): 367-376.

Gao, Y., D. O. Ferguson, W. Xie, J. P. Manis, J. Sekiguchi, K. M. Frank, J. Chaudhuri, J. Horner, R. A. DePinho and F. W. Alt (2000). "Interplay of p53 and DNA-repair protein XRCC4 in tumorigenesis, genomic stability and development." Nature 404(6780): 897900.

Gatti, R. A., I. Berkel, E. Boder, G. Braedt, P. Charmley, P. Concannon, F. Ersoy, T. Foroud, N. G. Jaspers, K. Lange and et al. (1988). "Localization of an ataxiatelangiectasia gene to chromosome 11q22-23." Nature 336(6199): 577-580.

Gatz, S. A., L. Ju, R. Gruber, E. Hoffmann, A. M. Carr, Z. Q. Wang, C. Liu and P. A. Jeggo (2011). "Requirement for DNA ligase IV during embryonic neuronal development." J Neurosci 31(27): 10088-10100.

Goodarzi, A. A., P. Jeggo and M. Lobrich (2010). "The influence of heterochromatin on DNA double strand break repair: Getting the strong, silent type to relax." DNA Repair (Amst) 9(12): 1273-1282.

Goodarzi, A. A. and P. A. Jeggo (2013). "The repair and signaling responses to DNA double-strand breaks." Adv Genet 82: 1-45.

Goodarzi, A. A., T. Kurka and P. A. Jeggo (2011). "KAP-1 phosphorylation regulates CHD3 nucleosome remodeling during the DNA double-strand break response." Nat Struct Mol Biol 18(7): 831-839.

Goodarzi, A. A., Y. Yu, E. Riballo, P. Douglas, S. A. Walker, R. Ye, C. Harer, C. Marchetti, N. Morrice, P. A. Jeggo and S. P. Lees-Miller (2006). "DNA-PK autophosphorylation facilitates Artemis endonuclease activity." EMBO J 25(16): 38803889.

Goodwin, J. F. and K. E. Knudsen (2014). "Beyond DNA repair: DNA-PK function in cancer." Cancer Discov 4(10): 1126-1139.

Gorski, J. A., T. Talley, M. Qiu, L. Puelles, J. L. Rubenstein and K. R. Jones (2002). "Cortical excitatory neurons and glia, but not GABAergic neurons, are produced in the Emx1-expressing lineage." J Neurosci 22(15): 6309-6314.

Greig, L. C., M. B. Woodworth, M. J. Galazo, H. Padmanabhan and J. D. Macklis (2013). "Molecular logic of neocortical projection neuron specification, development and diversity." Nat Rev Neurosci 14(11): 755-769.

Gruber, R., Z. Zhou, M. Sukchev, T. Joerss, P. O. Frappart and Z. Q. Wang (2011). "MCPH1 regulates the neuroprogenitor division mode by coupling the centrosomal cycle with mitotic entry through the Chk1-Cdc25 pathway." Nat Cell Biol 13(11): 1325-1334. 
Gu, Y., S. Jin, Y. Gao, D. T. Weaver and F. W. Alt (1997). "Ku70-deficient embryonic stem cells have increased ionizing radiosensitivity, defective DNA end-binding activity, and inability to support V(D)J recombination." Proc Natl Acad Sci U S A 94(15): 80768081 .

Gu, Y., J. Sekiguchi, Y. Gao, P. Dikkes, K. Frank, D. Ferguson, P. Hasty, J. Chun and F. W. Alt (2000). "Defective embryonic neurogenesis in Ku-deficient but not DNAdependent protein kinase catalytic subunit-deficient mice." Proc Natl Acad Sci U S A 97(6): 2668-2673.

Gulston, M., J. Fulford, T. Jenner, C. de Lara and P. O'Neill (2002). "Clustered DNA damage induced by gamma radiation in human fibroblasts (HF19), hamster (V79-4) cells and plasmid DNA is revealed as Fpg and Nth sensitive sites." Nucleic Acids Res 30(15): 3464-3472.

Guo, Z., S. Kozlov, M. F. Lavin, M. D. Person and T. T. Paull (2010). "ATM activation by oxidative stress." Science 330(6003): 517-521.

Gurley, K. E. and C. J. Kemp (2001). "Synthetic lethality between mutation in Atm and DNA-PK(cs) during murine embryogenesis." Curr Biol 11(3): 191-194.

Gurley, K. E., R. Moser, Y. Gu, P. Hasty and C. J. Kemp (2009). "DNA-PK suppresses a p53-independent apoptotic response to DNA damage." EMBO Rep 10(1): 87-93.

Herzog, K. H., M. J. Chong, M. Kapsetaki, J. I. Morgan and P. J. McKinnon (1998). "Requirement for Atm in ionizing radiation-induced cell death in the developing central nervous system." Science 280(5366): 1089-1091.

Hevner, R. F. (2007). "Layer-specific markers as probes for neuron type identity in human neocortex and malformations of cortical development." J Neuropathol Exp Neurol 66(2): 101-109.

Hirao, A., A. Cheung, G. Duncan, P. M. Girard, A. J. Elia, A. Wakeham, H. Okada, T. Sarkissian, J. A. Wong, T. Sakai, E. De Stanchina, R. G. Bristow, T. Suda, S. W. Lowe, P. A. Jeggo, S. J. Elledge and T. W. Mak (2002). "Chk2 is a tumor suppressor that regulates apoptosis in both an ataxia telangiectasia mutated (ATM)-dependent and an ATM-independent manner." Mol Cell Biol 22(18): 6521-6532.

Hopfner, K. P., L. Craig, G. Moncalian, R. A. Zinkel, T. Usui, B. A. Owen, A. Karcher, B. Henderson, J. L. Bodmer, C. T. McMurray, J. P. Carney, J. H. Petrini and J. A. Tainer (2002). "The Rad50 zinc-hook is a structure joining Mre11 complexes in DNA recombination and repair." Nature 418(6897): 562-566.

Hoshino, K. and Y. Kameyama (1988). "Developmental-stage-dependent radiosensitivity of neural cells in the ventricular zone of telencephalon in mouse and rat fetuses."

Teratology 37(3): 257-262. 
Hoshino, K., Y. Kameyama and M. Inouye (1991). "Split-dose effect of X-irradiation on the induction of cell death in the fetal mouse brain." J Radiat Res 32(1): 23-27.

Jazayeri, A., J. Falck, C. Lukas, J. Bartek, G. C. Smith, J. Lukas and S. P. Jackson (2006). "ATM- and cell cycle-dependent regulation of ATR in response to DNA doublestrand breaks." Nat Cell Biol 8(1): 37-45.

Kass, E. M. and M. Jasin (2010). "Collaboration and competition between DNA doublestrand break repair pathways." FEBS Lett 584(17): 3703-3708.

Kastan, M. B., O. Onyekwere, D. Sidransky, B. Vogelstein and R. W. Craig (1991). "Participation of p53 protein in the cellular response to DNA damage." Cancer Res 51(23 Pt 1): 6304-6311.

Kastan, M. B., Q. Zhan, W. S. el-Deiry, F. Carrier, T. Jacks, W. V. Walsh, B. S. Plunkett, B. Vogelstein and A. J. Fornace, Jr. (1992). "A mammalian cell cycle checkpoint pathway utilizing p53 and GADD45 is defective in ataxia-telangiectasia." Cell 71(4): 587-597.

Katyal, S., Y. Lee, K. C. Nitiss, S. M. Downing, Y. Li, M. Shimada, J. Zhao, H. R. Russell, J. H. Petrini, J. L. Nitiss and P. J. McKinnon (2014). "Aberrant topoisomerase-1 DNA lesions are pathogenic in neurodegenerative genome instability syndromes." Nat Neurosci 17(6): 813-821.

Klement, K. and A. A. Goodarzi (2014). "DNA double strand break responses and chromatin alterations within the aging cell." Exp Cell Res.

Kong, X., Y. Shen, N. Jiang, X. Fei and J. Mi (2011). "Emerging roles of DNA-PK besides DNA repair." Cell Signal 23(8): 1273-1280.

Kumagai, A., J. Lee, H. Y. Yoo and W. G. Dunphy (2006). "TopBP1 activates the ATRATRIP complex." Cell 124(5): 943-955.

Laurie, N. A., S. L. Donovan, C. S. Shih, J. Zhang, N. Mills, C. Fuller, A. Teunisse, S. Lam, Y. Ramos, A. Mohan, D. Johnson, M. Wilson, C. Rodriguez-Galindo, M. Quarto, S. Francoz, S. M. Mendrysa, R. K. Guy, J. C. Marine, A. G. Jochemsen and M. A. Dyer (2006). "Inactivation of the p53 pathway in retinoblastoma." Nature 444(7115): 61-66.

Lavin, M. F. (2013). "The appropriateness of the mouse model for ataxia-telangiectasia: neurological defects but no neurodegeneration." DNA Repair (Amst) 12(8): 612-619.

Leclerc, C., I. Neant and M. Moreau (2012). "The calcium: an early signal that initiates the formation of the nervous system during embryogenesis." Front Mol Neurosci 5: 3.

Lee, Y., D. E. Barnes, T. Lindahl and P. J. McKinnon (2000). "Defective neurogenesis resulting from DNA ligase IV deficiency requires Atm." Genes Dev 14(20): 2576-2580. 
Lee, Y., M. J. Chong and P. J. McKinnon (2001). "Ataxia telangiectasia mutateddependent apoptosis after genotoxic stress in the developing nervous system is determined by cellular differentiation status." J Neurosci 21(17): 6687-6693.

Lee, Y., E. R. Shull, P. O. Frappart, S. Katyal, V. Enriquez-Rios, J. Zhao, H. R. Russell, E. J. Brown and P. J. McKinnon (2012). "ATR maintains select progenitors during nervous system development." EMBO J.

Li, J., J. Chen, C. L. Ricupero, R. P. Hart, M. S. Schwartz, A. Kusnecov and K. Herrup (2012). "Nuclear accumulation of HDAC4 in ATM deficiency promotes neurodegeneration in ataxia telangiectasia." Nat Med 18(5): 783-790.

Li, J., R. P. Hart, E. M. Mallimo, M. R. Swerdel, A. W. Kusnecov and K. Herrup (2013). "EZH2-mediated H3K27 trimethylation mediates neurodegeneration in ataxiatelangiectasia." Nat Neurosci 16(12): 1745-1753.

Liu, Q., S. Guntuku, X. S. Cui, S. Matsuoka, D. Cortez, K. Tamai, G. Luo, S. CarattiniRivera, F. DeMayo, A. Bradley, L. A. Donehower and S. J. Elledge (2000). "Chk1 is an essential kinase that is regulated by Atr and required for the G(2)/M DNA damage checkpoint." Genes Dev 14(12): 1448-1459.

Lobrich, M., A. Shibata, A. Beucher, A. Fisher, M. Ensminger, A. A. Goodarzi, O. Barton and P. A. Jeggo (2010). "gammaH2AX foci analysis for monitoring DNA doublestrand break repair: strengths, limitations and optimization." Cell Cycle 9(4): 662-669.

Mahaney, B. L., K. Meek and S. P. Lees-Miller (2009). "Repair of ionizing radiationinduced DNA double-strand breaks by non-homologous end-joining." Biochem J 417(3): 639-650.

Mazon, G., E. P. Mimitou and L. S. Symington (2010). "SnapShot: Homologous recombination in DNA double-strand break repair." Cell 142(4): 646, 646 e641.

Mazouzi, A., G. Velimezi and J. I. Loizou (2014). "DNA replication stress: Causes, resolution and disease." Exp Cell Res.

McKinnon, P. J. (2009). "DNA repair deficiency and neurological disease." Nat Rev Neurosci 10(2): 100-112.

McKinnon, P. J. (2012). "ATM and the molecular pathogenesis of ataxia telangiectasia." Annu Rev Pathol 7: 303-321.

McKinnon, P. J. (2013). "Maintaining genome stability in the nervous system." Nat Neurosci 16(11): 1523-1529.

Meek, K., A. Jutkowitz, L. Allen, J. Glover, E. Convery, A. Massa, T. Mullaney, B. Stanley, D. Rosenstein, S. M. Bailey, C. Johnson and G. Georges (2009). "SCID dogs: similar transplant potential but distinct intra-uterine growth defects and premature replicative senescence compared with SCID mice." J Immunol 183(4): 2529-2536. 
Meek, K., L. Kienker, C. Dallas, W. Wang, M. J. Dark, P. J. Venta, M. L. Huie, R. Hirschhorn and T. Bell (2001). "SCID in Jack Russell terriers: a new animal model of DNA-PKcs deficiency." J Immunol 167(4): 2142-2150.

Molyneaux, B. J., P. Arlotta, J. R. Menezes and J. D. Macklis (2007). "Neuronal subtype specification in the cerebral cortex." Nat Rev Neurosci 8(6): 427-437.

Mordes, D. A., G. G. Glick, R. Zhao and D. Cortez (2008). "TopBP1 activates ATR through ATRIP and a PIKK regulatory domain." Genes Dev 22(11): 1478-1489.

Moreno-Herrero, F., M. de Jager, N. H. Dekker, R. Kanaar, C. Wyman and C. Dekker (2005). "Mesoscale conformational changes in the DNA-repair complex Rad50/Mre11/Nbs1 upon binding DNA." Nature 437(7057): 440-443.

Moynahan, M. E. and M. Jasin (2010). "Mitotic homologous recombination maintains genomic stability and suppresses tumorigenesis." Nat Rev Mol Cell Biol 11(3): 196-207.

Nam, E. A. and D. Cortez (2011). "ATR signalling: more than meeting at the fork." Biochem J 436(3): 527-536.

Neema, M., I. Navarro-Quiroga, M. Chechlacz, K. Gilliams-Francis, J. Liu, K. Lamonica, S. L. Lin and J. R. Naegele (2005). "DNA damage and nonhomologous end joining in excitotoxicity: neuroprotective role of DNA-PKcs in kainic acid-induced seizures." Hippocampus 15(8): 1057-1071.

Niimi, N., N. Sugo, Y. Aratani and H. Koyama (2005). "Genetic interaction between DNA polymerase beta and DNA-PKcs in embryogenesis and neurogenesis." Cell Death Differ 12(2): 184-191.

Noon, A. T., A. Shibata, N. Rief, M. Lobrich, G. S. Stewart, P. A. Jeggo and A. A. Goodarzi (2010). "53BP1-dependent robust localized KAP-1 phosphorylation is essential for heterochromatic DNA double-strand break repair." Nat Cell Biol 12(2): 177-184.

O'Driscoll, M. (2009). "Mouse models for ATR deficiency." DNA Repair (Amst) 8(11): 1333-1337.

O'Driscoll, M., W. B. Dobyns, J. M. van Hagen and P. A. Jeggo (2007). "Cellular and clinical impact of haploinsufficiency for genes involved in ATR signaling." Am J Hum Genet 81(1): 77-86.

O'Driscoll, M., A. R. Gennery, J. Seidel, P. Concannon and P. A. Jeggo (2004). "An overview of three new disorders associated with genetic instability: LIG4 syndrome, RSSCID and ATR-Seckel syndrome." DNA Repair (Amst) 3(8-9): 1227-1235.

O'Driscoll, M., A. P. Jackson and P. A. Jeggo (2006). "Microcephalin: a causal link between impaired damage response signalling and microcephaly." Cell Cycle 5(20): 2339-2344. 
O'Driscoll, M., V. L. Ruiz-Perez, C. G. Woods, P. A. Jeggo and J. A. Goodship (2003).

"A splicing mutation affecting expression of ataxia-telangiectasia and Rad3-related protein (ATR) results in Seckel syndrome." Nat Genet 33(4): 497-501.

O'Neill P (O'Niell, P. F., EM (Fielden, EM) (1993). PRIMARY FREE-RADICAL PROCESSES IN DNA, ACADEMIC PRESS INC, 525 B STREET, SUITE 1900, SAN DIEGO, CA 92101-4495.

Orii, K. E., Y. Lee, N. Kondo and P. J. McKinnon (2006). "Selective utilization of nonhomologous end-joining and homologous recombination DNA repair pathways during nervous system development." Proc Natl Acad Sci U S A 103(26): 10017-10022.

Paridaen, J. T. and W. B. Huttner (2014). "Neurogenesis during development of the vertebrate central nervous system." EMBO Rep.

Puck, T. T. and P. I. Marcus (1956). "Action of x-rays on mammalian cells." J Exp Med 103(5): 653-666.

Rajagopalan, S., M. W. Moyle, I. Joosten and E. O. Long (2010). "DNA-PKcs controls an endosomal signaling pathway for a proinflammatory response by natural killer cells." Sci Signal 3(110): ra14.

Rogakou, E. P., W. Nieves-Neira, C. Boon, Y. Pommier and W. M. Bonner (2000). "Initiation of DNA fragmentation during apoptosis induces phosphorylation of H2AX histone at serine 139." J Biol Chem 275(13): 9390-9395.

Romero, A. A., S. R. Gross, K. Y. Cheng, N. K. Goldsmith and H. M. Geller (2003). "An age-related increase in resistance to DNA damage-induced apoptotic cell death is associated with development of DNA repair mechanisms." J Neurochem 84(6): 1275 1287.

Rosenthal, N. and S. Brown (2007). "The mouse ascending: perspectives for humandisease models." Nat Cell Biol 9(9): 993-999.

Ruzankina, Y., C. Pinzon-Guzman, A. Asare, T. Ong, L. Pontano, G. Cotsarelis, V. P. Zediak, M. Velez, A. Bhandoola and E. J. Brown (2007). "Deletion of the developmentally essential gene ATR in adult mice leads to age-related phenotypes and stem cell loss." Cell Stem Cell 1(1): 113-126.

Saviozzi, S., A. Saluto, A. M. Taylor, J. I. Last, F. Trebini, M. C. Paradiso, E. Grosso, A. Funaro, G. Ponzio, N. Migone and A. Brusco (2002). "A late onset variant of ataxiatelangiectasia with a compound heterozygous genotype, A8030G/7481 ins A." J Med Genet 39(1): 57-61.

Scully, R. and A. Xie (2013). "Double strand break repair functions of histone H2AX." Mutat Res 750(1-2): 5-14.

Sedgwick RP, B. E. (1991). Ataxia-telangiectasia. New York, USA, Elsevier. 
Serrano, M. A., Z. Li, M. Dangeti, P. R. Musich, S. Patrick, M. Roginskaya, B. Cartwright and Y. Zou (2013). "DNA-PK, ATM and ATR collaboratively regulate p53RPA interaction to facilitate homologous recombination DNA repair." Oncogene 32(19): 2452-2462.

Shibata, A., S. Conrad, J. Birraux, V. Geuting, O. Barton, A. Ismail, A. Kakarougkas, K. Meek, G. Taucher-Scholz, M. Lobrich and P. A. Jeggo (2011). "Factors determining DNA double-strand break repair pathway choice in G2 phase." EMBO J 30(6): 10791092.

Shibata, A. and P. A. Jeggo (2014). "DNA double-strand break repair in a cellular

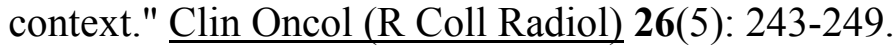

Shiloh, Y. (1995). "Ataxia-telangiectasia: closer to unraveling the mystery." Eur J Hum Genet 3(2): 116-138.

Shiloh, Y. (2003). "ATM and related protein kinases: safeguarding genome integrity." Nat Rev Cancer 3(3): 155-168.

Shiloh, Y. (2014). "ATM: Expanding roles as a chief guardian of genome stability." Exp Cell Res.

Shiloh, Y. and Y. Ziv (2013). "The ATM protein kinase: regulating the cellular response to genotoxic stress, and more." Nat Rev Mol Cell Biol 14(4): 197-210.

Shull, E. R., Y. Lee, H. Nakane, T. H. Stracker, J. Zhao, H. R. Russell, J. H. Petrini and P. J. McKinnon (2009). "Differential DNA damage signaling accounts for distinct neural apoptotic responses in ATLD and NBS." Genes Dev 23(2): 171-180.

Sirbu, B. M. and D. Cortez (2013). "DNA damage response: three levels of DNA repair regulation." Cold Spring Harb Perspect Biol 5(8): a012724.

Smith, J., L. M. Tho, N. Xu and D. A. Gillespie (2010). "The ATM-Chk2 and ATR-Chk1 pathways in DNA damage signaling and cancer." Adv Cancer Res 108: 73-112.

Stiff, T., M. O'Driscoll, N. Rief, K. Iwabuchi, M. Lobrich and P. A. Jeggo (2004). "ATM and DNA-PK function redundantly to phosphorylate H2AX after exposure to ionizing radiation." Cancer Res 64(7): 2390-2396.

Stiff, T., S. A. Walker, K. Cerosaletti, A. A. Goodarzi, E. Petermann, P. Concannon, M. O'Driscoll and P. A. Jeggo (2006). "ATR-dependent phosphorylation and activation of ATM in response to UV treatment or replication fork stalling." EMBO J 25(24): 57755782.

Stracker, T. H., J. W. Theunissen, M. Morales and J. H. Petrini (2004). "The Mre11 complex and the metabolism of chromosome breaks: the importance of communicating and holding things together." DNA repair 3(8-9): 845-854. 
Suberbielle, E., P. E. Sanchez, A. V. Kravitz, X. Wang, K. Ho, K. Eilertson, N. Devidze, A. C. Kreitzer and L. Mucke (2013). "Physiologic brain activity causes DNA doublestrand breaks in neurons, with exacerbation by amyloid-beta." Nat Neurosci 16(5): 613621.

Tavani, F., R. A. Zimmerman, G. T. Berry, K. Sullivan, R. Gatti and P. Bingham (2003). "Ataxia-telangiectasia: the pattern of cerebellar atrophy on MRI." Neuroradiology 45(5): 315-319.

Taylor, A. M., D. G. Harnden, C. F. Arlett, S. A. Harcourt, A. R. Lehmann, S. Stevens and B. A. Bridges (1975). "Ataxia telangiectasia: a human mutation with abnormal radiation sensitivity." Nature 258(5534): 427-429.

Tibbetts, R. S., K. M. Brumbaugh, J. M. Williams, J. N. Sarkaria, W. A. Cliby, S. Y. Shieh, Y. Taya, C. Prives and R. T. Abraham (1999). "A role for ATR in the DNA damage-induced phosphorylation of p53." Genes Dev 13(2): 152-157.

Tomimatsu, N., B. Mukherjee and S. Burma (2009). "Distinct roles of ATR and DNAPKcs in triggering DNA damage responses in ATM-deficient cells." EMBO Rep 10(6): 629-635.

Tomimatsu, N., C. G. Tahimic, A. Otsuki, S. Burma, A. Fukuhara, K. Sato, G. Shiota, M. Oshimura, D. J. Chen and A. Kurimasa (2007). "Ku70/80 modulates ATM and ATR signaling pathways in response to DNA double strand breaks." J Biol Chem 282(14): 10138-10145.

Uematsu, N., E. Weterings, K. Yano, K. Morotomi-Yano, B. Jakob, G. Taucher-Scholz, P. O. Mari, D. C. van Gent, B. P. Chen and D. J. Chen (2007). "Autophosphorylation of DNA-PKCS regulates its dynamics at DNA double-strand breaks." J Cell Biol 177(2): 219-229.

Uziel, T., Y. Lerenthal, L. Moyal, Y. Andegeko, L. Mittelman and Y. Shiloh (2003). "Requirement of the MRN complex for ATM activation by DNA damage." EMBO J 22(20): 5612-5621.

Valentin-Vega, Y. A. and M. B. Kastan (2012). "A new role for ATM: regulating mitochondrial function and mitophagy." Autophagy 8(5): 840-841.

van der Burg, M., H. Ijspeert, N. S. Verkaik, T. Turul, W. W. Wiegant, K. MorotomiYano, P. O. Mari, I. Tezcan, D. J. Chen, M. Z. Zdzienicka, J. J. van Dongen and D. C. van Gent (2009). "A DNA-PKcs mutation in a radiosensitive T-B- SCID patient inhibits Artemis activation and nonhomologous end-joining." J Clin Invest 119(1): 91-98.

van der Burg, M., J. J. van Dongen and D. C. van Gent (2009). "DNA-PKcs deficiency in human: long predicted, finally found." Curr Opin Allergy Clin Immunol 9(6): 503-509.

Vemuri, M. C., E. Schiller and J. R. Naegele (2001). "Elevated DNA double strand breaks and apoptosis in the CNS of scid mutant mice." Cell Death Differ 8(3): 245-255. 
Vignard, J., G. Mirey and B. Salles (2013). "Ionizing-radiation induced DNA doublestrand breaks: a direct and indirect lighting up." Radiother Oncol 108(3): 362-369.

White, D., I. U. Rafalska-Metcalf, A. V. Ivanov, A. Corsinotti, H. Peng, S. C. Lee, D. Trono, S. M. Janicki and F. J. Rauscher, 3rd (2012). "The ATM Substrate KAP1 Controls DNA Repair in Heterochromatin: Regulation by HP1 Proteins and Serine 473/824 Phosphorylation." Mol Cancer Res.

Williams, G. J., M. Hammel, S. K. Radhakrishnan, D. Ramsden, S. P. Lees-Miller and J. A. Tainer (2014). "Structural insights into NHEJ: building up an integrated picture of the dynamic DSB repair super complex, one component and interaction at a time." DNA Repair (Amst) 17: 110-120.

Wong, R. H., I. Chang, C. S. Hudak, S. Hyun, H. Y. Kwan and H. S. Sul (2009). "A role of DNA-PK for the metabolic gene regulation in response to insulin." Cell 136(6): 10561072.

Wong, R. H. and H. S. Sul (2009). "DNA-PK: relaying the insulin signal to USF in lipogenesis." Cell Cycle 8(13): 1977-1978.

Woodbine, L., J. A. Neal, N. K. Sasi, M. Shimada, K. Deem, H. Coleman, W. B. Dobyns, T. Ogi, K. Meek, E. G. Davies and P. A. Jeggo (2013). "PRKDC mutations in a SCID patient with profound neurological abnormalities." The Journal of clinical investigation 123(7): 2969-2980.

Yan, S., M. Sorrell and Z. Berman (2014). "Functional interplay between ATM/ATRmediated DNA damage response and DNA repair pathways in oxidative stress." Cell Mol Life Sci 71(20): 3951-3967.

Zhao, H. and H. Piwnica-Worms (2001). "ATR-mediated checkpoint pathways regulate phosphorylation and activation of human Chk1." Mol Cell Biol 21(13): 4129-4139.

Ziv, Y., D. Bielopolski, Y. Galanty, C. Lukas, Y. Taya, D. C. Schultz, J. Lukas, S. Bekker-Jensen, J. Bartek and Y. Shiloh (2006). "Chromatin relaxation in response to DNA double-strand breaks is modulated by a novel ATM- and KAP-1 dependent pathway." Nat Cell Biol 8(8): 870-876. 


\section{VITA}

Vanessa Enriquez-Rios was born to a teen mom in Southern California in 1981. She graduated from the University of California, Santa Cruz, with a Bachelor of Science in Chemistry with Honors in 2004. She was a Pediatric Oncology Education (POE) student at St. Jude Children's Research Hospital during the summers of 2003 and 2004. She then attended the University of California, Los Angeles, where she completed coursework for a Master's degree in Organic Chemistry in 2007. Finally, she returned to St. Jude Children's Research Hospital to complete a PhD through the Integrated Program in Biomedical Sciences (IPBS) based at the University of Tennessee Health Science Center, Memphis, Tennessee. 